Portland State University

PDXScholar

Summer 8-17-2017

\title{
"First"-Matters: Projecting the Displacement of Responses to Questions in the Context of Presidential Primary-Campaign Debates
}

Kristella Marie Montiegel

Portland State University

Follow this and additional works at: https://pdxscholar.library.pdx.edu/open_access_etds

Part of the Political Science Commons, and the Social Influence and Political Communication Commons

Let us know how access to this document benefits you.

\section{Recommended Citation}

Montiegel, Kristella Marie, "'"First"-Matters: Projecting the Displacement of Responses to Questions in the Context of Presidential Primary-Campaign Debates" (2017). Dissertations and Theses. Paper 3836. https://doi.org/10.15760/etd.5730

This Thesis is brought to you for free and open access. It has been accepted for inclusion in Dissertations and Theses by an authorized administrator of PDXScholar. Please contact us if we can make this document more accessible: pdxscholar@pdx.edu. 
"First"-Matters: Projecting the Displacement of Responses to Questions in the Context of Presidential Primary-Campaign Debates

by

Kristella M. Montiegel

A thesis submitted in partial fulfillment of the requirements for the degree of

Master of Science

in

Communication

Thesis Committee:

Jeffrey D. Robinson, Chair

L. David Ritchie

John Hellermann

Portland State University

2017 
(C) Kristella M. Montiegel 


\begin{abstract}
This thesis takes a conversation-analytic approach examining the pragmatic functions of the linguistic marker "first (off/of all)" in second-pair-part (i.e., responsive) position relative to questions. Using data from question-answer sequences in the 2015-2016 U.S. Presidential Republican primary debates, I propose six claims regarding the composition, position, and action of what is referred to as the practice of "First"-prefacing. Analysis reveals that "First"-prefacing projects the displacement of a response (conforming or non-conforming) to a question. In projecting the displacement of a response, "First"prefacing does two things: (1) it projects that the unit(s) of talk to come immediately next will be something other than a response, and thus this 'first' matter should not be heard as being designedly 'responsive' to the question; and (2) it claims that a conditionally relevant response to the question is forthcoming after the 'first' matter is resolved. Debaters largely used 'First"-prefacing to temporarily 'get out from under' a question's conditional relevancies in order to 'reach back' beyond the question and perform actions more properly sequentially fitted to earlier portions of the debate (e.g., defend themselves, make additional comments, counter-criticize other debaters). The more general function of "First"-prefacing as a misplacement marker is discussed, and its existence in ordinary conversation is briefly demonstrated.
\end{abstract}

Keywords: Conversation analysis, media, debate, politics, Trump, sequence organization, misplacement 


\section{Dedication}

This thesis is dedicated to my mother, father, and younger sister.

Thank you for the unconditional love and support.

I hope to always make you proud. 


\section{Acknowledgements}

To my thesis chair and mentor, Dr. Jeffrey D. Robinson, who has been a constant source of knowledge and encouragement. I cannot thank you enough for the time and commitment you have given to this research and to my academic endeavors overall. I am grateful to have been your student.

I would also like to thank Drs. David Ritchie and John Hellermann for their valuable insight and support towards the completion of this thesis.

Lastly, my heartfelt gratitude to Dr. Tanya Romaniuk, who kindled my academic curiosities and inspired me to pursue my ambitions. Thank you for giving me the future I have always dreamed of. 
Table of Contents

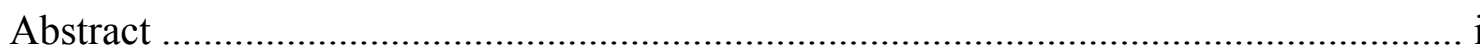

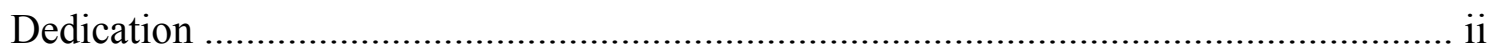

Acknowledgments ............................................................................................. iii

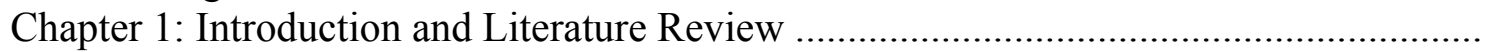

Background and Introduction ........................................................................ 1

The Adjacency Pair and Conditional Relevance ......................................................

The adjacency pair: Question-answer sequences ...................................... 4

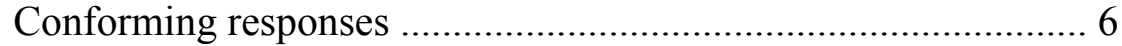

Non-conforming responses ......................................................... 8

The difference between responding and not responding ........................ 10

Questioning and Answering in the Context of the Broadcast-News Interview .. 14

The interviewer: Norms and tasks ...................................................... 16

Question design ..................................................................... 17

The interviewee: Norms and tasks ...................................................... 19

Responsive turn design ........................................................... 20

Contextualizing the political-campaign debate ……………………...... 22

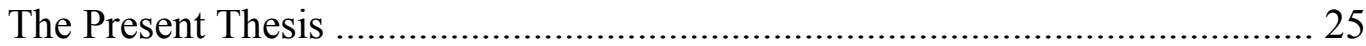

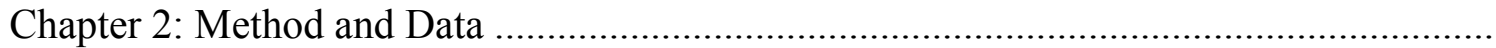

Method: A Brief Review of Conversation Analysis ………………………….... 26

Initial Motivations for Selecting Data ………………………………………. 29

Initial Data-Selection Procedure ……………………………………………. 30

Subsequent Data-Selection Procedure: The Evolution of the Research Focus ... 31

The 2015-2016 CNN U.S. Presidential Republican Primary Debates ................. 32

Chapter 3: Analysis

4.1 Introductory Exemplars of "First"-Prefacing ……………………………... 34

4.2 Excursus: The Practice of "First"-Prefacing and the Action it Implements.. 43

4.2 .1

4.2 .2

4.3.3 44

4.3.4

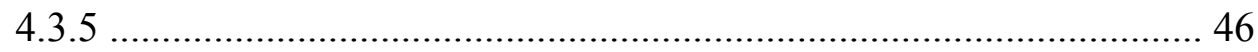

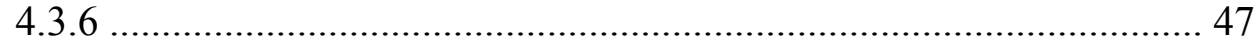

4.3 Participants' Orientations to "First"-Prefacing as a Practice .............................

4.3.1. Cases in which speakers orient to the action .................................. 49

4.3.2. Cases in which moderators orient to the action .............................. 59

4.3.3. Cases in which other candidates orient to the action ...................... 66

4.4 The Operation of "First"-Prefacing in Less-Clear Cases ............................... 70

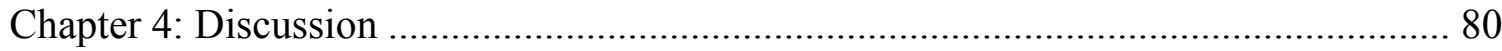

Future Research: Expanding the Scope of "First"-Prefacing .............................. 85

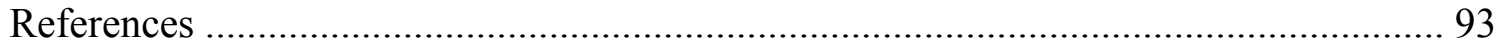

Appendices

Appendix A: List of 2015-2016 CNN Republican Primary Debates ................ 112

List of 2015-2016 Republican Primary Debates ..................................... 114 


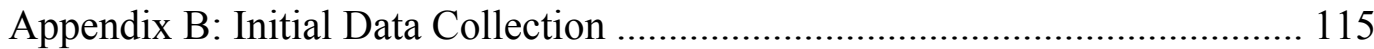

Appendix C: Transcription Conventions ................................................... 124 


\section{Chapter 1:}

\section{Introduction and Literature Review}

\section{Background and Introduction}

In the 1960s, the sociologist Harvey Sacks (1992) proposed a set of ideas that challenged what social-scientific research had previously thought about conversation that, rather than being disorderly, and thus unfit for systematic analysis (c.f., Parsons, 1937/1949), talk-in-interaction actually possesses a systematic and describable social organization (for review, see Heritage, 1984). In his published series of lectures, Sacks introduced what he called "rules" of both turn taking and conversational sequence (ibid., p. 4), and demonstrated that conversation can be studied at the level of both individual turns of talk and as sequences of turns. Furthermore, these rules - which apply in a multitude of different languages/cultures, and thus are rules for humans as a species (Sacks, Schegloff, \& Jefferson, 1974) - are some of the key building blocks of recognizable social action (Schegloff, 1988), and thus of human intersubjectivity (Heritage, 1984). These early ideas pioneered what would become the discipline of Conversation Analysis, a distinctive theoretical and methodological approach to studying social interaction (Heritage, 1995, 2009; Sidnell \& Stivers, 2013).

In the very opening of the introduction to his book, Sequence Organization, Schegloff (2007) wrote,

For there to be the possibility of responsiveness - of one participant being able to show that what they are saying and doing is responsive to what another has said and done - one party needs to talk after the other, and, it turns out, that they have to talk singly. [...] that is; one at a time and each participant's talk is inspectable, and is 
inspected, by co-participants to see how it stands to the one that preceded, what sort of response it has accorded the preceding turn. (p. 1)

Along these lines, 'initiating' actions place significant constraints on both what can be normatively done with 'responsive' actions, as well on how 'responsive' actions are to be interpreted and morally evaluated (see Garfinkel, 1967). One of the most powerful types of 'initiating' actions are 'questions' (Schegloff, 1968; Schegloff \& Sacks, 1973), which are a central focus of this thesis. Much literature has expounded on the pragmatic functions of questions (Bolinger, 1957; Enfield, Stivers, \& Levinson, 2010; Hayano, 2013; Schegloff, 1978; Stivers, 2010) and responses (Lee, 2013; Schegloff, 1968; Schegloff \& Sacks, 1973; Stivers \& Hayashi, 2010; Stivers \& Robinson, 2006; Stivers \& Rossano, 2010) as initiating (first-position) actions and responsive (secondposition) actions, respectively. This thesis generally examines the socially organized activities of question-answer sequences in the CNN Republican primary debates of the 2015-2016 United States’ Presidential election season.

Relative to mundane conversation, the institutional context of political debates places unique, normative constraints on speakers' roles, such that only debate moderators are allowed to ask questions, and that debaters are accountable - to both moderators and the viewing public - for answering questions (Greatbatch, 1986a; Heritage \& Greatbatch, 1991). In this context, not answering, or answering evasively, can have serious political ramifications (Clayman, 2001). Although debate moderators are beholden to journalistic norms of neutrality (Clayman, 1988, 1992; Clayman \& Heritage 2002a; Heritage \& Greatbatch, 1991), they nonetheless can craftily design their questions so as to corner debaters into controversy and marginality (Clayman, 2016, Clayman \& Heritage 2002a; 
Heritage, 2002, 2003; Heritage \& Roth, 1995; Roth, 2005). In their answers, debaters struggle to parry or evade questions' potential injuries. Historically, researchers have been interested - in the context of both mundane conversation and contentious political debates - in the strategies that respondents have at their disposal for getting out from under the constraints of questions with the least amount of relational and reputational damage. The present study contributes to this area of research by examining one such type of counter-maneuver.

The main title of the thesis - "First"-Matters - is designed to allude to four issues: (1) Going sequentially 'first' - for example, a debate-moderator asking a question 'matters' because (via conditional-relevance rules; Schegloff, 1968; Schegloff \& Sacks, 1973 ) it sets powerful parameters on both what politicians should normatively 'do' next and when they should do it; (2) One resource that politicians have for temporarily 'getting out from under' these constraints, and their various accountabilities (Garfinkel, 1967; Schegloff, 1988), is the practice of prefacing their responsive turn with "first (of all/off);" (3) This practice allows politicians to 'first' address 'matters' that are unrelated to the question, while nonetheless promising a response upon their completion; and (4) Because these 'matters' typically address interactional events that occur before the question, they are framed as ones that should be dealt with 'first,' that is, before engaging in the activity of responding to the question. This thesis uses the theory and method of Conversation Analysis (e.g., Drew \& Curl, 2008; Goodwin \& Heritage, 1990; Heritage, 1995; Psathas, 1995; Raclaw, 2015; Robinson, 2012; Sidnell, 2009; Sidnell \& Stivers, 2013) to describe a practice of action called "First"-prefacing, which is used by politicaldebate candidates to project the displacement of a response to a question in order to deal 
with distal interactional events, adjacent to which the 'first matters' would have more normatively been placed.

This introductory chapter reviews two areas of literature relevant to this thesis, both dealing with the social actions of questioning and answering. First, this chapter reviews the conversation-analytic concepts of the adjacency pair and, relatedly, conditional relevance. Second, this chapter reviews the structure and consequences of the specialized turn-taking system of political debates, which is primarily constituted by moderators doing questioning and candidates doing answering.

\section{The Adjacency Pair and Conditional Relevance}

As Schegloff (2007) argued, “a great deal of talk-in-interaction - perhaps most of it - is better examined with respect to action than with respect to topicality, more for what it is doing than for what it is about" (p. 1, emphasis in original). As suggested by Austin (1962), people 'do things with words,' such as invite, offer, request, apologize, assess, inform, tease, criticize, and, relevant to the present thesis, ask for information. Much of social action - including that implemented through questions and answers - is organized into sequences of talk, and the adjacency pair is the most fundamental unit for sequence construction.

The adjacency pair: Question-answer sequences. The adjacency pair is characterized by five main features: “(1) [it is] composed of two turns; (2) [these turns are produced] by different speakers; (3) [these turns are] adjacently placed; that is, one after the other; (4) these two turns are relatively ordered; that is, they are differentiated into 'first pair parts' and 'second pair parts' [...]; (5) [these components are] pair-type related; that is, not every second pair part can properly follow any first pair part" 
(Schegloff, 2007, p. 13). In other words, first-pair parts initiate specific actions that expect specific, matched, responsive actions (i.e., second-pair parts), and this relationship is governed by rules of 'conditional relevance' (Schegloff , 2007):

The very feature of "first-ness" sets up the relevance of something else to follow; it projects the relevance of a "second." It is the occurrence of a first-pair part that makes some types of second-pair part relevant next; that relevance is conditioned by the [first-pair part]. (p. 20)

For example, greetings (e.g., "Hi”/“Hello") make conditionally relevant second greetings (e.g., "Hi"/“Hello") whereas apologies make conditionally relevant some type of absolution (or lack thereof; e.g., "That's okay;" Robinson, 2004), and these second-pair part types cannot be mixed and matched without generating confusion (e.g., "Hello" --> “That's okay").

This relationship between first- and second-pair parts allows participants to coorganize and manage meaning and understanding in conversation. Specifically, secondpair parts (e.g., their design, action, etc.) display their speaker's understanding of what was said and done in and through first-pair parts (Schegloff, 2007). That is, the contiguity of this 'nextness' (Sacks, 1987) between turns at talk encourages participants to design their turns to be connected in some way with what came immediately before, largely by producing an appropriate next action to the action recognizably initiated in a prior speaker's turn (Drew, 2013). Thus, first turns favor or prefer certain types of responses toward conversational progressivity, or the pressure to interactionally complete the action(s) initiated by a first turn and thereby facilitate the progression of the ongoing activity (Sacks, 1987; Sacks et al., 1974; Schegloff, 2007, pp. 13-21; Stivers \& Robinson, 
2006). Once a first turn is uttered, a second turn is conditioned to be a relevant responsive action to the talk immediately prior; failure to be produced as such becomes noticeable to interlocutors and is accountable.

Questions and answers are types of actions that constitute first- and second-pair parts of an adjacency sequence, respectively. Different types of questions (i.e., with different syntactic designs and different action implications) constitute different types of first-pair parts, each setting up different conditional-relevance rules for answers, and thus for what are 'normatively fitted' or pair-typed second-pair parts. Thus, we can describe responses to questions in terms of whether or not they 'conform' to the question's conditional relevancies.

Conforming responses. Conforming responses are ones that are type-fitted (Fox \& Thompson, 2010; Raymond, 2003; Stivers, 2010) to the conditional relevancies (Schegloff, 1968; Schegloff \& Sacks, 1973) of the question. For example, 'Yes'/'No' interrogatives and 'Yes'/`No' declaratives make some version of 'Yes' or 'No' (or myriad equivalents) conditionally relevant (for extensive analysis, see Park, 2008; Raymond, 2003); 'Yes'- and 'No'-type responses confirm or disconfirm the circumstances of the question. For an example of a conforming response, see Extract 1 (taken from Raymond, 2000). Mum's question at line 01 is a request for information in the syntactic form of a polar interrogative. Leslie's "Ye:s" at line 03 embodies a conforming response.

Extract 1 [Holt; taken from Raymond, 2000]

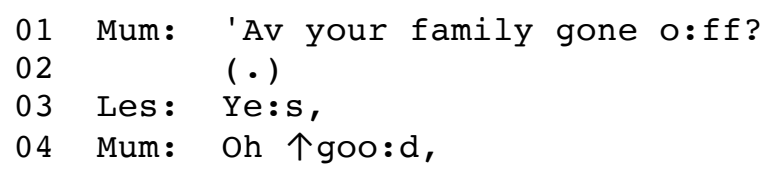

Note that a 'No' answer would also have embodied a conforming answer, albeit a 
dispreferred one (Pomerantz, 1984; Pomerantz \& Heritage, 2013).

For another example, 'Wh'-questions (e.g., who, what, when, where, why, and how) make conditionally relevant various formulations of persons, things, times, places, reasons, and explanations, respectively (Schegloff \& Lerner, 2009). In Extract 2, Lottie's question makes conditionally relevant a time reference, which Emma provides.

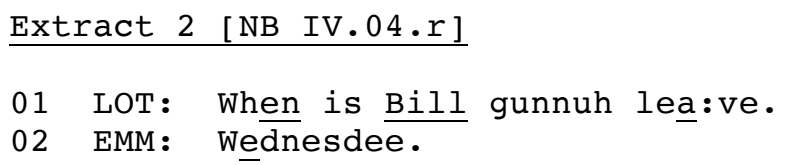

Conditional-relevance rules apply just as strongly in the context of broadcastnews interviews (Harris, 1991). In Extract 3 (drawn from Clayman, 2001), the interviewer asks a 'Yes'/ ${ }^{\circ}$ ' ' interrogative, "Are you willing (.) personally to renounce the violence (.) in that country." (lines 01-02), and the interviewee (AB) provides a conforming response: "Yes I will." (line 04).

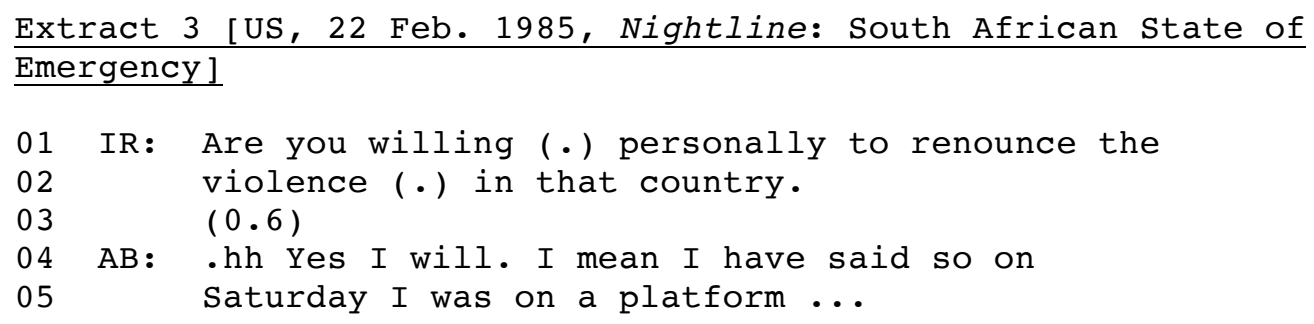

For another example, in Extract 4, the interviewer asks a 'How long' question that makes conditionally relevant a time frame, "how long has he got to prove he can do it?" (lines 01-02), which the interviewee (ZM) provides: "maybe it take uh one or two years (.) to to do that." (lines 03-04). Extract 4 [UK, Newsnight: China 2; taken from Clayman, 2001]

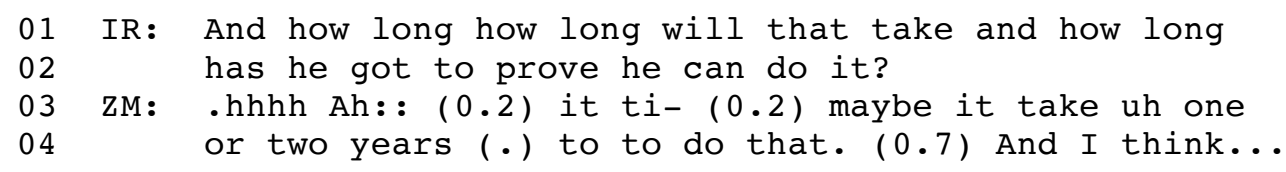


Conforming responses are commonly referred to as either 'sequence-conforming responses' or 'answers' (Heritage, 1984; Stivers \& Robinson, 2006). Conforming responses are hearable as responses, per se, due to the social and sequential organization of initiating actions (Schegloff, 2007).

Non-conforming responses. Alternatively, responses can be nonconforming in that they "depart from, disappoint, or avoid the constraints set in motion by the [question]" (Raymond, 2003, p. 946). For example, in Extract 5, Gerri's 'Yes'/'No' interrogative (lines 01-02) makes conditionally relevant a 'Yes'- or 'No'-type response, but Shirley instead responds with: "Shhe already is in a great deal of pain." (line 03). Extract 5 [Gerri \& Shirley; taken from Raymond 2000]

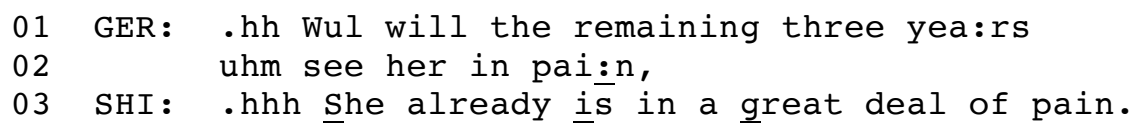

Because non-conforming responses are non-normative, they are examined for 'what else' they might be doing or communicating. As Raymond (2003) observed, while Shirley's response confirms Gerri's question (i.e., it implies a 'Yes'-type response), the non-conforming nature of Shirley's response challenges the presupposition of the question that the woman in question is not currently in pain.

For another example, see Extract 6. Leslie's question, "When::." (line 10), makes conditionally relevant a time reference, but Mum responds instead with: "Oh well I've written it do:w:n.” (line 11).

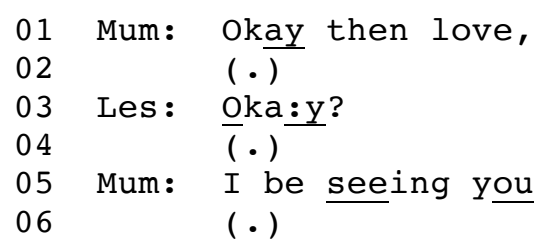




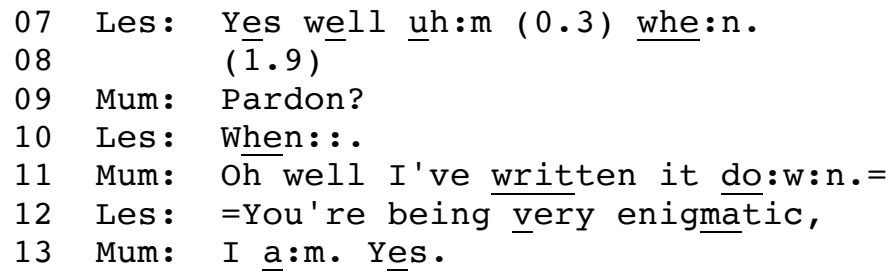

Again, Mum's non-conforming response is non-normative and, in this case, is perceived by Leslie as being 'enigmatic': "You're being very enigmatic," (line 12).

Akin to ordinary conversation, in the context of broadcast-news interviews, because non-conforming responses are non-normative, they are commonly perceived by interviewers as being evasive, and frequently engender various types of sanctions from interviewers, such as blatantly pursuing the question (i.e., in a fashion that overhearing audience members understand as a 'pursuit'). For example, in Extract 7 (drawn from Clayman 2001), the interviewer's question makes conditionally relevant a 'Yes'- or 'No'type answer ("Would you like to see him reappointed to the Fed?;" lines 02-03), yet the interviewee (BD) responds with a non-conforming response: “I think he's been very effective." (line 04).

Extract 7 [US, This Week: Senator Bob Dole (from Donaldson 1987)]

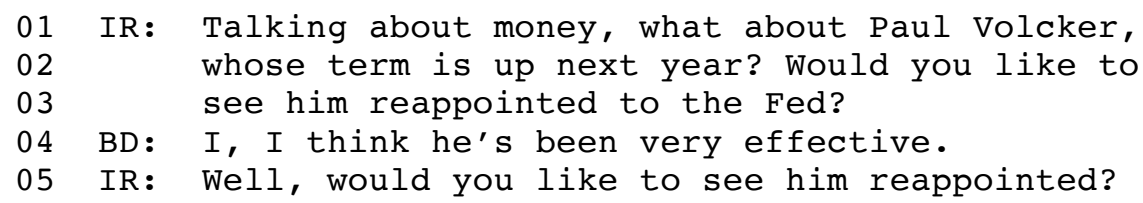

BD's non-conforming response implies a 'Yes'-type answer. However, as in ordinary conversation, this response is non-normative and, in this case, is perceived to be evasive, evidenced by the interviewer's pursuit: "Well, would you like to see him reappointed?" (line 05).

For a second example in the context of broadcast news, see Extract 8 (drawn from Clayman \& Romaniuk, 2011). The interviewer's 'When'-question makes conditionally 
relevant a concrete time reference, "When would you shut down Gitmo." (line 01), yet the interviewee (BO) provides a non-conforming response: "I want to: (.) close Gitmo: a::s uh- as quickly as we can do- (that)" (lines 04-05).

Extract 8 [CNN Situation Room, 31 Oct. 2008: Barack Obama]

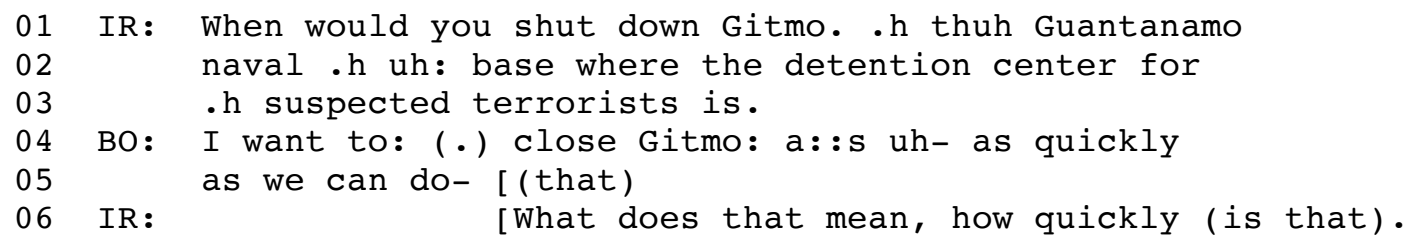

BO's non-conforming response implies, but does not constitute, a concrete time reference. Similar to Extract 7 (immediately above), the interviewer orients to this response as being evasive, as evidenced by his pursuit: "What does that mean, how quickly (is that)." (line 06).

The difference between responding and not responding. So far, this section has discussed two different types of responses, conforming and non-conforming; the former is normative, essentially accepting and confirming the question's presuppositions, while the latter is non-normative, frequently challenging or otherwise resisting the question's presuppositions. However, what about non-responses, or second-positioned turns that are hearably not responsive to questions, and thus do not constitute secondparts at all? The distinction between responses (conforming or non-conforming) and nonresponses to questions warrants explanation because the latter have received almost no attention in prior research.

Determining the status of a response as being non-conforming is almost always done via a procedure of 'diagnosis by exclusion,' that is, through eliminating its status as a conforming response. For example, as a response to a 'Yes'/'No' interrogative, 
responses such as "that's right," "of course," and repeats (Schegloff, 1996b) have all been considered to be non-conforming because they are not versions of 'Yes' or 'No.' While not entirely valid, this procedure of 'diagnosis by exclusion' is grounded in the massive, and massively accountable (Garfinkel, 1967), influence that the conditional relevance of first-pair parts has over how second-pair parts are both produced and, more importantly for the present discussion, how they are understood. According to Schegloff (1968):

The property of conditional relevance is formulated to address [at least the following problem]: How can we rigorously talk about two items as a sequenced pair of items, rather than as two separate units, one of which might happen to follow the other? [...] By conditional relevance of one item on another we mean: given the first, the second is expectable; upon its occurrence it can be seen to be a second item to the first; upon its nonoccurrence it can be seen to be officially absent - all this provided by the occurrence of the first item. (p. 1083)

Thus, as Schegloff and Sacks (1973) noted, a defining - indeed, an almost always sufficient - condition for an utterance to be heard as a response, per se, is simply being placed 'next' after a question: "Finding an utterance to be an answer, to be accomplishing answering, cannot be achieved by reference to phonological, syntactic, semantic, or logical features of the utterance itself, but only by consulting its sequential placement, e.g., its placement after a question" (p. 299).

Sequence organization (Schegloff, 2007) is a major source of coherence (Schegloff, 1990) precisely because the properties of conditional relevance form part of the foundation underlying humans' achievement of intersubjectivity (Schegloff, 1992). As Schegloff and Sacks (1973) noted: 
By an adjacently positioned second, a speaker can show that he understood what a prior aimed at, and that he is willing to go along with that. Also, by virtue of the occurrence of an adjacently produced second, the doer of a first can see that what he intended was indeed understood, and that it was or was not accepted. Also, of course, a second can assert his failure to understand, or disagreement, and inspection of a second by a first can allow the first speaker to see that while the second thought he understood, indeed he misunderstood. (pp. 297-298)

In sum, due to the property of conditional relevance, virtually any utterance positioned next after some question is prone to being hearable as a response, even if it is not a conforming response. This is so even when that utterance is clearly oblique, as in Extract 9 (taken from Raymond, 2000):

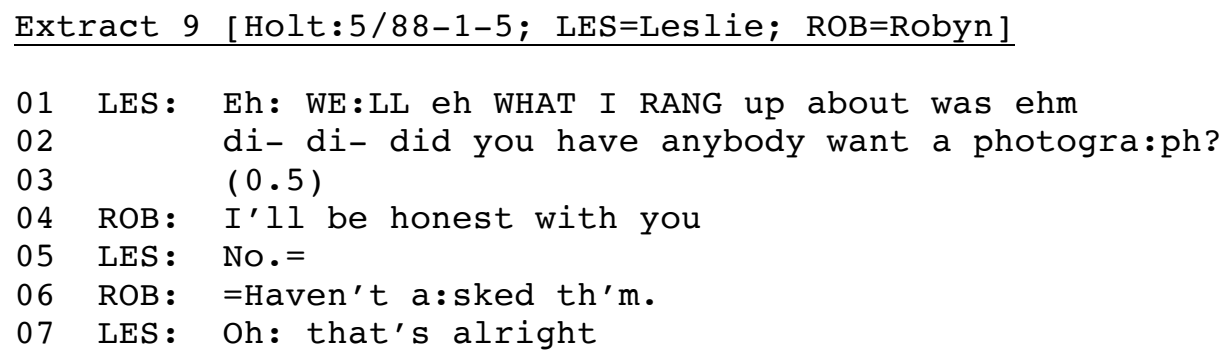

In a decontextualized analysis of English language structures, Robyn's "I'll be honest with you" (line 04) could appear to be tangential to Leslie's question; however, it is not treated as such by Leslie, who hears it as an answer. Specifically, in the wake of Leslie's 'Yes'/'No' interrogative (line 02), "I'll be honest with you" (line 04) is interpreted as a 'No'-type response by Leslie, who answers for Robyn with: "No." (line 05). This interpretation comes largely from the fact that Robyn's "I'll be honest with you" (line 04) is not a conforming response, and thus is non-normative, and therefore, 
due to preference organization, projects the possibility of a dispreferred, 'No'-type response.

For similar reasons, even next-turns that are clearly not responses because they themselves initiate courses of action are nonetheless prone to being heard as projecting dispreferred responses. For example, see Extract 10. After the police dispatcher asks, "Is she pregnant?" (line 01), the caller initiates repair with, "Huh?” (line 02), and thus specifically defers a response in order to resolve some sort of trouble (e.g., hearing the police dispatcher; ibid.).

Extract 10 [IND PD: 14; taken from Schegloff, 2007]:

01 POL: Is she pregnant?

02 CAL : Huh?

03 POL: She's not pregnant is she?

04 CAL: I don't know.

Despite the fact that the caller's "Huh?" (line 02) is hearably not a response, the police dispatcher nonetheless hears it as possibly projecting a 'No'-type response, as evidenced by their revised question that now assumes a 'No'-type response: "She's not pregnant is she?" (line 03).

All of the aforementioned review begs the question: Is it possible for utterances positioned next after questions to be produced and understood as non-responses, that is, as turns/actions whose understanding 'should not' be accountable in terms of the question's conditional-relevance rules? Schegloff and Lerner (2009), albeit in a footnote (7), offered one possible example, reproduced here as Extract 11:

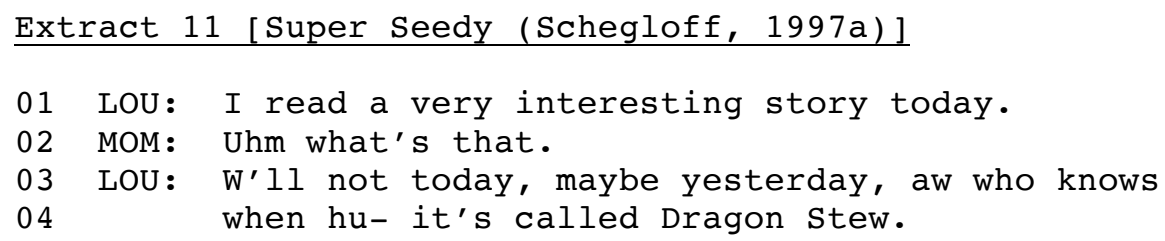


Mom's 'Wh'-question, “what's that." (line 02), makes conditionally relevant at most a name of a story (which Mom ultimately provides: "Dragon Stew;" line 04), and at least talk that somehow addresses a particular 'very interesting story.' Schegloff and Lerner (2009) argued that Lou's "W'll not today, maybe yesterday," is produced and understood as a non-response, specifically as third-turn repair (Schegloff, 1997) on "today" in her pre-telling at line 01 . Their observation clears a path for research into respondents' practices for 'doing non-responding' (c.f., Clayman, 2001). This thesis argues that "First"-prefacing is one such practice.

\section{Questioning and Answering in the Context of the Broadcast-News Interview}

The Republican primary debates examined in this thesis embody a form of institutional talk, or talk that is affected by distinct institutional and organizational parameters (Drew \& Heritage, 1992). In institutional talk, the procedures of ordinary conversation (Sacks et al., 1974) are modified according to the particularized, professional roles and their relevant tasks or specialized role-based activities that are incumbent upon the interactional participants (Heritage \& Greatbatch, 1991). CA has demonstrated that the 'institutionality' of an interaction is determined not by its setting, but rather through participants' co-constructed, turn-by-turn conduct that "realize[s] the occasion of their talk, together with their social roles in it, as having some distinctively institutional character" (Drew \& Heritage, 1992, p. 21). The political debate is a genrespecific type of conduct under the umbrella of the broadcast-news-interview context (Clayman, 1992, 2013; Clayman \& Heritage, 2002a; Greatbatch, 1986a, 1988; Heritage, 1985; Heritage \& Greatbatch, 1991); that is, talk in a political debate is adapted from the generic interactional template of question and answer sequences that characterize news 
interviews. Thus, in order to contextualize the primary-campaign debate as an interactional object of study, a preliminary understanding of the broadcast-news interview's inherent interactional properties is necessary.

As a specialized type of speech-exchange system (Sacks et al., 1974), the broadcast-news interview is actualized through interaction that is locally managed under specific constraints that partially predetermine turn length, content, and order (Clayman, 2013). Because of its more formalized nature, the broadcast-news interview situates the institution-relevant identities of participants (i.e., journalist and public figure), which invokes their relevant interactional roles (i.e., interviewer and interviewee) as well as their corresponding goals (i.e., interviewers should hold interviewees accountable and interviewees should account for their words or actions), which resultantly prescribes how interaction takes place (i.e., through the question-answer format; Clayman, 2013; Clayman \& Heritage, 2002a; Greatbatch, 1988; Heritage, 1985; Heritage \& Greatbatch, 1991). Research on question and answer sequences in broadcast-news-interview settings have expounded on question design (e.g., Clayman, 2010; Clayman, Elliott, Heritage, \& McDonald, 2006; Clayman \& Heritage, 2002a/b; Heritage, 2002, 2003; Heritage \& Roth, 1995; Roth, 2005) and answering practices (e.g., Clayman, 2001; Ekström, 2009; Lee, 2013; Piirainen-Marsh, 2005) to illustrate how participants accomplish certain actions and achieve certain goals (according to the interactional constraints of each particular broadcast setting) through their turns at talk.

As articulated by Heritage and Greatbatch (1991), the "interviewer and interviewee collaboratively sustain a definition of their joint circumstances as 'an interview' (rather than a 'discussion') by restricting themselves to the production of 
questions and answers" (p. 55), and it is overwhelmingly the case that participants comply with the rules of this format, a consequence due in large part to the principle that interview talk is produced for an overhearing audience (ibid.). Thus, social actions are performed and accomplished in the broadcast-news interview through the basic turntaking system of question-answer sequences. Furthermore within these fixed parameters lie interactional norms and practices that participants use to negotiate what counts as genuine questions (i.e., appropriate and/or relevant) that are worthy of suitable (i.e., elaborate) answers (Clayman \& Heritage, 2002a). Taken together, there are certain standards of conduct that participants are expected to follow in broadcast-news interviews.

The interviewer: Norms and tasks. When the interviewee role involves a politician or candidate for public office, the broadcast interaction that takes place is most often conducted with the same (or very similar) norms, goals, and practices as the accountability news interview (Montgomery, 2008, 2011), a type of interview where interviewees are called upon to account for their statements and actions. Imposed with the primary task of holding an interviewee accountable, the interviewer must serve as a tribune of the people (Clayman, 2002); that is, interviewers must speak on behalf of the audience (Clayman, 2007; Heritage, 1985) and elicit answers to questions that are virtually on everyone's mind while also playing 'watchdog' (Clayman \& Heritage, 2002a; Clayman, Heritage, Elliott, \& McDonald, 2007) and persistently scrutinizing interviewee positions. Additionally, as the interactional manager of the broadcast-news interview, the interviewer is given license to control the interview through rounds of different topics, being careful so as not to let interviewees speak on a subject in any way they please 
(Clayman \& Heritage, 2002a). Thus, the interviewer role requires a journalistic duty to maintain a balance of neutralism and adversarialness throughout their line of questioning (ibid., 2002a/b). The challenge, then, is balancing assertiveness with objectivity to manage any interviewee reluctance or resistance in a professional manner. Yet, the news interview's turn-taking system licenses such undertakings, for as long as interviewers stick to asking questions, they can ostensibly present themselves as following the rules.

Question design. Interviewers can design their questions in such a way that allows them to maneuver the interaction in a particular manner. For instance, interviewers can craft questions aimed at soliciting specific information, and can do so by relying on certain question features to impose such constraints. Drawing from Heritage's (2003) discussion of the basics of question design in news interviews, an interviewer's question inherently sets a particular agenda through two dimensions: topical domains (which dictates the content that an interviewee's responsive answer should include) and action domains (which establish conditional-relevance rules that guide what action an interviewee 'should' perform when responding).

Interviewers' questions can be 'loaded' in a variety of ways (Clayman \& Heritage, 2002a, pp. 188-237). For example, questions can be designed so as to embed various presuppositions (Clayman, 2013; Clayman \& Heritage, 2002a, pp. 188-237; Heritage, 2002, 2003). Additionally, questions can be designed to prefer (Clayman \& Heritage, 2002a, pp. 188-237; Heritage, 1984, 2002, 2003; Pomerantz, 1984; Pomerantz \& Heritage, 2013; Schegloff, 2007, pp. 58-96) certain responses. Such is the case with polar, 'Yes'/'No' interrogatives, which prefer a 'Yes'- type answer (Hayano, 2013; Heritage, 2003, 2010). Interviewers can further 'tighten' this preference organization with 
modifications to syntax, such as designing a question as a negative interrogative (e.g., "Didn't you..." and "Isn't this..."), which is routinely understood as an opinionated (and thus non-neutral) assertion because it presupposes a state of affairs and strongly prefers a 'Yes'-type answer (Clayman \& Heritage, 2002b; Heritage, 2002). ${ }^{1}$ In addition to the question itself, interviewers' question prefaces - which are frequently multi-faceted and lengthy - can include background information and presuppositions that add to the ultimate question's constraints (Carlin, Morris, \& Smith, 2001; Clayman, 2013; Clayman \& Heritage, 2002a, pp. 188-237; Heritage, 2003; Heritage \& Roth, 1995).

While interviewers have many methods of "loading" their questions, they are nonetheless journalistically accountable for being "neutral" and have another set of methods for designing legitimately neutral questions. For example, interviewers employ a variety of interactional "footings" (Goffman, 1981; Goodwin, 2007), wherein they attribute their background information and/or positions to other established, credible, third-party sources; this includes being a "tribune for the people" (Clayman, 2002). Interviewers also refrain from affiliating or disaffiliating from the statements they report and present both sides of issues.

In some cases, though, interviewers may be contrarily "non-neutral" (Hutchby, 2011) and challenge interviewees with more aggressive or hostile forms of questioning (Heritage, 2002). For example, Roth (2005) described a form of hostile questioning found in electoral-campaign news coverage called "pop-quizzes," in which interviewers ask candidates questions "in attempts to vet, and potentially discredit" (p. 29) them for not knowing what they ought to know. In a similar vein, Hutchby $(2011,2016)$ described

\footnotetext{
${ }^{1}$ See Heritage (2010b) for a list of polar question constructions and their preferred answers.
} 
instances in the hybrid political interview (i.e., an interview format centered on politics that blends interactional features of the traditional broadcast-news interview and other broadcast genres), where interviewers engage in "assertoric" questioning, stance-taking, personal criticisms, aggressive arguments, and overall increased confrontation. In fact, the literature has revealed that journalists' questions have grown more adversarial in recent years (Clayman \& Heritage, 2002b; Ekström \& Patrona, 2011; Heritage \& Clayman, 2013; Hutchby, 2011, 2016; Montgomery, 2008, 2011; Piirainen-Marsh, 2005). One type of question that tends to functionally go beyond inquiry is the 'supplementary' question, which can be used to probe interviewees for more information, counter or challenge interviewees' assertions/positions, and/or pursue answers when they are absent, inadequate, or otherwise evasive (Greatbatch, 1986b; Romaniuk, 2013). Indeed, the use of supplementary questions is characteristic of the interviewer's role as watchdog to ensure that the constraints of their questions are met.

All of that said, for the most part, interviewers can claim neutrality when launching accountability questions so long as their turns are built as questions and as outwardly implementing the action of seeking information (Heritage \& Clayman, 2013). In conclusion, it is through the socially organized activity of asking questions that speakers are able to enact their professional roles as interviewers and correspondingly accomplish their primary journalistic duties of holding interviewees accountable while maintaining a neutralistic posture.

The interviewee: Norms and tasks. Interviewees, too, are imposed with norms, tasks, and goals relevant to their institutional identities. As Montgomery (2008) explained, "Interviewees are public figures in the sense that they hold institutional 
positions and by their official status are treated as "having some locus"' on the matter at hand (p. 262). As such, interviewees are expected to justify the accounts held in question by the interviewer, and should do so with lengthy, elaborate answers, to the extent that brief responses are typically recognized as being oppositional (Clayman, 2001). Interviewees are expected and pressured to adhere to an interviewer's question-agenda in their responses, and failure to do so can be recognized as being as devious, resistant, or evasive (Clayman, 2001). With these considerations in mind, it makes sense that interviewees have methods for extricating themselves from the various 'bonds' of interviewers' questions, and for designing responses in ways that best achieve interviewees' own goals (e.g., promoting a policy or criticizing a political opponent) while still hearably attending to the constraints of a question (i.e., while still hearably 'responding').

Responsive turn design. Considerable research has been done on how an interviewee does answering in a broadcast-news interview, and how interviewees demonstrate resistance when responding to seemingly unfavorable questions (Clayman, 2001, 2013; Piirainen-Marsh, 2005; Stivers \& Hayashi, 2010). Because questions can be potentially damaging to interviewees' reputations, interviewees frequently use resistant responses in an effort to 'save face.' However, resistant responses risk being seen as resistant and/or evasive precisely because they depart from a question's agenda, that is, because they are non-normative relative to the question's conditional relevancies. As in ordinary conversation (see above), interviewees' responses can be either pair-type conforming or non-conforming (see above, Extracts 1-8). While type-conforming responses are not resistant or evasive, they are generally understood as accepting the 
question as delivered, including its (sometimes adversarial or hostile) background information and presuppositions. Alternatively, resisting or challenging such information entails producing non-conforming responses, which are characterized as forms of resistance and constitute departures from the question's agenda (Clayman, 2013). Thus, not every response is doing answering directly.

Greatbatch's (1986a) work on news interview interactions elucidates how interviewees deploy agenda-shifting procedures in an attempt to control the topical organization of the news interview and/or avoid reputational damages. For example, interviewees can produce violative talk before an interviewer's question is complete (thereby engaging in 'pre-answer agenda shifting' [p. 443]) or in conjunction with their answer, after the question's agenda has been established. The latter form includes a variety of agenda-shifting procedures that can be performed overtly or covertly (Clayman, 2001). Clayman describes practices of resistance that allow interviewees to perform 'damage control;' for example: deferring to the interviewer with requests for permission to shift the agenda, as well as downplaying or defending the shift, which are often used to avoid or prevent further sanctions from the interviewer. Other practices work to disguise interviewee resistance/evasion in the 'clothes' of a direct answer. Such is the case with transformative answers (Stivers \& Hayashi, 2010), or responsive turns that either transform the design (i.e., by specifying or replacing certain question components) or the agenda (i.e., by adjusting its focus, bias, or presuppositions) of a question. Another practice of agenda-shifting is that of reformulating the question (i.e., paraphrasing or rerepresenting the question), which is employed in an effort to either manage or avoid particular aspects of an interviewer's question (Clayman, 1993). However, as Clayman 
writes, "an explicit reformulation can be a somewhat transparent way of sidestepping the question, one that is vulnerable to the journalist's follow-up questions as well as the audience's negative judgment" (p. 185). In rare cases, interviewees can be even more defiant by overtly refusing to answer, which can be a way of dealing with the moral order of the interaction (Ekström, 2009).

In sum, reformulations, refusals, and other covert and overt agenda-shifting practices tend to be used less frequently by interviewees, even when faced with constraining questions, as doing so can be "accountably noticeable" to listeners and observers (including interviewers), which risks unfavorable perceptions (Greatbatch, 1986a, p. 454), especially if interviewer-watchdogs publicly expose such evasion with follow-up questions, and even sanctions (e.g., "You didn’t answer my question!"). Of course, this accountability stems directly from the conditional relevancies embodied by interviewers' questions; returning to a point made earlier, that any talk next after an interviewer's question is prone to being understood as 'some type of response' by reference to the question's conditional relevancies. There are instances, however, where interviewees initially do not respond to the question. Given the influence of a question's conditional relevancies, the present study examines one strategy for getting a stretch of talk understood as being non-responsive.

Contextualizing the political-campaign debate. As an extension of the traditional debate format, the political-campaign debate is a formal speech-exchange system (Sacks et al., 1974) that has its own specialized tasks and variations in turn-taking (Bilmes, 1999, 2001). Previous studies have examined talk in American and European political debates (e.g., Benoit \& Wells, 1996; Bilmes, 1999, 2001; Carlin et al., 2001; De 
Smedt \& Vandenbrande, 2011; Tolson, 2013). However, the breadth of research on political broadcast talk has primarily centered on the generic interactional norms and turn-taking system of the news interview. Recent research has begun to analyze diversified political-interview formats that have emerged in the news media over the past decade, as well as their constitutive features of talk and turn-taking (Clayman \& Romaniuk, 2011; Hutchby, 2011, 2016; Patrona, 2009). Taken together, within each variation of the political-news-interview format, previous studies have demonstrated that participants manage their institutional roles as interviewer and interviewee in a variety of ways, thus accomplishing certain actions and achieving certain goals (according to the constraints of each particular setting) through their turns at talk. In the evolving landscape of political broadcast talk, different dimensions and, moreover, hybridized formats (Hutchby, 2011, 2016) offer distinct communicative resources and strategic possibilities (Tolson, 2013) within the interaction taking place. Diverse settings thus require separatecase analyses in order to describe what is going on interactionally under a format's specialized conditions and unique circumstances.

Scant research has focused on interaction in political-campaign debates in particular, which is inherently a distinct broadcast genre in light of its unique rules, roles, and norms. Bilmes (1999) suggested that the interactional system of political-campaign debates cannot be specified since formats may vary significantly across episodes. While this may be true, a more general understanding of the basic format is still useful in analyzing the performances of its participants. Sacks et al. (1974) described debates as "the most extreme transformation of conversation" (p. 731) due its unique constraints on talk and turn taking. Bilmes (1999) distinguished the traditional debate format from that 
of a political debate, whereby the former's objective is for participants to argue with their co-interlocutors and convince them of their standpoints while the latter's objective is for participants to convince the audience for the purpose of winning votes. Bilmes' (1999, 2001) analysis of the 1992 U.S. Vice-Presidential debate illustrates basic features that are characteristic of talk in political-campaign debates: (1) participants are identified as moderators and candidates; (2) formal topics are fixed and raised by moderators; (3) turns are pre-allocated such that moderators ask questions relative to the topic and candidates provide answers in their turn; (4) time limits are implemented; (5) talk is oriented toward the audience; and (6) opportunities are often given to candidates to address each other. Within this particular context, the moderators and candidates are now imposed with certain tasks (albeit similar to those in broadcast-news interviews in many cases) that are specialized to these roles. For example, in addition to questioning, moderators mediate the interactions that unfold, not only between themselves and candidates, but between the candidates themselves. Likewise, candidates are not only expected to answer questions, but to persuade the audience of their electability for office.

Similar to Bilmes' analyses, Benoit and Wells (1996) offer insight into the discursive conduct in the 1992 U.S. Presidential debates. The authors portray debates as events that present "a widely televised opportunity [for candidates] to clash" (p .7). Furthermore, presidential debates usually frame candidates' performances as being compared to that of their opponents; hence, candidates often seek to attack their opponents and tarnish their opponent's image in an effort to gain a competitive advantage. Together, Bilmes, and Benoit and Wells describe the political-campaign 
debate context as having blended qualities of traditional debate formats, that is, as exemplifying a hybrid form influenced by broadcast production (Benoit \& Wells, 1996).

\section{The Present Thesis}

This introductory chapter discussed the question-answer sequence in terms of the adjacency-pair sequence, reviewed the concept of conditional relevance, and discussed how it shapes and constrains the production and understanding of responses. This chapter also reviewed the actions of questioning and answering in the context of the broadcastnews interview and political debates. In these contexts, the ways that political candidates design and manage their responses apropos the conditional relevancies of moderators' questions becomes an intriguing area of study. This thesis contributes to the literature by

discovering, describing, and analyzing the social organization of a heretofore unexamined practice of action called "First"-prefacing. As noted earlier, one resource that politicians have for temporarily 'getting out from under' the constraints of interviewers' questions, and their various accountabilities (Garfinkel, 1967; Schegloff, 1988), is the practice of prefacing their responsive turn with "first (of all/off)." This practice allows politicians to first address matters that are unrelated to the question, while nonetheless promising a response upon their completion. In this way, "First"-prefacing is a type of practice through which politicians manage agenda-shifting. 
Chapter 2:

\section{Method and Data}

\section{Method: A Brief Review of Conversation Analysis}

Much work has been done to summarize Conversation Analysis (hereafter CA) in detailed overviews (e.g., Drew \& Curl, 2008; Goodwin \& Heritage, 1990; Psathas, 1995; Raclaw, 2015; Robinson, 2012; Sidnell, 2009; Sidnell \& Stivers, 2013). What follows is merely a sketch of CA's background and purpose.

The field of CA lies at the intersection of the work of Erving Goffman (1963, 1964, 1967) and Harold Garfinkel (1967). On the one hand, Goffman was studying what he called 'the interaction order' (Goffman, 1983), or direct, naturally occurring interaction between humans in naturalistic settings. Goffman argued that the interaction order was a socially organized system whose orderly features could be systematically described in their own right, independent from other social systems, such as the family (c.f., Parsons, 1937/1949). On the other hand, Garfinkel was studying how humans make their conduct sensible to each other, that is, how humans achieve intersubjectivity (for review, see Heritage, 1984). CA was founded by Harvey Sacks (who was a student of Goffman), Emanuel Schegloff, and Gail Jefferson. Sacks (1992) and Schegloff (1987b) argued that the interaction order - or, as Schegloff described it, 'talk-in-interaction' - is the "primordial site of sociality" (ibid., p. 208). CA describes how humans produce and understand recognizable social action in and through talk-in-interaction and its social organizations (i.e., those of turn taking, sequence, repair, reference, and many others).

The crux of CA rests on the belief that there exists orderliness to everyday talk, "conceived of as the product of shared methods of reasoning and action to which all 
competent social interactants attend" (Stivers \& Sidnell, 2013, p. 2), which can be explored by examining the structural and organizational characteristics of talk. In their pioneering work of talk-in-interaction, Sacks et al. (1974) proposed a model of turntaking systematics fundamental to mundane conversation. They posited that the turntaking system of conversation exists in "a variety of transformations" (p. 730) across different speech environments (e.g., ordinary conversations, interviews, debates, etc.), and that the differing rules of these speech-exchange systems fundamentally shape the production and understanding of action.

$\mathrm{CA}$ is an empirical, qualitative approach that uses "observation as a basis for theorizing" (Sacks, 1984, p. 25). CA's data are audio- and video-recordings of the interaction order - which can include mundane or institutional talk-in-interaction - which are then transcribed using a highly complex system (Hepburn \& Bolden, 2013; Jefferson, 2004) designed to capture how interaction is actually produced (i.e., nonstandard words and sounds, silences, overlapping talk, amplitude, pace, intonation, etc.). With data in hand, analysts are encouraged to hold "in abeyance premature questions about why a social activity is organized in a particular way, focusing instead on what is being done and how it is accomplished" (Clayman \& Gill, 2005, p. 595, emphasis in original). Optimally, data are examined in an unmotivated manner (Sacks, 1984), that is, "giving some consideration to whatever can be found in any particular conversation we happen to have our hands on, subjecting it to investigation in any direction" (ibid., p. 27). As Clayman and Gill described it, one common way of beginning an analysis is to 'begin with a noticing;' that is, the analyst repeatedly views and re-views their data until they notice: 
...something about the way a speaker says or does something at a given point within interaction, something that strikes the analyst as in some way interesting [...] Having noticed a [possibly orderly phenomenon], the analyst can then proceed to analyze it in terms of what it might be "doing" - the action(s) that it accomplishes, and how it figures within and contributes to an ongoing course of interaction. (p. 596)

Any phenomenon discovered in this fashion is only possibly orderly because that order must be shown. As opposed to relying on analysts' own speculations about what the phenomenon might be doing (e.g., auto-ethnography and some forms of critical discourse analysis), and as opposed to relying on members' retrospective opinions about what the phenomenon might be doing (e.g., from interviews or focus groups), CA demands that analyses are grounded in the understandings and orientations of the participants themselves (for review, see Heritage, 1984; Mills, 1940). Indeed, as Schegloff and Sacks (1973) noticed, the interaction order contains a built-in proof procedure:

We have proceeded under the assumption [...] that insofar as the materials we worked with exhibited orderliness, they did so not only for us [...] but for the coparticipants who had produced them. If the materials $[\ldots]$ were orderly, they were so because they had been methodically produced by members of the society for one another, and it was a feature of the conversations that we treated as data that they were produced so as to [...] allow the participants to display to each other their analysis, appreciation and use of that orderliness. (p. 290)

In order to reveal that a phenomenon is a social practice of action, analysts must prove that it is systematically produced and understood similarly on repeated occasions. Thus, once a possible phenomenon is identified, analysts go about collecting multiple 
instances of it. These instances are used to determine the phenomenon's constitutive features, validity (i.e., through an analysis of deviant and negative cases; Robinson, 2007), and, ultimately, the social action it performs (Schegloff, 1996b).

\section{Initial Motivations for Selecting Data}

On August 6, 2015, the first of the U.S. primary Republican Presidential campaign debates was broadcast live by Fox News. Nine candidates for the Republican Party's nomination and three debate moderators took the stage for just over two hours discussing a range of political issues. This debate is reported to have earned the highest ratings for a single live broadcast non-sporting cable program in history, drawing in approximately 24 million viewers (Fox News, 2015). In the days to follow, the media unleashed a flood of reviews on the event; however, there was one particular participant who was markedly spotlighted and subjected to a significant amount of media attention that of U.S. Presidential candidate, Donald Trump.

Indeed, Trump made controversial statements in the debate - both in response to the moderators' questions and in rebuttal to other candidates' accusations - that are constitutive of behavior typically unseen in political interactions. Various news stories reported on Trump's discursive conduct in the debate in comparison to the other participants. While many stories criticized Trump's performance as unconventional and shocking, some reinterpreted the atypical features of his conduct as advantageous relative to other candidates' more traditional political demeanors. Take, for example, the following news headlines produced within 48 hours after the debate aired: (1) Republican Debate: Trump was Garbled, Incoherent - but Dominant (The Guardian, 07, August 2015); (2) In the GOP Debate Playbook, Trump Has Written His Own Rules (The 
Washington Post, 07, August 2015); and (3) Trump Steals Show With Mix of Pizazz and Politics; Outrageous, Unapologetic and Demeaning, He Kept Opponents Off Balance (International New York Times, 08, August 2015). Initially, this thesis intended to focus on the 2015-2016 Republican primary debates generally, and the behavior of Donald Trump specifically, because multiple media outlets from the U.S. to the U.K. independently noticed something interactionally interesting about Trump's behavior and the social actions it was being used to implement.

\section{Initial Data-Selection Procedure}

Preliminarily, the initial research focus was on how Donald Trump's behavior compared to that of other traditional political candidates. The general unit selected for analysis was the question-answer sequence. Participating in virtually all of the 12 debates were the four candidates that ended up being the finalists in the Republican primary election, and these candidates were selected for comparison: Donald Trump (a nontraditional politician), and Marco Rubio, Ted Cruz, and John Kasich (all traditional, current holders of some political office). To promote comparability, an attempt was made to hold constant the debate's broadcasting network, the question thread, and the debate moderators. ${ }^{2}$ Four of the 12 debates (numbers $2,5,10$, and 12) were broadcast by CNN and were moderated by Jake Tapper, Wolf Blitzer, Dana Bash, and Hugh Hewitt, and these were selected for analysis. High definition videotapes of all live debate broadcasts were available through YouTube, which is a public online video hosting service that allows users to view, upload, and/or share videos free of charge

\footnotetext{
${ }^{2}$ See Table 2, Appendix A for a full list of debate schedules, locations, hosting broadcast networks, and participants.
} 
(https://www.youtube.com). The total amount of video footage for analysis is just over nine hours. Standardized transcripts for these debates were retrieved through The American Presidency Project (http://www.presidency.ucsb.edu), which is a non-partisan, public, online database of presidential documents.

Within these four debates, 25 question threads were selected (e.g., on topics such as Social Security, immigration, terrorism) in which the same moderator (e.g., Jake Tapper) asked a question of both Trump and one of the other more traditional political candidates. ${ }^{3}$ The resulting data were 50 question-answer sequences, 25 involving Trump and 25 involving the other candidates. These 50 question-answer sequences were then retranscribed according to Jefferson's (see e.g., 2004) system of transcription. ${ }^{4}$ As Hepburn and Bolden (2013) explained, this selective and highly detailed process of transcription does not replace the data; rather, it is a way to represent the data in a way that reveals the orderliness of talk and the production of actions in social interaction. During analysis, video observation was used in tandem with transcripts.

\section{Subsequent Data-Selection Procedure: The Evolution of the Research Focus}

Although this project's initial research focus was on how Donald Trump's behavior compared to that of other candidates, the process of unmotivated looking and analysis (described above) revealed a possible phenomenon that was not comparative. Specifically, in 12 of the 50 question-answer sequences (24\%), candidates began their responsive turn with some version of "first of all" and then immediately produced talk that seemingly 'ignored' the question. In order to pursue this phenomenon, the four focal

\footnotetext{
${ }^{3}$ See Appendix B for initial data collection of selected question threads.

${ }^{4}$ See Appendix C for a list of CA transcription conventions.
} 
debates were reexamined for all of their question-answer sequences, resulting in 47 cases of what this thesis calls "First"-prefacing. ${ }^{5}$ These became the focal data, all of which were re-transcribed according to CA conventions. 12 cases were selected to present in this thesis. These cases represent both particularly clear and unclear demonstrations of "First"-prefacing in responsive turns; however, the non-presented cases do not contradict the main argument.

\section{The 2015-2016 CNN U.S. Presidential Republican Primary Debates}

The following subsection describes basic features of the four CNN primary debates (2nd, 5th, 10th, and 12th) examined in this thesis. ${ }^{6}$ The 2 nd and 12 th primary debates were moderated by Jake Tapper, a professional journalist and Chief Washington Correspondent for CNN. The 5th and 10th primary debates were moderated by Wolf Blitzer, also a professional journalist and CNN television news anchor. All four debates had joining hosts, including Dana Bash, an American journalist and CNN's Chief Political Correspondent, and Hugh Hewitt, a talk show host for Salem Radio Network. Other participating hosts included Maria Celesta Arrasás (10th debate), who is a television journalist for the American-Spanish language television network Telemundo, and Stephen Dinan (12th debate), a reporter for the Washington Times.

The rules for each debate were stated by the leading moderator during the opening segment. In the 2nd primary debate, candidates were allotted one minute to answer questions and 30 seconds for follow-ups and rebuttals. In the 5th and 10th debate, candidates had one minute and 15 seconds to answer and 30 seconds for follow-ups and

\footnotetext{
${ }^{5}$ A description of how this thesis characterizes "First"-prefacing is provided in Chapter 3: Analysis.

${ }^{6}$ See Table 1, Appendix A for a detailed list of the CNN Republican primary debates.
} 
rebuttals. Candidates were also informed that they would be given time to respond if singled out for criticism. In the 12th primary debate, candidates had one minute and 15 seconds to answer each question, with 45 seconds to respond to follow-ups or for rebuttals if their names were invoked. Audience viewers were informed that the debates implemented timing lights that were visible to the candidates to warn them when their time was up. A buzzer - audible to the candidates and the viewing audience - rang when candidates' times had ended. In each debate, candidates were lined up on the stage based on their rankings in recent polls. Candidates were given 30 seconds for introductory statements (one minute in the $12^{\text {th }}$ debate), and one minute for closing remarks (in all but the 2nd debate), which occurred before and after the questioning portion, respectively.

Typical of political-debate formats, in addition to laying out the ground rules, the moderators managed the debates by introducing subject rounds, by selecting specific candidates to respond to specific questions and, of course, by asking questions. Subject rounds tended to deal with one large/general topic (e.g., Social Security, terrorism, immigration). During subject rounds, moderators asked slightly different sub-topical questions to different candidates. The order of questioning often, but not necessarily, began with the candidate who was currently leading in the polls. 
Chapter 3:

Analysis

The analysis section contains four subsections. The first subsection briefly introduces readers to the practice of "First"-prefacing by making a number of common observations about three data extracts in ways that expose the phenomenon relatively clearly. Before continuing the analysis, the second subsection outlines this thesis' claims about the practice of "First"-prefacing and the action it implements; although supported by the three initial introductory cases, these claims are defended in much greater detail in subsequent subsections. The third subsection includes cases in which participants including the speakers of "First"-prefaces, other debate candidates, and debate moderators - somehow overtly orient to the action implemented by "First"-prefacing. Finally, having grounded the practice of "First"-prefacing, the fourth subsection examines two challenging data cases in which the practice is less vernacularly obvious, especially because participants do not overtly orient to the practice; however, neither case constitutes clear, contradictory evidence.

\subsection{Introductory Exemplars of "First"-Prefacing}

This subsection is designed to introduce readers to the phenomenon of "First"prefacing by making a number of common observations about three data fragments (Extracts 12, 13, and 14). For the first example, see Extract 12. As context, immediately prior to the focal question-answer sequence between Jake Tapper and New Jersey Governor Chris Christie (lines 04-37), Tapper had asked candidate, Donald Trump, a question regarding his own plan for how to deal with immigration, including its cost and the logistics of deporting 11 to 12 million undocumented immigrants. Part of Trump's 
answer is represented at lines 01-03.

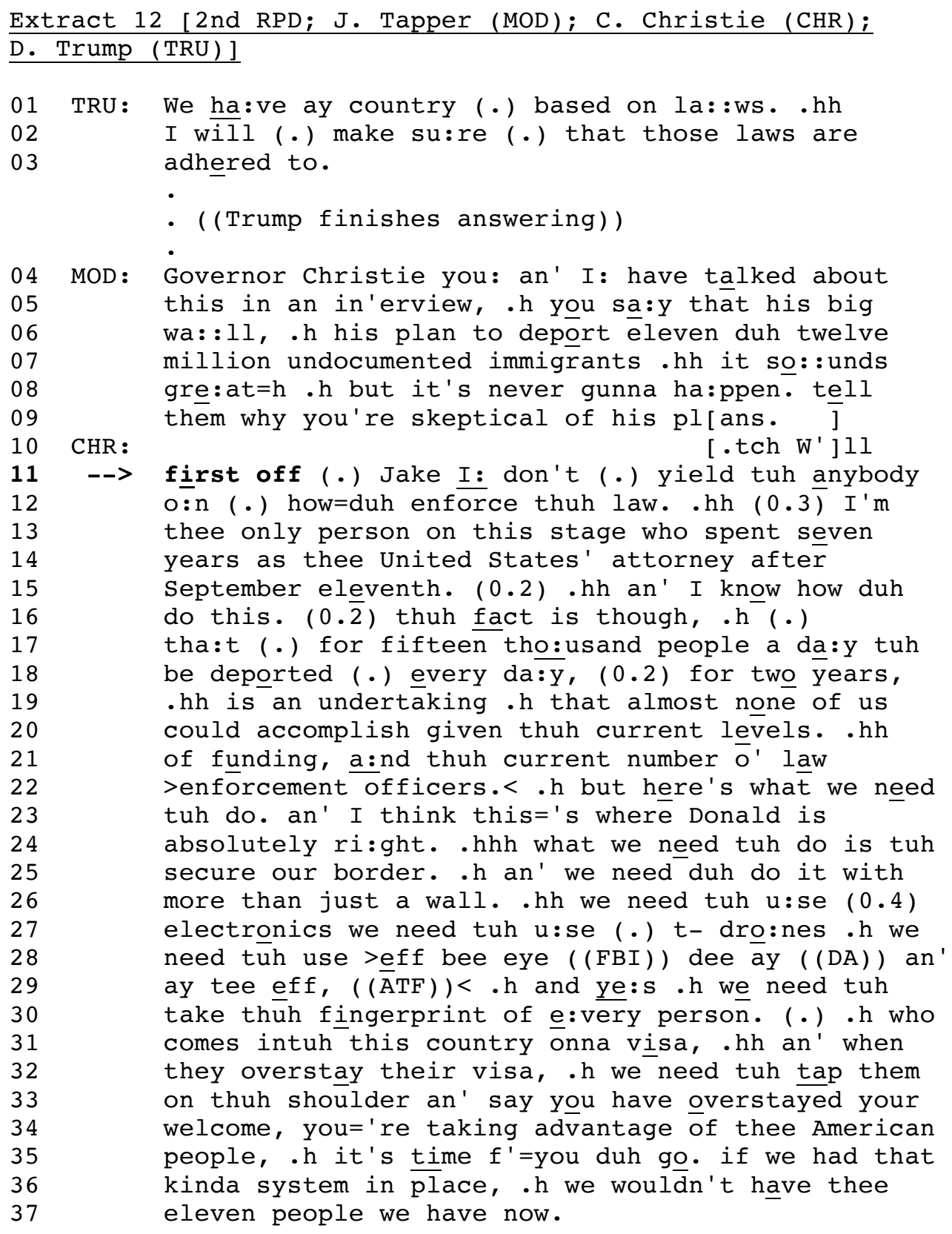

In the preface to his question, Tapper establishes the topical agenda of his

question by using the anaphoric pronoun "this" ("Governor Christie you: an' I: have

talked about this in an in'erview;" lines 04-05), which refers to Trump's immigration plan

("you sá:y that his big wa::1l, .h his plan to deport eleven duh twelve million 
undocumented immigrants;" lines 05-07). Tapper works to neutralize (Clayman, 1988, 1992; Clayman \& Heritage 2002a, pp. 150-187; Heritage \& Greatbatch, 1991) his question preface by quoting Christie (“you sa::y;" line 05), and then frames Trump's plan as improbable: “...it so::.unds gre:at=h .h but it's never gunna ha:ppen.” (lines 07-08). Although not structurally designed as an interrogative, Tapper's question comes at lines 08-09: "tell them why you're skeptical of his plans.". Tapper's question makes conditionally relevant a justification for Christie's doubts about Trump's immigration plan (this is the question's action agenda; Heritage, 2003).

Christie begins his turn in terminal overlap (Jefferson, 1984) with Tapper's question: “.tch W'll” (line 10). Although more will be said later about the practice of prefacing responsive turns with "Well" (see 4.2.3, below), note for now that it can claim that what is to immediately follow is a non-straightforward response, that is, one that does not directly respond to the question's action agenda (Heritage, 2015; Schegloff \& Lerner, 2009). Christie continues by producing the focal practice of this thesis: "firrst off" (line 11). On the one hand, given that Tapper's question makes conditionally relevant a justification, Christie's "first off" might be expected to project the 'first' of more than one (part of a) justification. On the other hand, this thesis demonstrates that such an expectation - made in the absence of analysis - turns out to be incorrect, and recollects Sacks' (1984) cautionary note:

I want to argue that, however rich our imaginations are, if we use hypothetical, or hypothetical-typical versions of the world we are constrained by reference to what an audience, an audience of professionals, can accept as reasonable. That might not 
appear to be a terrible constraint until we come to look at the kinds of things that actually occur. (p. 25)

Christie continues by addressing the moderator by name: "Jake" (line 11). In line with Christie's turn-initial 'Well,' in the context of the broadcast-news interview, such address terms at the beginning of responsive turns frequently project that the interviewee will depart from the question's topical and/or action agenda (Clayman, 2010). This is, in fact, what happens when Christie continues with: “I: don't (.) yield tuh anybody o:n (.) how=duh enforce thuh law" (line 11-12), which has nothing to do with Trump's immigration plan or Christie's opinion of it. Instead, here Christie begins to defend his unique epistemic authority (Heritage, 2012) regarding law enforcement generally, continuing with: "I'm thee only person on this stage who spent seven years as thee United States' attorney after September eleventh.” (lines 12-15). Christie's defense (including the words: "how=duh enforce thuh law;" line 12) appears to be directed not at Tapper's question, but rather at Trump's claim in his prior answer ("I will (.) make su:re (.) that those laws are adhered to;" lines 02-03), which may have been understood (at least by virtue of being asserted first, temporally, in the interaction) as tacitly claiming epistemic/practical authority over law enforcement (Heritage, 2012, 2013; see also Heritage \& Raymond, 2005). In sum, Christie's “first off” does not project a 'first' of more than one (part of a) justification, which would be directly responsive to Tapper's question, but rather an action - that is, a defense of his relative expertise in terms of law enforcement, and thus a form of identity management (c.f., Brown \& Levinson, 1987; Goffman, 1963) - that is wholly unrelated/unresponsive to the question. 
Finally, note that, immediately after his self defense - specifically, after “.hh an' I know how duh do this." (lines 15-16) - Christie does begin to respond to Tapper's question: "thuh fact is though, .h (.) tha:t (.) for fifteen tho:usand people a da:y tuh be deported every da:y, (0.2) for two years, .hh is an undertaking .h that almost none of us could accomplish given thuh current levels. .hh of funding, a:nd thuh current number o' law >enforcement officers." (lines 16-22). This unit can be heard as a response (Clayman, 2001) insofar as Christie: (1) topicalizes Trump's immigration plan by referencing the deportation of all undocumented immigrants ("for fifteen tho:usand people a da:y tuh be deported every da:y, (0.2) for two years;"' lines 17-18), which contains a lexical repeat from the question preface ("deport;" c.f., line 06); and (2) describes inadequate funds and manpower as reasons for his doubt about Trump's plan ("is an undertaking .h that almost none of us could accomplish given thuh current levels. .hh of funding, a:nd thuh current number o' law >enforcement officers;' lines 19-22), which directly responds to Tapper's request for a justification of skepticism. In sum, in addition to projecting a 'first' action that will precede a response to the question, Christie's "first off" also appears to project an ultimate response to the question.

For a second example, see Extract 13. At lines 06-12, through a series of neutralizing quotes (see especially "Your wo:rds the good ones;" line 11; Clayman 1988, 1992; Holt, 1996), the moderator, Wolf Blitzer, establishes a controversial position (Clayman, 2017; see Schegloff, 1988) by Donald Trump (i.e., the question recipient) on immigration. Then, at lines 12-16, Blitzer quotes another political candidate, Ted Cruz, who accusatively characterized Trump's position as constituting "amnesty" (line 16). 
Ultimately, Blitzer asks Trump to agree or disagree with Cruz's characterization: "Is it."

(line 16).

Extract 13 [10th RPD; W. Blitzer (MOD); D. Trump (TRU)]

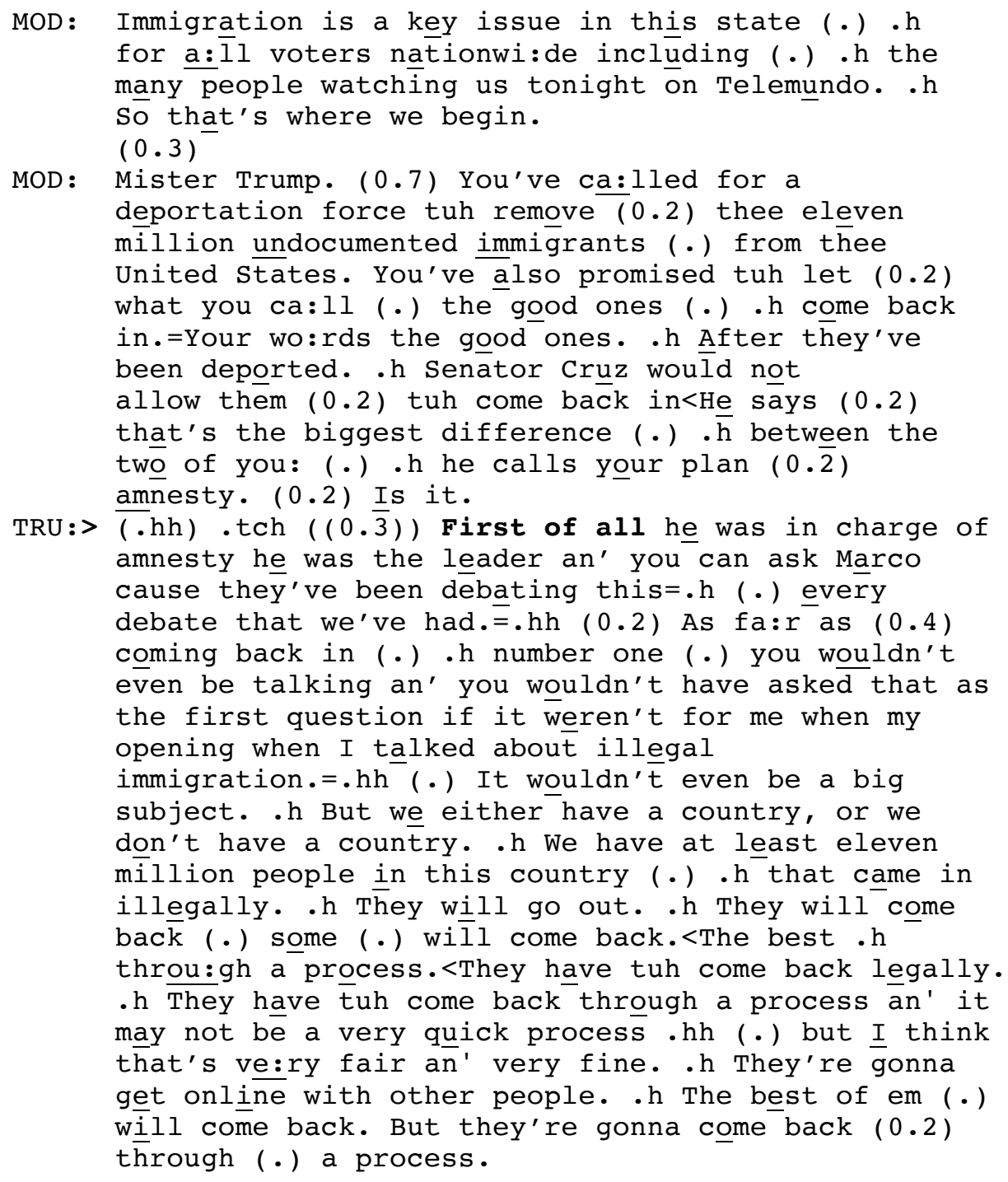

Blitzer's question makes conditionally relevant either a 'Yes'- or 'No'-type

answer (this is the question's action agenda; Heritage 2003) regarding a specific topical

agenda (ibid.), that being whether or not Trump's immigration plan can be characterized

as constituting amnesty. After a brief in-breath and tongue click, "(.hh) .tch" (line 17),

Trump begins his responsive turn with "First of all" (line 17). On the one hand, compared 
to Extract 12, where the format was 'first off,' here the format is 'first of all;' furthermore, Trump's "First of all" is not preceded by "Well," nor is it followed by an address term, as we saw in Extract 12. On the other hand, similar to Extract 12, the talk that immediately follows "First of all" is wholly unrelated/unresponsive to the question. That is, rather than producing a 'Yes'- or 'No'-type answer, Trump produces a counteraccusation of Cruz and his immigration plan, "he [Ted Cruz] was in charge of amnesty" (lines 17-18; note the contrastive stress on "he"), which Trump then upgrades: "he [Ted Cruz] was the leader" (line 18; again note the contrastive stress on "he"). Another way of grounding the assertion that this talk is 'unresponsive' to the question is that it constitutes a first-part action, that is, an accusation (which is sequentially akin to a 'counter;' Schegloff, 2007). Trump continues to justify his accusation by appealing to consensus, both explicitly (i.e., from Marco Rubio, who is another debater) and implicitly (i.e., from any debate-watching audience): “an’ you can ask Marco cause they’ve been debating this=.h (.) every debate that we've had;"' lines 18-20). In sum, Trump's counteraccusation addresses the accusation embodied in Blitzer's question preface, ".h he [Ted Cruz] calls your plan (0.2) amnesty." (lines 15-16), and thus addresses Cruz's plan, rather than addressing either Trump's own immigration plan or Trump's agreement/disagreement with it being characterized as 'amnesty.'

Also similar to Extract 12, Trump does eventually respond to Blitzer's question. Immediately after his justification, Trump says: “.hh (0.2) As fa:r as (0.4) coming back in (.) .h number one (.) you wouldn't even be talking an' you wouldn't have asked that as the first question if it weren't for me when my opening when I talked about illegal immigration." (lines 20-25). This unit is designed as a response, per se, in at least two 
ways (Clayman, 2001). First, Trump signals a shift to something 'else' or 'new' with "As fa:r as" (line 20), and then repeats “coming back in" (line 21) from Blitzer's question (c.f., "come back in;" lines 10-11). Second, Trump addresses the topical agenda of Blitzer's question by dealing with his own immigration plan: "if it weren't for me when my opening when I talked about illegal immigration” (lines 23-25).

Admittedly, Trump's ultimate response contains an agenda shift (Greatbatch, 1986a). Specifically, Trump never ultimately speaks to the status of his immigration plan as 'amnesty,' and thus never addresses the question's action agenda (Heritage, 2003) by providing some type of 'Yes'- or 'No'-type answer. Nevertheless, similar to Christie's 'first off' in Extract 12, Trump's 'first of all' in Extract 13 appears to project a 'first' action/matter that will precede a response to the question, and thus that such a response will also be forthcoming.

For a final introductory example, see Extract 14. The moderator, Hugh Hewitt, prefaces his question by asserting, as well as grounding, a position taken by Donald Trump regarding the release of his tax returns: "a ye:ar ago:: (0.4) you to:ld me: (0.4) on my radio show. thee audio an' the transcripts are out they're on youtube. that you would release yer tax returns." (lines 01-05). Hewitt follows this with his question, which is accusatory insofar as it seeks (dis)confirmation of a possible infelicity (Schegloff, 1988): “Are you going back on yer (.) commitment." (lines 05, 07). Hewitt's question arguably prefers a 'No'-type answer (Pomerantz, 1984).

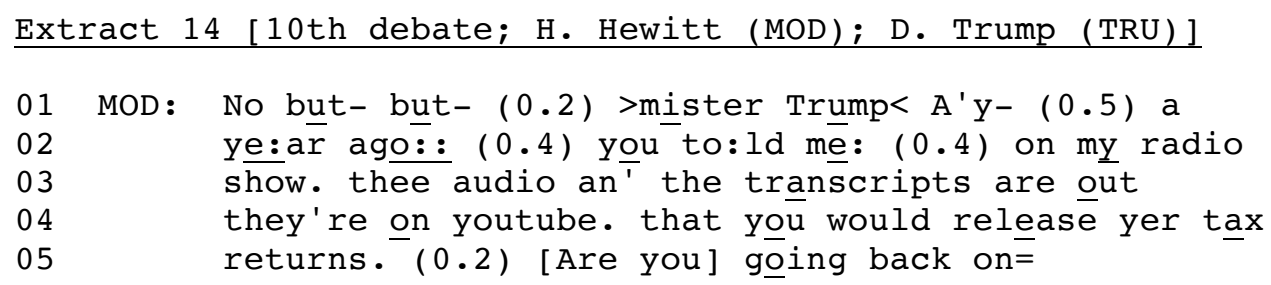




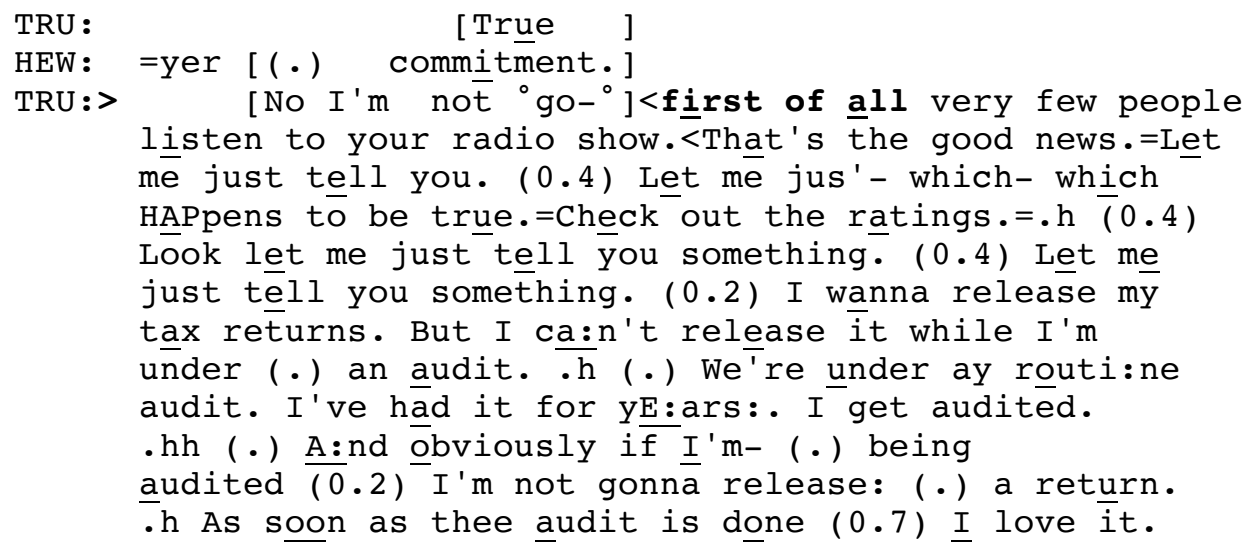

Hewitt's question makes conditionally relevant either a 'Yes'- or 'No'-type answer (this is the question's action agenda) regarding a specific topical agenda, that being Trump's release of his tax returns. Trump begins to respond to both agendas, respectively with "No" (line 08 ) and "I'm not ${ }^{\circ}$ go- ${ }^{\circ}$," which effectively repeats Hewitt's "Are you going..." (Note that Trump responds early, in overlap with Hewitt's question, and thus in a 'preferred' manner; Pomerantz, 1984; Pomerantz \& Heritage, 2013). However, Trump cuts himself off (symbolized by the hyphen) prior to completing his utterance, "No I'm not ${ }^{\circ}$ go- $-"$ (line 08), which projects self repair (Kitzinger, 2013; Schegloff, Jefferson, \& Sacks, 1977). Importantly, this utterance is produced as a single intonational unit (Du Bois, 1991), with "No" being prosodically 'blended' into "I'm" (Raymond, 2013), and thus we can say that Trump cuts off the first intonational unit of his turn. Along these lines, Trump restarts his entire turn (which included his "No"), and proposes to replace it with "first of all" (line 08). This analysis is supported by the fact that Trump restarts precisely upon possible completion of Hewitt's question (i.e., after “commitment;" line 07), and thus precisely when Trump's subsequent talk is likely to be produced 'clear' of overlapping talk, which is similar to a phenomenon Schegloff (1987c) described as a recycled turn beginning. 
Similar to Extracts 12 and 13, Trump immediately follows "fịrst of all" with talk that is wholly unrelated/unresponsive to the question and its agendas: "very few people listen to your radio show.<That's the good news." (lines 08-09). Here, Trump personally criticizes the moderator by asserting a dearth of listenership to his show (see Schegloff, 1988), as well as characterizing that absence as being positive.

Again similar to Extracts 12 and 13, immediately after this digression, Trump begins to respond to the question: "Let me just tell you." (lines 09-10). Although Trump briefly diverts back to his criticism at lines $10-11$, there is evidence that "Let me just tell you." began a response because Trump eventually repeats it ("Look let me just tell you something;" line 12) and then addresses the question's topical agenda: "I wanna release my tax returns. But I ca:n't release it while I'm under (.) an audit.” (lines 13-15). Here, Trump provides an account for his initial 'No'-answer, which is a pragmatic component of such responses (c.f., Heritage, 1984; Levinson, 1983).

\subsection{Excursus: The Practice of "First"-Prefacing and the Action it Implements}

Armed with the analysis of Extracts 12-14 (above), this subsection previews six claims being made about "First"-prefacing as an interactional practice of action, broken down into claims about the practice's composition, position, and action (Schegloff, 1996a). To be clear, while these claims will be further supported in subsequent subsections, this current subsection does not engage in analysis, per se. For the purposes of this thesis, all of the following claims are restricted to the institutional context of political-campaign debates. While "First"-prefacing is found - and, in fact, may operate similarly - in other contexts, such as broadcast-news interviews and even ordinary conversation, these observations are addressed in the final Discussion chapter. 
4.2.1. The composition of the practice is most commonly "first of all" (40/47; 85\%; see Extracts 13 and 14, above; see also Extracts 16, 17, 18, 19, 20, 22, 23, and 24, below). There was one case in the data in which the format was "first off" (Extract 12). At least semantically, these two formats have a 'bracketing' feature in that they initiate and frame an upcoming action or activity in a way that is "marked off from the ongoing flow of surrounding events" (Goffman, 1974, p. 251). As Goffman (1974) wrote:

The bracket initiating a particular kind of activity [...] not only will establish an episode but will also establish a slot for signals which will inform and define what sort of transformation is to be made of the materials within the episode. (p. 255-256) Additionally, there is one example presented in this thesis where the composition is merely "First" (6/47; 13\%; Extract 21, below). However, in this case, "First" is immediately followed by a token request for permission, "lemme say," a meta-linguistic clause that can function as a type of initial 'bracket' (Schiffrin, 1980). Note that, in 11/47 (23\%) cases, the format 'first (off/of all)' is immediately followed by similar bracketing talk, such as "I gotta say" (Extract 16), "lemme go back" (Extract 17), and "lemme just add" (Extract 18). Given these caveats, and for the sake of simplicity, here and throughout the rest of this thesis the focal practice will be referred to as "First"-prefacing.

4.2.2. In 45 of out 47 cases (96\%), the composition of 'first (off/of all)' involves increased amplitude/stress on the word 'first' (symbolized in the transcript by underlining).

4.2.3. In the data, "First"-prefacing is prefaced by the particle "Well" in $30 / 47$ cases (64\%; see Extract 12, above; see also Extracts 18, 19, 22, and 24). Among the wide range of actions accomplished by the practice of "Well"-prefacing turns (Heritage, 2015), 
this thesis focuses on two accomplished by "Well”-prefaced responsive turns. First, as investigated by Schegloff and Lerner (2009), and elaborated on by Heritage (2015), the practice of "Well"-prefacing responses to questions claims that the talk to follow will be somehow 'non-straightforward' relative to the questions' constraints, most notably those entailed by the question's conditional relevance rules (Schegloff, 1968, 2007; Schegloff \& Sacks, 1973) and/or the multiple actions implemented by such questions (e.g., a request for confirmation that is also an accusation). For example, Schegloff and Lerner observed that "Well"-prefaced responses to 'Wh'-questions were either variously nontype conforming (Raymond, 2003) and/or multi-unit responses. Second, according to Heritage (2015):

Well-prefacing functions as an alert that the talk to follow will privilege its speaker's perspectives, interests or projects in the ensuing talk, regardless of whether these perspectives etc. are supportive, antithetical, or neutral with respect to those of others. (p. 89)

As will be demonstrated, both of these functions of "Well"-prefaced responses to questions support the claims made (below) about the function of "First"-prefacing.

4.2.4. Excepting 'pre-turn-beginning' behaviors (Schegloff, 1996a) such as silence, breathing, tongue clicking, and 'Uh,' and excepting the particles "Well," "Okay," "Look," and "Alright," "First"-prefacing is effectively turn-initial. In cases where "First"prefacing is not turn-initial, it appears to implement a very different action of projecting responsive listing. Along these lines, Schegloff (1982) briefly referred to 'first of all' as a "list-initiating marker," which projects "that after the turn-unit in which the 'first' is done, more will follow. Note that there may otherwise be no particular need to pre-mark 
an item as a first in a list $[\ldots]$ other than the problem of getting to produce subsequent items" (p. 75). Importantly, the claim that non-turn-initial 'first of all' projects 'responsive listing' involves the observation that it prefaces a response, per se, which the practice of "First"-prefacing does not appear to do.

For an example of a non-turn-initial 'first of all,' see Extract 15 (below).

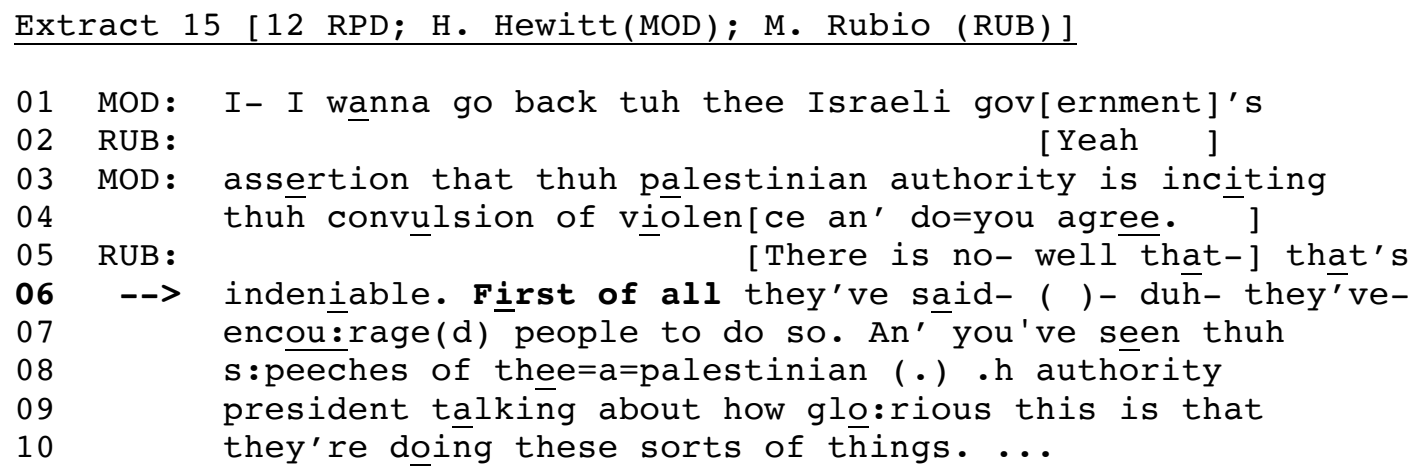

The moderator's question is a 'Yes'/'No'-interrogative (i.e., the question's action agenda: "do=you agree;" line 04), referring to the statement: "thee Israeli government's assertion that thuh palestinian authority is inciting thuh convulsion of violence" (i.e., the question's topical agenda; lines 01, 03-04). In this case, Rubio's "First of all" (line 06) is not turninitial because his turn begins with a non-conforming, agreeing response to the question, and this responding unit is brought to possible completion (unlike Trump's incomplete unit in Extract 14, above, which was cut off): "that's indeniable." (lines 05-06). Instead, Rubio's "First of all” (line 06) immediately precedes the beginning of a justification for his response, which addresses the question's topical agenda: “they’ve said- ( )- duhthey've- encou:rage(d) people to do so." (lines 06-07).

4.2.5. The practice of "First"-prefacing described in this thesis comes in second (pair part) position (Schegloff, 2007; Stivers, 2013) relative to questions, specifically polar ('Yes'/'No' interrogatives) and 'Wh'-type questions (Fox \& Thompson, 2010; 
Schegloff \& Lerner, 2009). As noted in the discussion, the utterance 'first (off/of all)' can come in turn-initial position in sequence-initiating (or first-pair part) turns, and these turns can implement actions other than questions, per se. However, these instances are not the focus of this thesis.

4.2.6. This thesis argues that "First"-prefacing implements the following actions. Generally, as foreshadowed in section 4.2.1 (above), "first (off/of all)" projects a multiunit turn comprised of talk arranged as 'points in succession.' Specifically, "First"prefacing projects the displacement of a response (conforming or non-conforming) to the question. In projecting the 'displacement' of a response, it does two things. First, "First"prefacing projects that something other than a response (conforming or non-conforming) will come immediately next. Because this 'first' matter is not the 'first' item in a list of responses, the 'first' matter should not be understood as being designedly 'responsive' to the question. It can be argued, then, that "First"-prefacing projects that this 'first' matter should not be understood as being accountable (Garfinkle, 1967) to the constraints of the primary action of questioning (i.e., its agendas), at least in the same way as 'responses' are (e.g., non-conforming responses; see Extracts 5-8, Chapter 1). This claim is similar to a footnoted remark by Schegloff (1982): "not all utterances of 'first' or 'first of all' are list-initiating, although they do commonly project some form of extended talk, if only by indicating that before an already relevant action, something else is to be done" (p. 90, footnote 4).

Insofar as it projects a non-response, "First"-prefacing is a type of misplacement marker. Referring to another type of misplacement marker - that is, "by the way" Schegloff and Sacks (1973) said: 
Misplacement markers, thus, display an orientation by their user to the proper sequential-organizational character of a particular place in a conversation, and a recognition that an utterance that is thereby prefaced may not fit, and that the recipient should not attempt to use this placement in understanding their occurrence. The display of such orientation and recognition apparently entitles the user to place an item outside its proper place. (p. 320)

Prior literature has examined a number of different types of misplacement markers, such as “look” (Sidnell, 2007), “listen” (Jefferson, 1972; Sidnell, 2007), “so” (Bolden, 2008), “oh” (Bolden, 2006; Heritage, 1998; Jefferson, 1978), “okay” (Beach, 1993; Liddicoat, 2007, pp. 125-170), and "now" (Aijmer, 2002, pp. 57-95). The key difference between these markers and "First"-prefacing is that the former markers all preface talk in first position (i.e., talk that initiates action), whereas "First"-prefacing prefaces talk in second position. $^{7}$

Finally, again in line with the notion of 'displacement,' "First"-prefacing projects that an actual response (conforming or non-conforming) to the question is forthcoming after the 'first' matter. To say that "First"-prefacing 'projects' a forthcoming response is not to say that it always occurs (there is one case in the data where a response is never provided, although it is oriented to as 'missing' by the moderator; see Extract 21, below). This 'projection' is a 'claim,' not a guarantee, and thus 'First"-prefacing can be used manipulatively (for a discussion of 'claims,' see Pomerantz, 1990; Sacks, 1984; Schegloff, 1987a).

\footnotetext{
${ }^{7}$ One exception might be "look." Sidnell (2007) provides two examples of "look"-prefaces in first position turns, but it is not clear if they are misplacement markers, per se.
} 


\subsection{Participants' Orientations to "First"-Prefacing as a Practice}

Now that the claims of "First"-prefacing - its structural design as well as its implementing actions - as a social practice in debate interaction have been reviewed, let us examine these claims alongside participants' own explicit orientations to the disjunctive nature of "First"-prefaced talk. This subsection itself contains three subsections, including cases in which the practice of "First"-prefacing is oriented to by: (1) the speaker of the practice; (2) the moderator; and (3) other debate candidates.

4.3.1. Cases in which speakers orient to the action. This subsection contains four cases in which speakers (i.e., political-debaters who use the practice) orient to the action implemented by "First"-prefacing. For the first example, see Extract 16. The moderator, Jake Tapper, goes 'down the line' (line 02) of candidates and asks each to respond to the same question: "what woman would you like tuh see on thuh ten dollar bill.” (lines 05-06). Respondents, and their answers, included (in order): Rand Paul, who answered with Susan B. Anthony; Mike Huckabee, with his wife; Marco Rubio, with Rosa Parks; Ted Cruz, who answered that he would leave the face as is; Ben Carson, with his mother; Donald Trump, who also answered with Rosa Parks; and Jeb Bush, with Margaret Thatcher. ${ }^{8}$ At the arrival of his turn, Scott Walker, Governor of Wisconsin, responds as follows (lines 09-13):

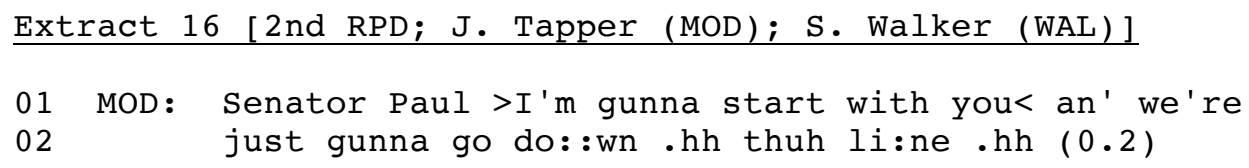

\footnotetext{
${ }^{8}$ Rand Paul is a U.S. Senator for the state of Kentucky. Mike Huckabee is a former Governor of Arkansas. Marco Rubio is a U.S. Senator for the state of Florida. Ted Cruz is a Texas state Senator. Ben Carson is a retired neurosurgeon and, prior to the start of the campaign election, had not assumed political office. Donald Trump is a business mogul and celebrity and, prior to the start of the campaign election, had not assumed political office. Jeb Bush is a former Governor of Florida. Scott Walker is the current Governor of Wisconsin.
} 
Earlier this year thuh treasury department anno:unced that ay w:oman will appe:ar on thuh ten dollar bill what woman would you like tuh see on thuh ten dollā bill.

-((other candidates answer))

MOD: Governor Walker. (.)

WAL: > > First ' $\mathbf{f}=\mathbf{a l l}$ < I gotta say duh Carson and Huckabee thanks a lot for makin' thuh rest of us look like chumps up here. B't uh (0.4) uh I('d) pick Clara Barton. I once worked f'r thee American red cross she was a great founder u- of thuh red cross.

Tapper's ‘Wh'-question (lines 05-06), which is reinvoked by his addressing “Governor Walker.” (line 07), makes conditionally relevant a female person reference (i.e., the question's action agenda; Schegloff \& Lerner, 2009) whose face would appear on the ten-dollar bill (i.e., the question's topical agenda). Walker begins his responsive turn with: ">First 'f=all<" (line 09); this is produced relatively quickly (symbolized in the transcript by inward-pointing carrots), which can be a practice for orienting to such talk as being superfluous (Bolden \& Hepburn, 2013). Walker orients to the action implemented by "First"-prefacing insofar as he goes on to address his immediately next unit of talk to speakers other than the moderator, who asked the question and thus who would normatively be understood as a respondent's addressed recipient (Sacks et al., 1974; Schegloff \& Sacks, 1973): "I gotta say duh Carson and Huckabee...” (line 09). In doing so, Walker explicitly orients to his following talk, "thanks a lot for makin' thuh rest of us look like chumps up here." (lines 10-11), as not responding to the moderator's question, but rather as addressing other speakers' prior interactional conduct. Additionally, this talk does not hearably relate to either of the question's agendas. This unit of talk embodies a sarcastic, backhanded expression of gratitude to Carson and Huckabee for their prior answers, which can be categorized (Sacks, 1972) as immediate 
family members (i.e., mother and wife, respectively), and which, by comparison, make others' answers (Walker's included) appear 'callous' through their contrasting categorization (i.e., non-family members).

Immediately after his first unit of talk (prefaced by “>First ' $\mathrm{f}=$ =all $<$ ”), Walker begins to respond to Tapper's question. Walker begins with the contrastive connective, "B't uh" (line 11), which, in turn-medial position, can project a return to a prior 'point' (Schiffrin, 1987, pp. 128-190) and that what follows somehow contrasts with what came prior (Park, 1997). As projected, Walker produces a conditionally relevant and topically affiliated answer to Tapper's question: "I('d) pick Clara Barton" (lines 11-12). In sum, as argued in the second analytic subsection (above), Walker's " $>$ First ' $\mathrm{f}=$ all $<$ " projects the displacement of a response, per se, to Tapper's question.

For a second example, see Extract 17. Lines 01-19 are provided as context to the focal question-answer sequence beginning at line 20. Lines 01-19 are part of a questionanswer chain initiated by Jake Tapper asking Trump to clarify his CNN-recorded quote: "Islam hates us." Trump answers with: "I will stick with exactly what I said to Anderson Cooper" (data not shown). Tapper then shifts to Marco Rubio, noting that, in response to Trump's CNN-recorded quote (above), Jeff Flake (then a junior Republican senator) commented: "Republicans are better than this." (line 01, below). Tapper then asks Rubio: “Do you agree?" (lines 01-02). After Rubio responds (lines 04-19 and data not shown), and after Kasich also responds (data not shown), Tapper shifts back to Trump and initiates a new/separate line of questioning (i.e., "something else"): "Mister Trump I wanna ask you about something else you've said during thuh course of this campaign.” (lines 20-22). 
Extract 17 [12th RPD; J. Tapper (MOD); M. Rubio (RUB); D. Trump (TRU)]

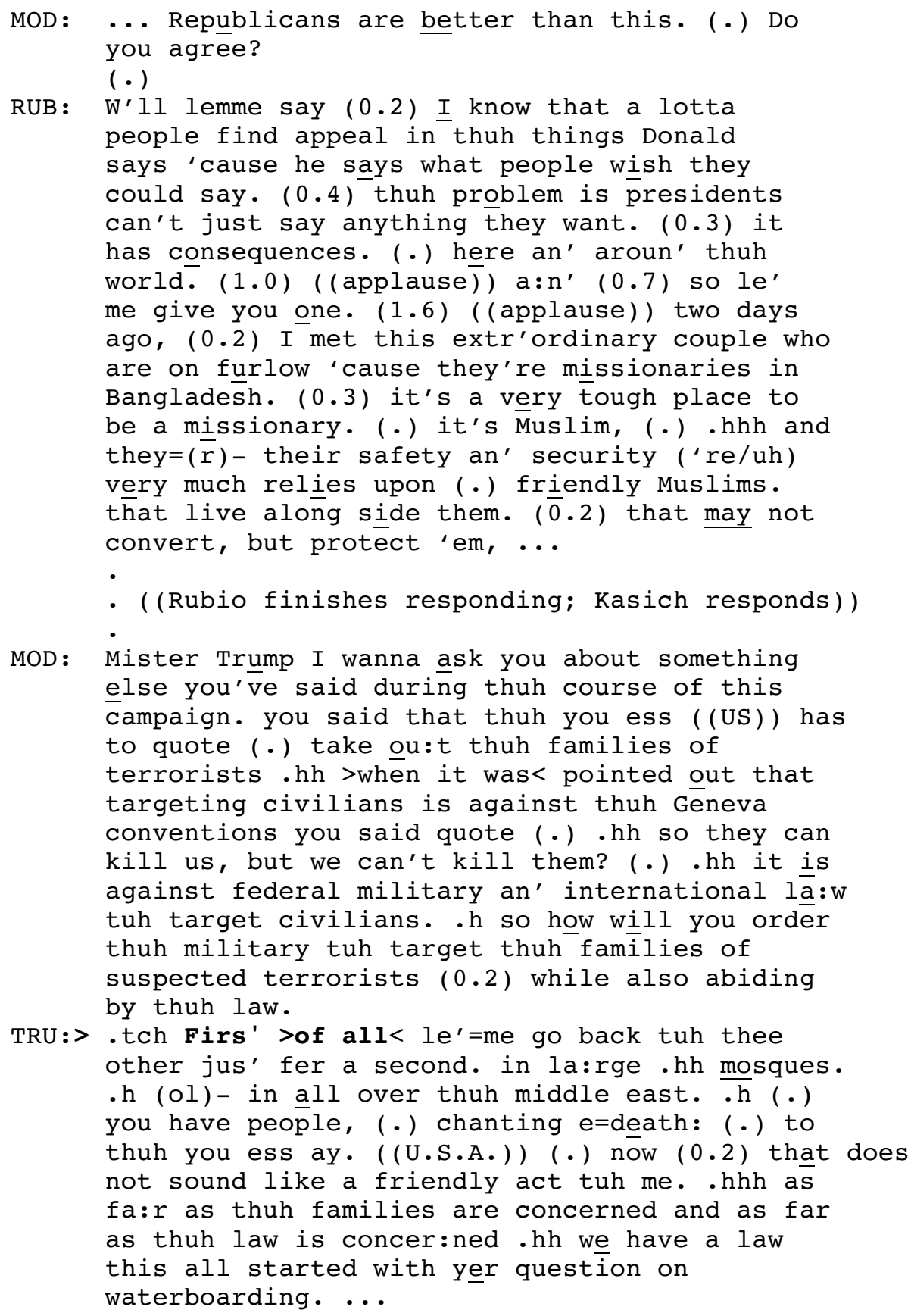

Tapper's question makes conditionally relevant an explanation (Schegloff \&

Lerner, 2009) related to the topic: "so ho:w will you order the military tuh target the

families of suspected terrorists (0.2) while also abiding by the la:w." (lines 29-32).

Although Tapper maintains his journalistic neutrality through footing shifts (Clayman, 
1992; Clayman \& Heritage 2002a, pp. 150-187) and reported speech (Holt, 1996), his question is accusatory insofar as it asks Trump to defend his currently illegal position. Trump begins his turn with a tongue click, ".tch" (line 33), followed by: "Firs' $>$ of all<" (line 33). Trump orients to the action implemented by "Firs' > of all <" by following it with a token request for permission (Clayman, 2001) to shift the question's agenda: "lett me go back tuh thee other jus' fer a seccon:d" (lines 33-34). There are at least three pieces of evidence that Trump specifically requests permission to address not the question, but rather the immediately prior and distinct line of questioning regarding Trump's CNN-recorded quote: "Islam hates us." (see above). First, Trump explicitly requests permission to "...go back tuh thee other..." (lines 33-34). Second, in his next unit of talk, Trump addresses the prior line of questioning by characterizing Muslims as effectively hating the United States of America: "in la:rge .hh mosques. .h (ol)- in all over thuh middle east. .h (.) you have people, (.) chanting e=death: (.) to thuh you ess ay.” (lines 34-37). Third, Trump follows this with "now (0.2) that does not sound like a friendly act tuh me." (lines 37-38), in which Trump repeats Rubio's prior formulation: "friendly" (line 17). None of these units of talk (lines 34-38) constitute a conditionally relevant explanation to Tapper's question (lines 29-32), nor do they address its topic. In sum, Trump uses "Firs' >of all<" to preface a rebuttal of Rubio's anecdote regarding “friendly Muslims" (line 17), which Rubio had used to critique Trump's CNN-recorded position that "Islam hates us."

Immediately after his rebuttal, Trump begins to respond to Tapper's question: "as fa:r as thuh families are concerned and as far as thuh law is concer:ned" (lines 38-40). This preface is hearable as being responsive (Clayman, 2001) through the lexical items 
"families" and "law," which repeat words from Tapper's question (i.e., "families" at line 30, and "law" at line 32), and repeat them in the same order. Ultimately, Trump does respond to the question in terms of desiring to expand U.S. law in order to more effectively defeat terrorism (data not shown).

For a third example, see Extract 18. The focus is on Wolf Blitzer's question to Ben Carson at lines 09-25. As context, this question is the last (i.e., "let=me wrap it up with you;" lines 09-10) in a thread of question-answer sequences dealing with the general topic of, in Blitzer's words: "filling the vacancy left by the late Justice Antonin Scalia" (data not shown). Carson's answer (beginning at line 15) comes after those of Cruz, Rubio, and Trump, all of whom have variously praised Scalia and his legacy (see lines 01-03, 04-06, and 07-08, respectively). However, their answers have also addressed the topic of religious freedom - that is, the first freedom mentioned in the first amendment which is the focus of Blitzer's question to Carson.

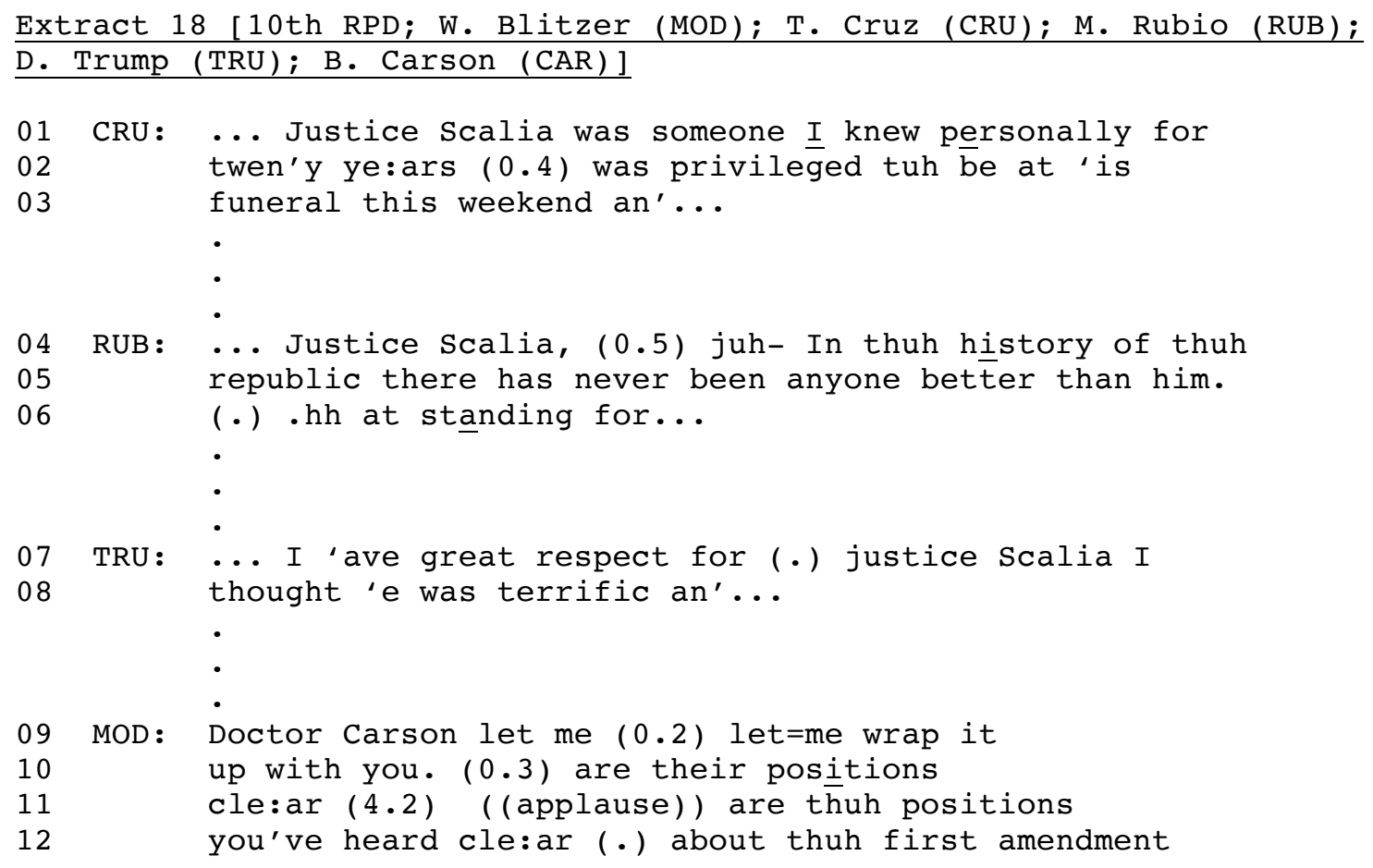


an' thuh first freedom.

$(0.4)$

CAR: $>$.tch=.hhh (.) Well (.) first of all lemme just uh add my praise t- tuh justice Scalia.=I f:=first met him wh'n we got a honorary degree together, (.) a

long time ago, $(0.2)$ tremendous wit, .hh (0.2) a: nd

uh intellect. $. \mathrm{hh}=. \mathrm{mtch}=. \overline{\mathrm{h}}$ as far as religious freedom

is concerned $(0.5)$ one=a thuh basic tenets (.) of

this nation. .hhh a:nd $u-$ I belie:ve that thuh

constitution protects (.) all of our rights

.hh (.) uh: (0.6) and it gives (.) people

who: $(0.3)$ eh=believe in same sex marriage (0.4)

uh thuh same rights as everybody e: lse.... ((cont.))

Blitzer's question makes conditionally relevant a 'Yes'- or 'No'-type answer

related to the topic of the first amendment generally, and religious freedom specifically:

“are thuh positions you've heard cle:ar (.) about thuh first amendment an' thuh first

freedom.” (lines 10-13). After pausing, “(0.4)” (line 14) and breathing in, “.tch=.hhh”

(line 15), Carson produces "Welll" (line 15), which, as argued above in section 4.2.3,

frames the immediately forthcoming talk as: (1) being non-straightforward in terms of its status as a response to the question; and (2) “[privileging] its speaker's perspectives, interests or projects" (Heritage, 2015, p. 89). Carson then begins his turn with "first of all" (line 15) and uses it to preface: "lemme just uh add my praise t- tuh justice Scalia." (lines 15-16). Regarding this talk, Carson explicitly characterizes its action as 'praising,' which is typically a sequence-initiating (vs. responding) action (Pomerantz, 1984), and which is not a type of response made conditionally relevant by Blitzer's question. Furthermore, Carson explicitly orients to 'adding' praise, and thus to linking this talk not to Blitzer's question, but rather to prior candidates' praise of Scalia. Finally, this talk is irrelevant to the topical agenda of Blitzer's question. In sum, with this talk, Carson orients to "first of all" as having projected a non-response to Blitzer's question. This is in line with Carson's "Welll"-preface (line 15), as is the fact that the non-response (i.e., 
praise of Scalia) was arguably used to further Carson's political-debate interests,

specifically being seen as a candidate who was personally associated with, and supportive of, a Supreme Court Justice popular with Republicans.

After praising Scalia, “...tremendous wit, .hh (0.2) a:nd uh intellect.” (lines 1819), Carson begins to respond to Blitzer's question, "as far as religious freedom is concerned..." (lines 19-20), and does so recognizably by repeating the word "freedom" from the question (c.f., "freedom;" line 13), and by referring to "religious freedom" (line 19), which is the "first freedom" referred to in the question. ${ }^{9}$ Thus, Carson eventually provides a response to the question, though it is displaced by several units of talk.

Extract 19 is a fourth and final example in which the speaker orients to the actions implemented by “First”-prefacing. At lines 01-09, the main moderator (Jake Tapper) moves, for the very first time in this debate, to the topic of Social Security (note that debaters have also not mentioned 'Social Security' prior to this point). Tapper hands the questioning over to his colleague (and fellow moderator) Dana Bash (lines 11-17, 19). Extract 19 [12th RPD; D. Bash (MOD); M. Rubio (RUB); J. Tapper (TAP)]

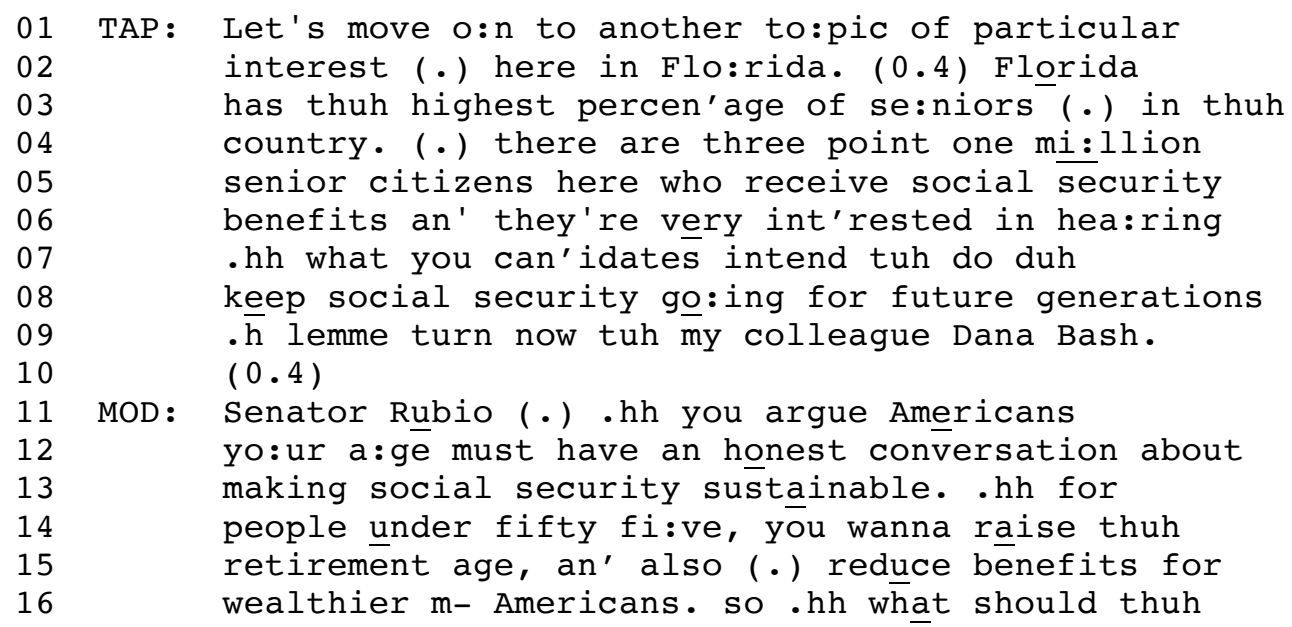

${ }^{9}$ Before praising Scalia, Carson establishes their longstanding personal connection, "I $\mathrm{f}:=$ first met him wh'n we got a honorary degree together, (.) a long time ago," (lines 16-18), which Cruz had also done previously (lines 01-03). 


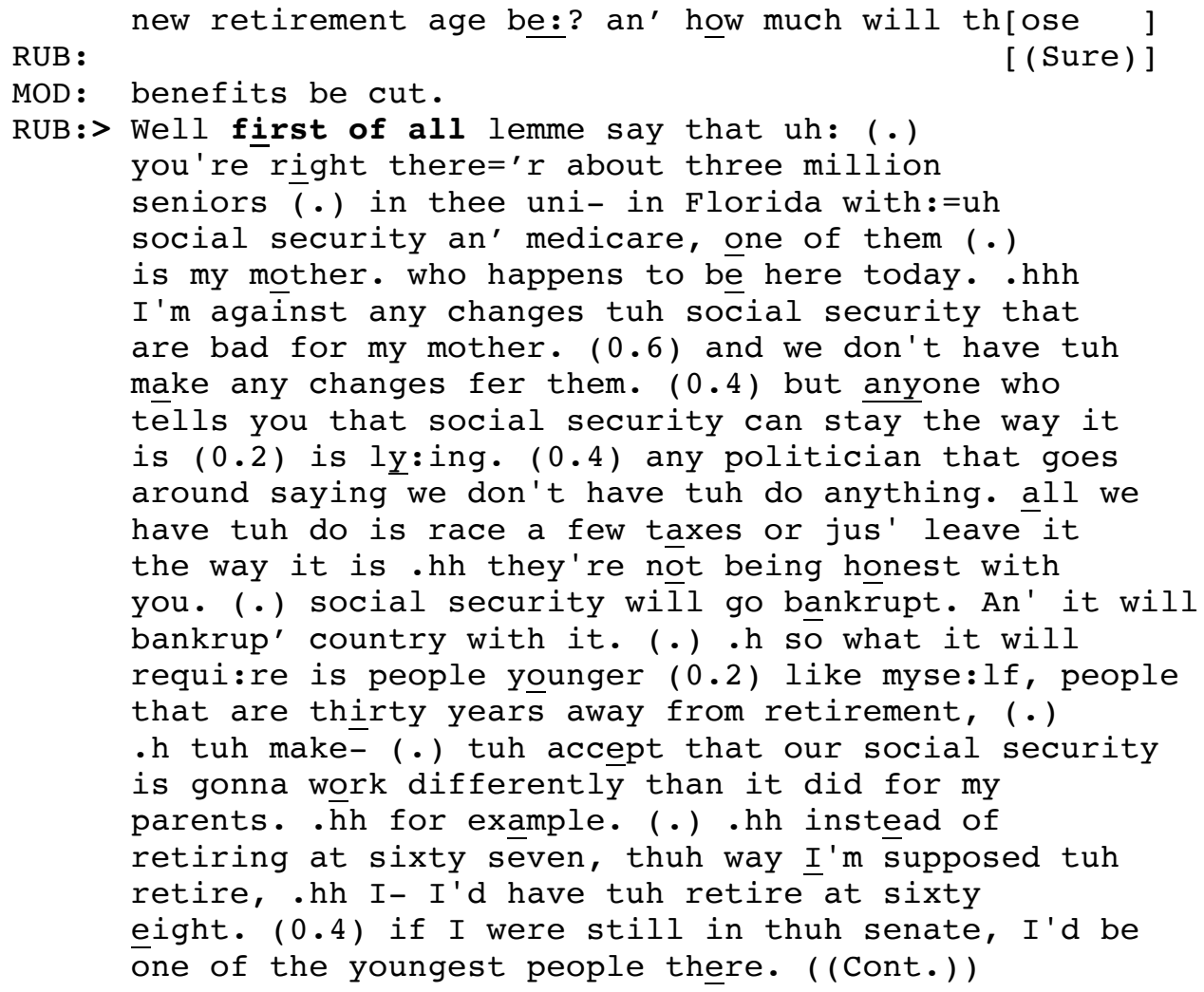

The question, asked by Bash to Marco Rubio, is composed of two parts and

makes conditionally relevant an age and an amount, respectively: "what should thuh new retirement age be:? an' how much will those benefits be cut." (lines 16-17, 19). There are four pieces of evidence that Rubio's “first of all” (line 20) projects the displacement of a response. First, as has already been reviewed, immediately prior to "firrst of all," Rubio produces "Well" (line 20), which projects that at least the immediately next talk will be non-straightforward in terms of its responsiveness (Heritage, 2015; Schegloff \& Lerner, 2009). Second, as we saw in Extracts 16, 17, and 18 (above), after "first of all," Rubio produces a token request for permission to say something, "lemme say" (line 20), which indicates that "an agenda shift is being contemplated" (Clayman, 2001, p. 418). Third and perhaps the most revealing way in which Rubio orients to his lack of responsiveness - when he continues, rather than addressing the question-asker (Dana Bash), he addresses 
the prior moderator, Jake Tapper: "you're right there='r about three million seniors (.) in thee uni- in Florida with:=uh social security an' medicare," (lines 21-23). Specifically, Rubio uses "you" as a known-recipient indicator ("you're right;" line 21; Lerner, 1993) to select Tapper by virtue of repeating words in his preface (at lines 01-06) specifically related to Florida, which was not a focus of Bash's question: 'there='r about three million seniors (.) in thee uni- in Florida with:=uh social security an' medicare," (c.f., “Florida;" line 02; c.f., "se:niors;” line 03; c.f., "three point one mi:llion;” line 04; c.f., "social security;" line 05). Fourth, when Rubio continues, he refers to: (1) his mother (lines 23-26), which is topically unrelated to the question at least because she is not "under fifty fi:ve," (line 14); and (2) not changing her Social Security plan/benefits, "and we don't have tuh make any changes fer them.” (lines 26-27), which specifically contradicts the question's presuppositions that changes will be made: "what should thuh new retirement age be:? an' how much will those benefits be cut." (lines 16-17, 19). With these 'first matters,' Rubio promotes himself: (1) personally, as someone who protects his supportive mother; (2) epistemically, as someone with direct knowledge of/experience with the ramifications of Social Security; and (3) politically, insofar as he is a senator of Florida, which has a large senior-citizen population.

Rubio hearably begins to respond to the question - which Bash prefaced in terms of Rubio calling for an "honest" (line 12) conversation about Social Security - when Rubio asserts: "but anyone who tells you that social security can stay the way it is $(0.2)$ is ly:ing." (lines 27-29). When Rubio reformulates this assertion, he specifically repeats the word "honest" (line 32; c.f., "honest;" line 12): "any politician that goes around saying we don't have tuh do anything. all we have tuh do is race a few taxes or jus' leave it the 
way it is .hh they're not being honest with you." (lines 29-33). Here, Rubio is likely alluding to, and indirectly critiquing, Donald Trump's publically stated position that he will neither change the retirement age nor cut Social Security benefits (data not shown). Rubio more clearly returns to the activity of responding to the question with: "so what it will requi:re..." (lines 34-35). According to Bolden (2008), the discourse marker:

'So' conveys to the addressee that the upcoming course of action is emerging from incipiency and has been on the interactional agenda. [...] 'So' prefacing is recurrently used in contexts where a particular course of action is oriented to by the interlocutors as having been pending or relevantly missing (p. 996).

Furthermore, "requi:re" (line 35) projects 'solutions' to the Social Security problem, which Bash's question made conditionally relevant. As projected, Rubio specifically answers one part of Bash's question when he provides a concrete, new retirement age: “sixty eight." (lines 41-42).

4.3.2 Cases in which moderators orient to the action. This subsection examines two cases in which moderators orient to the action implemented by "First"-prefacing. The first case is Extract 20, which actually contains such an orientation by the speaker as well (and thus could have properly 'fit' in the previous subsection). Prior to his question, Wolf Blitzer had introduced North Korea as a current threat to the U.S., particularly under Kim Jong Un's regime given his willingness to "use a weapon of mass destruction if he thought his regime was being threatened" (data not shown). Blitzer directs questions to Donald Trump and John Kasich before addressing Ben Carson, shown here (starting at line 01): 
Extract 20 [10th RPD; W. Blitzer (MOD); B. Carson (CAR)]

MOD: Doctor Carson- (0.4) how would you deal with north Korea.

(1.3)

CAR: > Okay $=(w)-($.$) uh first of a:ll (0.9) .mtch$

people say that I whis:ne a lot because I don't get time. . hh I'm gunna whis:ne. . hh becau:se I didn't get asked about tâ: xes, (0.3) I didn't get asked about I:srael, (0.3) Hugh you said you gunna be fair duh everybody you didn' ask me about taxes, $(0 . \overline{2})$ I had somethin' tuh say about that. .hhhh no: $w_{-}(0.5)$

MOD: Go [ahead (sir) th] is is your moment.

CAR: $\quad[$ As $\mathrm{fa}(r)-\quad]$ (.)

CAR: Okay. (3.2) ((applause)) we have a system (.) of tax (.) sation in this country (.) that is h:orribly (0.2) wrong. .hhhh >you know< I never had an audit (0.4) until I spoke at thuh=(n)- (.) national prayer breakfast. .hh an' then a:ll of =a sudden (.) they came i:n (.) they say we just wanna look at your real estate dealings. .hh an' the: $n$ (0.3) they didn' find anything. so they said let's look at thuh who:: le year. .hh an' they didn' find anything. so they said let's look at thuh next year. an' thuh next year. .h an' they didn't find anything an' they won't find anything. hh because I'm a very honest person. .hh but thuh fact of thuh matter is thuh eye:=are ess $((I R S))($.$) is n:$ ot honest, (.) an' we need duh get rid of them.

CAR: (.hh) (Now) ( )- (7.4) ((applause)) as far as Israel is concer:ned $(0.2)$ you know when $\bar{I}$ was there several months ago (.) I talked to a lotta people I couldn' find ay s:ingle <one> (.) .h who didn' think that we had turned our backs on Israel. .hhh you kno:w the:y a:re eh- a strategic partner for us .hh but a: Iso (.) recognize that we have a Judeo Christian foundation. .hh a:nd thuh last thing we need tuh do (.) is tuh reject Israel. . hh doesn't mean that we can't be fa: ir tuh other people. (.) we can always be fair ( $\bar{d})$ uh other people. . hh but >you know< it's like when you have a chi:ld. . hh you know you wanna be fair to all thuh children aro:und (.) but $\mathrm{ch}=00$ : have a special (.) uh:- n- attention for your own child. CAR: . hhh and now as far as North Korea is concerned...

Blitzer's question, "how would you deal with north Korea.” (lines 01-02) makes conditionally relevant a 'strategy' of some sort, and one that deals topically with North Korea. Carson begins his turn with "Okay=(w)-" (line 04), but cuts himself off (symbolized in the transcript by the hyphen) and restarts his turn with: "uh first of a:ll" 
(line 04 ). Carson immediately goes on to: (1) present a characterization of himself as a 'complainer' when he does not get equal debate time: "people say that I whin:ne a lot because I don't get time." (lines 05-06); (2) formulate himself as about to complain: "I'm gunna whi:ne." (line 06); and then (3) produce two complaints related to not getting equal debate time (Schegloff, 1988): “becau:se I didn't get asked about ta:xes, (0.3) I didn't get asked about I:srael," (lines 06-08). There are at least four ways in which we can ground these units of talk as being wholly unrelated/unresponsive to Blitzer's question. First, none of them constitute a conditionally relevant strategy. Second, none of them relate, in any way, to North Korea; in fact, they relate to distinct, already completed debate threads/topics (i.e., taxes and Israel). Third, as has been seen on two previous occasions (Extract 13 and 18, above), Carson's “first of a:11" precedes a sequence-initiating (vs. responding) course of action, this time involving complaining (Schegloff, 1988). Fourth, the complaint is ultimately addressed not to the question asker, Wolf Blitzer, but rather to a separate moderator, Hugh Hewitt, who was previously asking questions: "Hugh you said you gunna be fair duh everybody you didn' ask me about taxes, (0.2) I had somethin' tuh say about that." (lines 08-10). In sum, Carson explicitly orients to "First"-prefacing as projecting the displacement of a response. Carson displaces a response in order to publically complain about having been treated unfairly, which arguably mitigates damage to his positive face (Brown \& Levinson, 1987) as a political candidate and lobbies for additional debate time, which ultimately succeeds (see below). ${ }^{10}$

\footnotetext{
${ }^{10}$ The action of 'lobbying' can be evidenced in lines $08-11$, whereby Carson appeals to Hewitt's publicly made announcement of maintaining fairness ("Hugh you said you gunna be fair duh everybody;" lines 08$09)$ to fulfill and is granted his 'rightful' opportunity to speak on influential issues ("you didn' ask me about taxes, (0.2) I had somethin' tuh say about that. .hhhh no:w;" lines 09-11).
} 
Relevant for the present analytic subsection, the moderator (Blitzer) orients to the action implemented by "First"-prefacing by granting Carson permission, "Go ahead (sir)..." (line 12), to produce responses wholly unrelated to the question: “...this is your moment" (i.e., 'your chance to address taxes and Israel;' line 12), and thus orienting to Carson's complaining as being a non-response (i.e., a request for debate time/space). Evidence that Carson understands Blitzer's permission in this manner is found in the fact that: (1) Carson immediately goes on to address the two matters on which he was slighted, including taxes (lines 15-29) and Israel (lines 30-44), both of which are unresponsive to Blitzer's question; and (2) Carson is given approximately 130 seconds to answer (i.e., before the 'stop' bell rings), which is a significant amount of extra time given that candidates (in this debate) were normally allotted 75 seconds per response.

In line with the argument about "First"-prefacing, immediately after dealing with the topic of Israel, Carson begins to answer Blitzer's question: “.hhh and now as far as North Korea is concerned ..." (line 45), designing this beginning as a response by repeating a main component of the question (c.f., "North Korea;" line 02). Carson ultimately does go on to provide a conditionally relevant and conforming answer to the question (data not shown).

For a second example, see Extract 21. Prior research has demonstrated that broadcast journalists display their orientations to inadequate, resistant, or otherwise evasive answers by pursuing their original questions, which effectively sanctions respondents (Greatbatch, 1986b; Romaniuk, 2013). One possible reason why this did not happen in the immediately previous extract is precisely because Blitzer had given Carson permission to at least temporarily evade the question. However, even in the context of 
presidential primary debates where candidates are allotted extensive time to respond (e.g., 75 seconds), "First"-prefacing runs the risk of being perceived as constituting evasion (Clayman, 2001) if the 'first matters' threaten to occupy the entire allotted response space, which is what appears to happen in the next example.

The focal question-answer sequence (at lines 07-31) is part of a debate thread focusing on the topic of 'birthright citizenship;' this thread is relatively new, with Carly Fiorina only being the second debater to address it. As context, the immediately prior thread had focused on the topic - and, to many of these Republican candidates, the 'problem' - of illegal immigration, for which candidates had extensively debated various solutions, including deportation, enhancing border walls and security, etc. During that prior thread, as seen at lines 01-06, Fiorina had rejected Donald Trump's claim: “I don't think you'd even be talking about illegal immigration if it weren't for me" (data not shown). Specifically, Fiorina argued that Republicans (i.e., "we”) “"ave been ta:lking about it for twen'y five years." (lines 04,06$)$.

Immediately prior to Jake Tapper's question to Fiorina (starting at line 07), Tapper had initiated the debate thread on 'birthright citizenship' with a question to Trump; there, Tapper had asserted, "Ms. Fiorina says that you are pandering on this issue," and had asked: "What's your message to Ms. Fiorina on birthright citizenship?" (data not shown). Tapper then directs a question to Fiorina (beginning at line 07):

Extract 21 [2nd RPD; J. Tapper (MOD); C. Fiorina (FIO); D. Trump (TRU)]

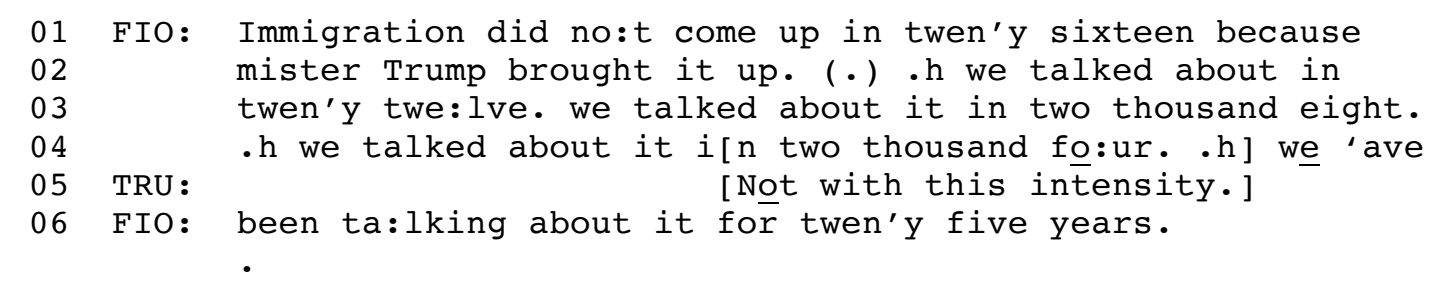




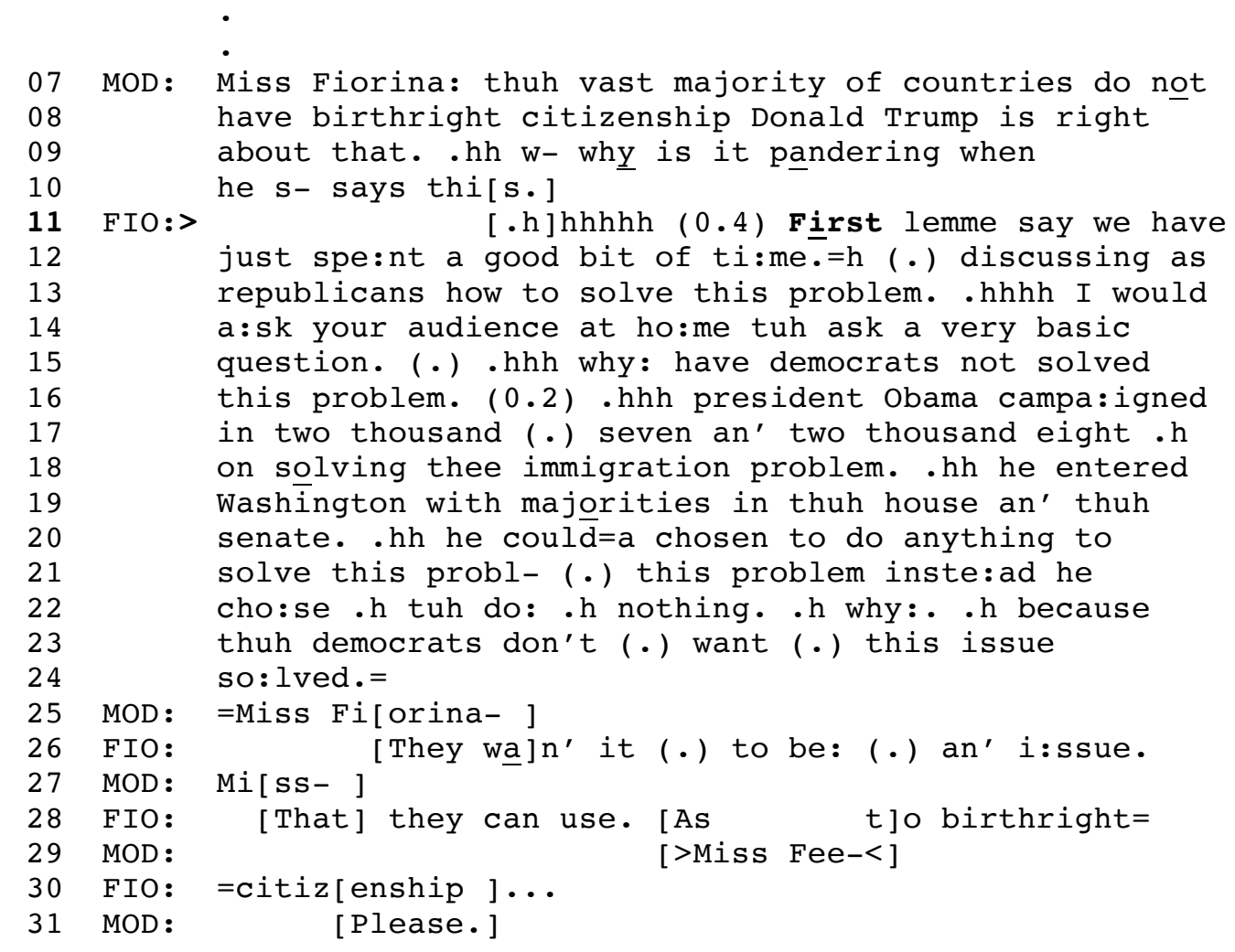

Tapper's question, "why is it pandering when he s- says this." (lines 09-10) makes conditionally relevant an account (Bolden \& Robinson, 2011; Robinson \& Bolden, 2010; Schegloff \& Lerner, 2009) related to the topic of Trump's position on birthright citizenship. Fiorina begins her turn with "First" (line 11) and then a token request for permission, "lemme say" (line 11), which may project some type of agenda shift (Clayman, 2001). When Fiorina continues, it may appear as if she begins to respond to the question: "we have just spe:nt a good bit of ti:me. $=\mathrm{h}$ (.) discussing as republicans how to solve this problem." (lines 11-13). This 'appearance' is generated by her use of "this problem" (line 13), which, due to the principle of adjacency (Schegloff, 2007), is possibly hearable as indexically referring to the question's topic of 'birthright citizenship' (Clayman, 2001). However, this hearing is rendered ambiguous by the facts that: (1) Fiorina shifts the question's focus away from herself to 'all Republican candidates' (i.e., 
"we ... as republicans"; lines 11-13); (2) the candidates have not "spe:nt a good bit of ti:me." discussing birthright citizenship, but rather illegal immigration (i.e., the previous debate thread/topic); and (3) it was illegal immigration, not birthright citizenship, that had been formulated as a "problem.” It becomes clear that Fiorina is referring to illegal immigration (and not birthright citizenship) when she refers to "solving thee immigration problem." (line 18). In sum, Fiorina's talk is unresponsive to the question; rather than providing an account for her own characterization of Trump's position on birthright citizenship, she uses these 'first' matters to re-topicalize the problem of illegal immigration and criticize the "democrats" (line 15) and President "Obama" (line 16) for failing to solve it.

After Fiorina says, "because thuh democrats don't (.) want (.) this issue so:lved." (lines 22-24), she has been speaking for 36 seconds (i.e., over half of her allotted time). Relevant for the present analytic subsection, the moderator (Tapper) orients to Fiorina's 'first' matters as being unresponsive and, thus, evasive (Clayman, 2001). Specifically, at line 25, Tapper comes in interruptively (i.e., well before Fiorina's allotted 75-second time limit, and thus in advance of Fiorina's 'time alarm' going off) and addresses her by name, "Miss Fiorina-," which projects a supplementary question and orients to her response-sofar as being somehow inadequate (Greatbatch, 1986b). After Fiorina completes her next unit, "They wann' it (.) to be: (.) an' i:ssue." (line 26), in which she continues to evade the question, Tapper begins to re-address, and thus re-sanction, her: "Miss-" (line 27). Here, Tapper works to 'tighten the reins' (Clayman \& Heritage, 2002b) of what can be heard as an acceptable response. This pattern repeats itself with Fiorina's increment (Schegloff, 2016), “That they can use." (line 28) and Tapper's re-addressing her: “>Miss Fee- $<$ " (line 
29). Ultimately, Fiorina orients to her 'first' matters as having been unresponsive when she explicitly claims to begin to respond to the question, including repeating words from the question's preface (c.f., "birthright citizenship;" line 08): "As to birthright citizenship..." (lines 28, 30). Tapper displays his approval, "Please." (line 31), and Fiorina goes on to provide a conditionally relevant response (data not shown).

4.3.3. Cases in which other candidates orient to the action. In addition to speakers who use "First"-prefacing, and in addition to moderators, there is also one case in the data (Extract 22, immediately below) where another candidate displays his orientation to the action implemented by "First"-prefacing. Initially, this subsection focuses on Trump's use of “First"-prefacing. Ultimately, the focus will be on Rand Paul's characterization of Donald Trump's 'first' matters as a "non sequitur" (line 59).

In the context of primary-campaign debates, if a candidate's name is invoked by another speaker - especially toward the goal of critique - then that speaker is commonly given a chance to respond. In Extract 22, although Fiorina does not herself critique Trump, Tapper attributes a critique to her in the preface to his question: "you as well (0.2) have raised (0.2) concer:ns about mister Trump's temper'ment, (0.2) you've dismissed him: as an entertainer.” (lines 07-09). Thus, after Fiorina ultimately refuses to answer Tapper's question (lines 01-29), he gives Trump a generic opportunity to chime in: "Mister Trump?" (line 30). While it is unclear what the specific action agenda is of Tapper's response proffer, it makes relevant a broad topical agenda, including Trump's temperament, his status as an entertainer, and his management of 'the nuclear codes' (c.f., Tapper's: “would y:ou feel comfortable with Donald Trump's finger on thuh nuclear 
codes;" lines 09-11). ${ }^{11}$

Extract 22 [2nd RPD; J. Tapper (MOD); C. Fiorina (FIO); D. Trump (TRU); R. Paul (PAU)]

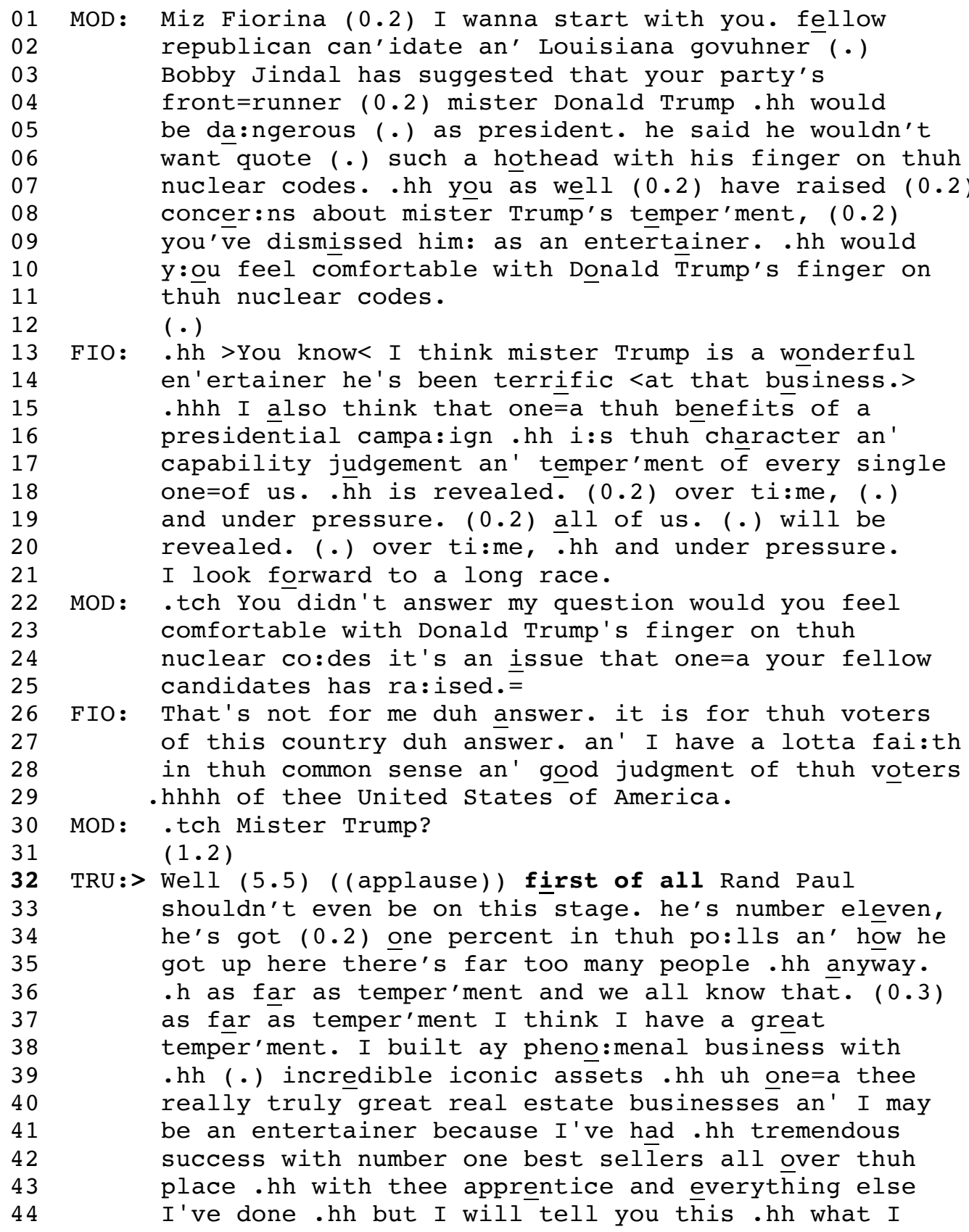

\footnotetext{
${ }^{11}$ This claim about the topical agenda made relevant by Tapper's "Mister Trump?" (line 30) is validated in two ways. First, Trump orients to such an agenda by ultimately responding in terms of his temperament ("as far as temper'ment...;" line 36) and status as an entertainer ("I may be an entertainer...;" lines 40-41). Second, Rand Paul orients to such an agenda: "he was a:sked whether 'r not he would be capable .hh an' it would be in good ha:nds to be in charge o' thuh nuclear weapons" (lines 59-61).
} 
After a "Well"-preface (line 32; see review in section 4.2.3), Trump begins his turn with "first of all" (line 32). While the precise action agenda of Tapper's "Mister Trump?" (line 30) is unclear, and while its topical agenda is admittedly broad (see above), what Trump produces next is arguably unresponsive and unrelated, respectively: “Rand Paul shouldn't even be on this stage. he's number eleven, he's got (0.2) one percent in thuh po:lls an' how he got up here there's far too many people" (lines 32-35). Here, Trump works to delegitimize Rand Paul's candidacy as a participant in this Republican primary-campaign debate, and thus arguably criticizes Paul (see especially Trump's rhetorical question, "how he got up here;" lines 34-35; Gibbs, 2000; note also that Paul ultimately orients to this as an 'attack;' line 62).

The argument that Trump's 'first'-matters are designedly unresponsive/unrelated to Tapper's question prompt is supported by Trump's “anyway." (line 35), which can project topical discontinuity (Drew, 1997) and claim that "what precedes is fitted not to the immediately preceding, but to what preceded that" (Schegloff, 1978, p. 89; see also 
Drew, 1997; Sacks, 1992; for review, see Bolden, 2009). That is, Trump's “anyway.” (line 35) claims that his 'first'-matters (i.e., his delegitimization of Paul) are rightfully fitted not to Tapper's “Mister trump?" (line 30), but to something before that. Along these lines, it is worth noting that Tapper's question to Fiorina (starting at line 01) is the very first question of the entire debate, preceded only by candidates' 30 -second selfintroductions to the audience (including Paul's). Thus, Trump appears to use "First"prefacing to 'reach back' to Paul's self-introduction as a candidate, which is still Paul's most interactionally proximate contribution (the action of delegitimizing Paul's candidacy is arguably more relevant before, versus after, Paul makes another contribution that constitutes a substantially different matter). As seen in all previous cases, immediately after his 'first' matters, Trump responds to Tapper's prompt (lines 36-54). Specifically, after "anyway.” (line 35), Trump hearably returns to the prompt's topical agenda, "as far as temper'ment” (line 36), repeating a word from Tapper's original question preface to Fiorina (c.f., “temper'ment;” line 08).

The ultimate focus of this case is found in Paul's rebuttal (lines 58-64). Here, Paul reformulates Tapper's question, "he was a:sked whether 'r not he would be capable .hh an' it would be in good ha:nds to be in charge o' thuh nuclear weapons" (lines 59-61), describes Trump's 'first' matters as an "attack at me” (line 62), and characterizes this attack as a "no:n sequitor" (lines 58-59), which Merriam-Webster dictionary defines as: "a statement (such as a response) that does not follow logically from or is not clearly related to anything previously said" (https://www.merriamwebster.com/dictionary/non\%20sequitur); similarly, Paul describes Trump's 'first' 
matters as having come "all of a sudden" (i.e., unexpectedly), and characterizes them as “sị:deways" (line 62).

\subsection{The Operation of "First"-Prefacing in Less-Clear Cases}

The first and third analytic subsections ( 4.1 and 4.3, respectively, above) provide evidence for the claims made about "First"-prefacing in the second analytic subsection (4.2, above). Now that "First"-prefacing has been established as a social practice of action (Heritage, 1984) - that is, one that is systematic, recurrent, and intersubjectively oriented to by all participants - we are able to more clearly see its operation in cases where it may not have initially been so clear. Along these lines, the current subsection examines two cases of "First"-prefacing in which the 'first' matters are not as clearly unresponsive to prior questions; nonetheless, the practice operates as claimed.

The first example is Extract 23. In order to highlight how this case provides 'less clear' evidence, it is useful to examine the focal question-answer sequence between Hugh Hewitt and Donald Trump (at lines 17-46) out of context (i.e., without examining lines 01-16, which will be returned to shortly).

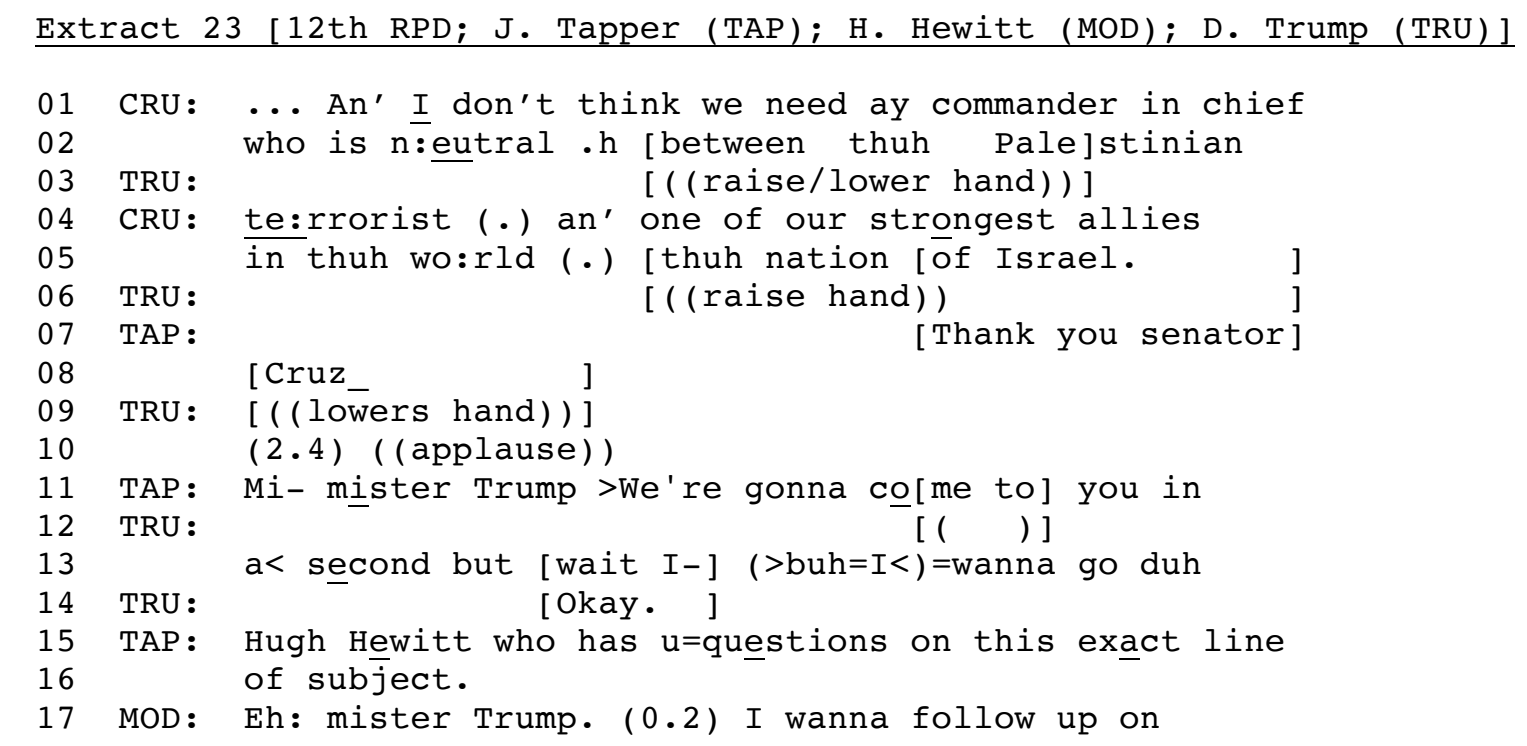




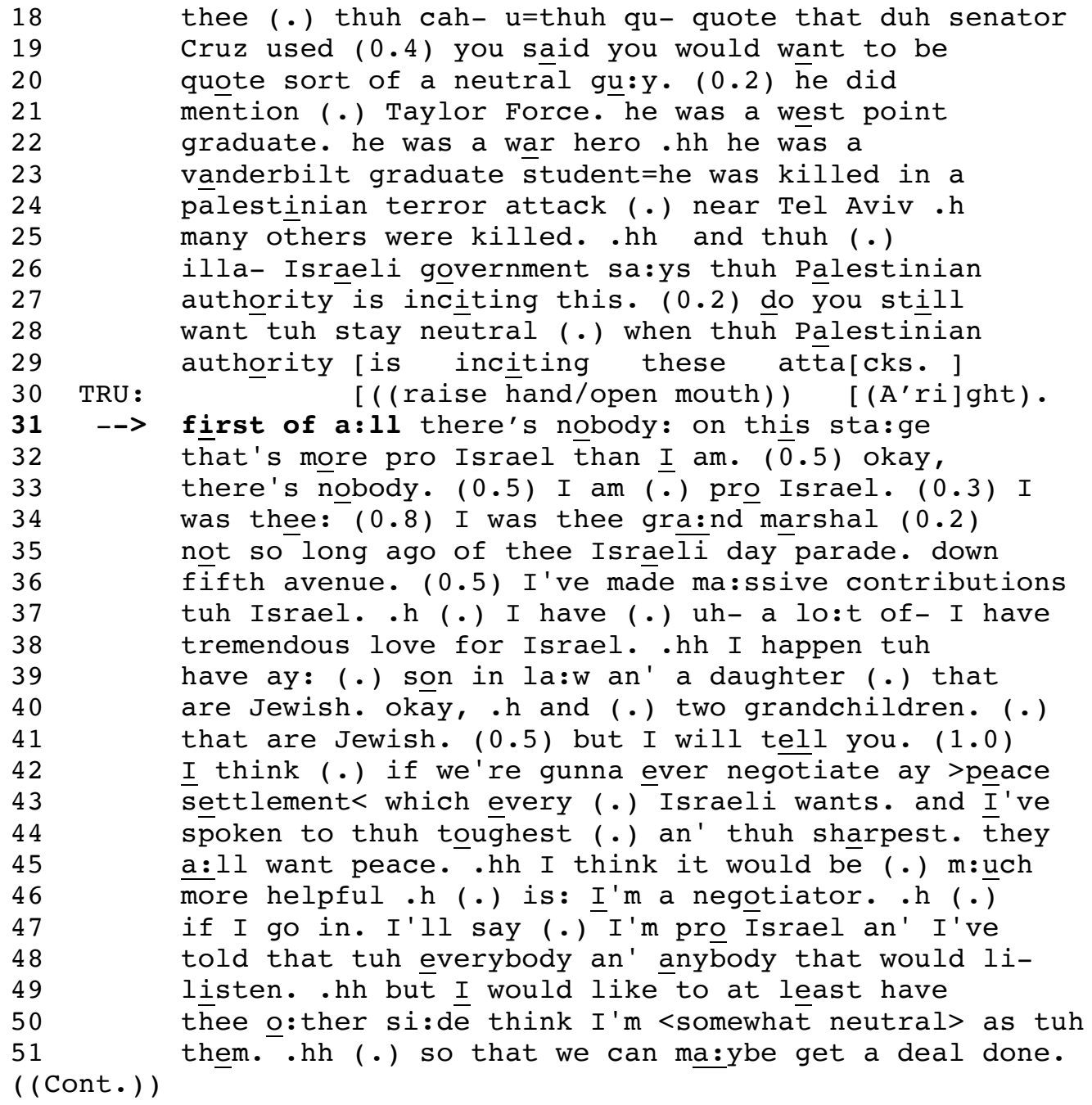

Hewitt's question, “ㅇo you still want tuh stay neutral (.) when thuh Palestinian authority is inciting these attacks." (lines 27-29) makes conditionally relevant a 'Yes'- or 'No'-type response (i.e., the question's action agenda; Raymond, 2003). Insofar as the question frames 'staying neutral' as being a socially untenable position - that is, 'staying neutral' when "thuh Palestinian authority is inciting" (lines 28-29) the killing of a U.S. "war hero" (line 22) and "many others" (line 25) - the question arguably prefers a 'No'type response (see Pomerantz, 1984; Pomerantz \& Heritage, 2013). Although Trump's utterance, "there's nobody: on this sta:ge that's more pro Israel than I am.” (lines 31-32), does not contain a 'Yes'- or 'No'-type response, it is difficult (at least, out of context) to 
hear it as being unresponsive to the question. With this unit, Trump arduously defends himself by producing an extreme-case (Pomerantz, 1986) boast about being incomparably pro-Israel. Thus, one interpretation might be that this utterance is a nontype-conforming response (Raymond, 2003) that embodies a 'No'-type response. It might be argued that the non-type-conforming response addresses and rejects the ('loaded') question's presupposition that Trump is, in fact, 'neutral' (i.e., “oo you still want tuh stay neutral...;" lines 27-28), which any type of conforming response (i.e., 'Yes'- or 'No'type) would have indirectly confirmed (ibid.). If this utterance is, in fact, directly responsive to Hewitt's question, then this case stands as counter evidence to this thesis' claims about "First"-prefacing.

However, a different picture emerges when four elements of interactional context are considered. First, return to line 01 , wherein Ted Cruz is finishing his response to the immediately prior question. Earlier in his answer (i.e., prior to line 01), Cruz had said about Trump: "Donald has said he wants to be neutral between Israel and the Palestinians." (data not shown). At lines 01-05, Cruz is again referring to, and now more explicitly attacking, Trump for being 'neutral,' and thus for not supporting "Israel” (line 05) over the "thuh Palestinian te:rrorist" (lines 02, 04). ${ }^{12}$

Second, as Cruz completes his response (and attack), Trump twice nonvocally solicits a bid for the floor (lines 03 and 06), presumably for a rebuttal. While Trump would normally be allowed a rebuttal immediately, Jake Tapper holds Trump off

\footnotetext{
${ }^{12}$ Regarding Cruz's reference to 'a commander in chief,' prior to this final debate before the Republican primary election, Trump (with an estimated $36 \%$ of the vote) led all Republican candidates in the polls by at least 14 percentage points (http://www.realclearpolitics.com/epolls/2016/president/us/2016_republican_presidential_nomination3823.html).
} 
because, as it turns out, Hugh Hewitt is (apparently coincidentally) planning on asking Trump the next question on the subject of Cruz's attack (lines 11-16).

Third, Hewitt's question is framed explicitly as a "follow up on ... thee (.) thuh cah- $\mathrm{u}=$ thuh qu- quote that duh senator Cruz used" (lines 17-19) regarding being "neutral" (line 20) relative to the Palestinians and Israelis. Thus, Hewitt's ultimate question, “do you still want tuh stay neutral...” (lines 27-29), not only presupposes that Trump is neutral, but reinvokes the relevance of the very attack by Cruz that Trump had attempted to rebut (at lines 02 and 03 ).

Fourth, Trump begins his turn with "(A'right).” (line 30), which research has shown can mark a shift in focus from prior talk (i.e., Hewitt's question) to next talk (i.e., Trump's 'first' matters; Filipi \& Wales, 2003; Gardner, 2005; Holt \& Drew, 2005). It is in this context that we get Trump's "first of a:1l" (line 31), which, as forecasted by the “(A'right)." (line 30), claims the displacement of a response to Hewitt's question.

It is now possible to hear Trump's boastful self defense, "there's nobody: on thịs sta:ge that's more pro Israel than I am.” (lines 31-32), as not a response to Hewitt's question, per se, but rather a response/rebuttal to Cruz's earlier attack. In line with this, three additional points can be made. First, whereas Hewitt prefaces his question with the term “Israeli government" (line 26), Trump formulates his defense in terms of being pro"Israel" (line 32), and it was Cruz who used the term "Israel" and who impugned Trump's 'alliance' with "the nation of Israel”. Second, Trump's reference to "nobody: on thịs stage" (line 31) orients to being criticized relative to Cruz, Rubio, and Kasich, the three candidates vying for the position of, as Cruz put it, "commander in chief" (line 01). Third, the nature of Trump's subsequent justifications for his claim - including his past 
title as a grand marshal (lines 33-34), his monetary benefactions to the country of Israel (lines 36-37), his personal affection for Israel (lines 37-38), and his four Jewish family members (lines 38-41) - orient more to defending his status as an 'ally' to "the nation of Israel" than to defending his position, quoted by Hewitt, as being "sort of a neutral gü:y." (line 20).

Further evidence for characterizing Trump's 'first' matters as being unresponsive to Hewitt's question is that, when Trump does eventually respond to the question, he begins with "but..." (line 41), which claims that the talk to follow (i.e., his response) somehow contrasts with the preceding talk (i.e., his unresponsive 'first' matters; Park, 1997; Schiffrin, 1987, pp. 128-190). ${ }^{13}$ Trump follows this with "I will tell you." (line 41), which explicitly claims a forthcoming response to the question. Trump continues by beginning to construct an 'if-then' unit, “...I think (.) if we're gunna ever negotiate ay >peace settlement...” (lines 42-43), but never actually completes it, “...I think it would be (.) m: $\underline{u c h}$ more helpful...” (lines 45-46), abandoning it for: "I'm a negotiator." (line 46). After Trump once again asserts that he is "pro Israel" (line 47), he repeats the contrast marker 'but' and responds to the question: "but I would like to at least have thee o:ther si:de think I'm < somewhat neutral $>$ as tuh them. hh (.) so that we can ma:ybe get a deal done." (lines 49-51). This unit is hearably responsive through the anaphoric noun "the other side" (line 50), which refers to "thuh Palestinian authority" (lines 26-27), and

\footnotetext{
13 This is only possible evidence because an alternative analysis is that the "but..." (line 41) projects a contrast between addressing and rejecting (and thus disagreeing with) the question's presupposition of 'neutrality,' and agreeing with the question 'in part.' If so, then Trump's 'first' matters are still responsive to the question.
} 
through a repeat of "neutral" (line 50; c.f., "neutral"; line 28). This unit is a non-typeconforming, 'Yes'-type response to the question.

Extract 24 (below) is another less-clear - and, perhaps, the most challenging example of the operative claims of "First"-prefacing in the data. As context, prior to this exchange, the moderator (Jake Tapper) introduced the topic of Russia (for the first time in this debate) with the following preamble: "Russia is sending troops and tanks into Syria right now to prop up a U.S. enemy, Bashar al-Assad. President Obama's incoming top general says, quote, 'Russia presents the greatest threat to our national security"' (data not shown). Trump then receives the first question (lines 01-05), to which he repeatedly asserts his intentions to talk to, and get along with, Putin (data not shown).

After a brief follow-up question to Trump (lines 06-09), Tapper addresses the next and focal question to Marco Rubio (starting at line 10):

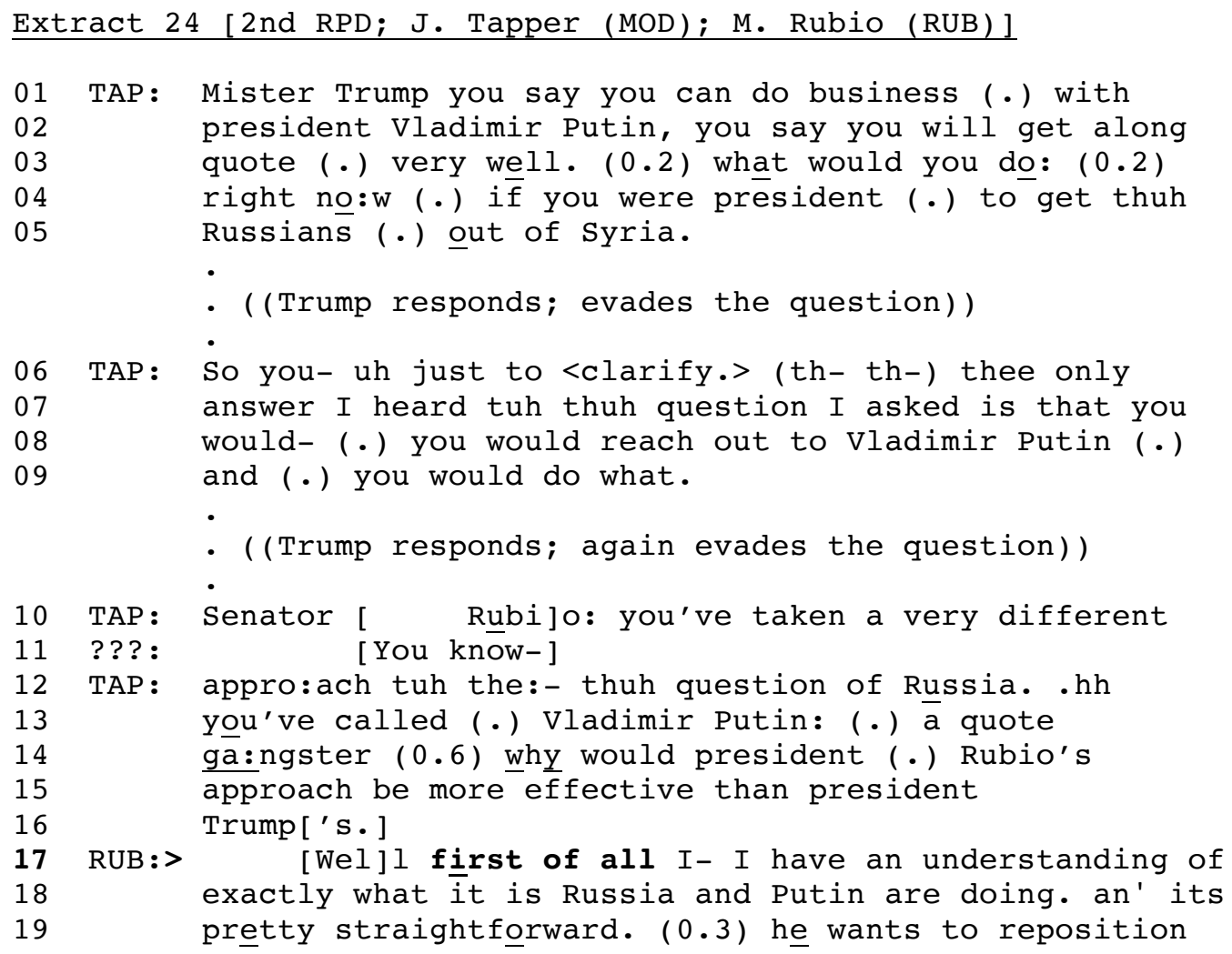


Russia once again as a geopolitical force. (0.2) he himself sa:id that thuh destruction of thuh Soviet Union, thuh fall of the Soviet Union was thuh greatest geopolitical catastrophe. .h of thuh twentieth century. (0.2) an' now he's tryin' duh reverse that. $>$ He's tryin'=duh< destroy nayto. ((NATO)) .hh an' this is what (izzes) a part of. (.) he is exploiting ay vacuum that this administration has left in thuh middle east. .h hêre's what=cher gunna see in thuh next few weeks. . $\bar{h}$ h the Russians will be begin duh fy- fly combat missions in that region. not just targeting Isis .h but in order duh prop up (.) Assa:d. .h he will also then turn duh other countries in thuh region and sa:y America's no longer a reliable ally Egypt, .h America's no longer a reliable ally sāudi Arabia, .h begin to rely on us. .h what he is doing is he is trying duh replace us. .h as thüh single, (.) most important power broke $\bar{r}$ in thuh middle east.h an' this president is allowing it. that is what (its) happening. .h in thuh middle east. that's what's happening with Russisi[a and everywhere ( ).]

TAP: [Thank you senator >Rubio.< I wan]n[a bri]ng in= FIO :

TAP :

$$
=
$$

One way of analyzing Tapper's question, “why would president (.) Rubio’s approach be more effective than president Trump's." (lines 14-16), is as a 'Why'interrogative that makes conditionally relevant a reason (Bolden \& Robinson, 2011; Schegloff \& Lerner, 2009), in this case a justification for Rubio's approach being 'more effective.' Along these lines, the initial unit of Rubio's turn, "I have an understanding of exactly what it is Russia and Putin are doing." (lines 17-18), is seemingly responsive to the question because it is hearable as a relevant 'reason.' If so, given that Rubio prefaces 
his turn with "Well” (line 17) and "fịrst of all" (line 17), this case provides counterevidence to the claims made about "First"-prefacing.

However, despite its syntactic form (i.e., as a 'Why'-interrogative), there are five pieces of evidence that the primary social action being implemented by Tapper's question (at lines 14-16) is more appropriately analyzed not as a solicitation of a 'reason for' Rubio’s 'approach,' but rather as a solicitation of Rubio's 'approach,' per se. First, Tapper asks his question to Rubio as 'the next candidate to address the topical thread,' and Tapper's original question to Trump solicited his concrete approach to dealing with Russia: "what would you dọ: (0.2) right no:w (.) if you were president (.) to get thuh Russians (.) out of Syria.” (lines 03-05). Second, Tapper specifically sanctions Trump for evading the original question (Clayman, 2001): "just to $<$ clarify. $>$ (th- th-) thee only answer I heard tuh thuh question I asked is that you would- (.) you would reach out to Vladimir Putin (.) and (.) you would do what." (lines 06-09). Tapper's sanction displays his orientation to his original question as having solicited a concrete approach to dealing with Russia. Third, Trump once again evades Tapper's follow-up question (data not shown). Thus, Tapper's original question remains unanswered, and thus its relevance is arguably still interactionally 'live,' when Tapper directs his question to Rubio. Fourth, although Tapper asserts that Rubio has "taken a very different appro:ach tuh the:- thuh question of Russia.” (lines 10 and 12), Rubio's approach remains unarticulated, by either Tapper or anyone else previously in this debate. It is difficult to hear Tapper's question as primarily soliciting a 'reason for' Rubio's approach without actually knowing it. Fifth, the next debater to be addressed, Carly Fiorina, independently orients to Tapper's 'line of questioning' as primarily soliciting an agenda, per se (vs. a 'reason for' an agenda). That 
is, simply in response to being selected as the next speaker, "I wanna bring in c-=uhm Carly Fiorina" (lines 41 and 43) - and thus without being asked a question - she begins to provide her agenda items: "what I would do immediately is begin rebuilding thuh sixth fleet, .hh I would begin rebuilding thuh missile defense program in Poland," (lines 53$56)$.

If Tapper's question makes conditionally relevant Rubio's agenda, per se, then Rubio's initial provision of a 'reason' - even though nominally topically related to "Russia" - can be characterized as being unresponsive. With "I have an understanding of exactly what it is Russia and Putin are doing." (lines 17-18), Rubio asserts his epistemic authority (relative to Trump) over the issue of Russia (Heritage \& Raymond, 2005, 2012) by displaying what Heritage and Raymond (2012) described as epistemic agency, where participants "claim primary rights to the information that, they claim, is fully within their purview" (p. 10). In the context of Trump's evasion of Tapper's original question, Tapper's sanction for such evasion, and Trump's continued evasion, Rubio can be heard as indirectly critiquing Trump for his ignorance of how to deal with Russia. Ironically, Rubio also evades the question, never speaking to his agenda, nor to the distinction between it and that of Trump's. Instead, the remainder of Rubio's turn is fully occupied with addressing one part of Tapper's question preface: “you've called (.) Vladimir Putin: (.) a quote ga:ngster" (lines 13-14). This is observable through the recurrent use of the indexical "he" (i.e., Putin) as Rubio lists adversarial assertions of Putin's activities.

Overall, Extracts 23 and 24 are cases where the 'first' matters following a "First"preface are more difficult to demonstrate as being unresponsive to prior questions. However, upon closer inspection of the sequential context of which each "First"-preface 
is situated, these examples do, in fact, constitute evidence for the claims of "First"prefacing as a social practice of action. 


\section{Chapter 4: Discussion}

This thesis used the theory and method of Conversation Analysis to describe an interactional practice called "First"-prefacing as it was deployed in the 2015-2016 Republican primary political debates, including its composition, its position, the action it implements, and its consequences for the ensuing organization of question-answer sequences. This thesis is the first study to document "First"-prefacing as a practice of action as defined by Heritage (2010a):

A "practice" is any feature of the design of a turn in a sequence that (i) has a distinctive character, (ii) has specific locations within a turn or sequence, and (iii) is distinctive in its consequences for the nature or the meaning of the action that the turn implements. (p. 210)

At least in the data examined (e.g., broadcast, Republican primary debates), "First"-prefacing was revealed to possess the following basic compositional and positional characteristics: ${ }^{14}$

(1) The composition of the phenomenon is most commonly "first of all," but can also be "first off," or even simply "first." In cases where the composition is "first," the phenomenon is usually combined with (i.e., immediately followed by) token requests for permission to speak (e.g., "let me say") and/or explicit orientations for not answering (i.e., "I gotta say").

\footnotetext{
${ }^{14}$ These features of "First"-prefacing are not exhaustive. Future research should continue to explore "First"-prefacing in different interactional contexts to see if other characteristics are associated with the practice.
} 
(2) The composition of "First"-prefacing tends to involve increased amplitude/stress on the word "first."

(3) "First"-prefacing is very commonly, but not necessarily, prefaced by the particle "Well," and sometimes followed by token requests for permission to speak (e.g., "let me say") both occurrences that support the action performed by "First"-prefacing.

(4) Excepting silence, breathing, tongue clicking, and 'Uh' (i.e., pre-turn-beginning behaviors; Schegloff, 1996a), and excepting the particles "Well," "Okay," and "Alright," "First"-prefacing is effectively turn-initial. The caveat 'effectively' recognizes that speakers can begin their responsive turns differently, cut them off, and specifically re-begin their turns with "First"-prefacing.

(5) "First"-prefacing is positioned in second-pair-part turns relative to polar ('Yes'/'No' interrogatives) and 'Wh'-type questions.

With these compositional and positional features in mind, "First"-prefacing implements the following action:

(6) "First"-prefacing projects the displacement of responses (conforming or nonconforming) to questions. Specifically, "First"-prefacing projects that something other than a response (conforming or non-conforming) will come immediately next, and it also claims that a conditionally relevant response (conforming or non-conforming) to the question is forthcoming after the 'first' matter. Akin to the practice of "Well"prefacing responsive turns (Schegloff \& Lerner, 2009), which generically projects a non-straightforward response but does not specify the nature of such non- 
straightforwardness, "First"-prefacing generically projects a non-response but does not specify its nature.

Although this thesis has described the action implemented by "First"-prefacing, it is worth discussing the larger-order interactional purposes or goals the practice is used to pursue. On the one hand, the turn-taking system organizing political party debates is even more restrictive than that for traditional broadcast-news interviews in which single persons are being interviewed. That is, in traditional broadcast-news interviews, interviewees can be assured that they, and only they, will be selected next by interviewers. In this situation, interviewees' responses are always adjacent (Schegloff, 2007) to interviewers' questions, and it is only interviewers' questions that must be 'dealt with.' However, in the context of political party debates, once debaters complete their responses, they are almost assured of not being selected to speak next, and in fact typically must wait for several other speakers to complete responses prior to regaining the rights to the floor; in the case of the 2nd primary debate, this was sometimes as many as ten other speakers.

On the other hand, the context of political primary debates is designed to pit more than one candidate against each other as they fight for their party's nomination (Benoit \& Wells, 1996; Bilmes, 1999, 2001); in the 2015-2016 debates examined, the 2nd debate included 11 candidates, and the 12th and final debate contained four candidates. Thus, when debaters are eventually selected to respond to a next question, there are frequently a range of non-adjacent 'matters' that they may want to contend with, but cannot normatively do so because of the conditional relevancies of the question at hand. For example, perhaps the currently selected debater wants to address an indirect criticism 
leveled against them 'three speakers ago,' or wants to address a sub-topic, or even an entire topical thread, that was changed 'two speakers ago.'

"First"-prefacing is uniquely suited to dealing with this sequential conundrum of non-adjacency. In the present data, "First"-prefacing is universally used to interactionally 'reach back' into the debate in order to address or raise matters that are off topic and/or off-agenda relative to the question at hand. Put differently, "First"-prefacing allows politicians to re-open previously closed matters, which can be vernacularly characterized as 'getting in the last word.' For example, 'First"-prefacing was used to address (either directly [Extract 16] or indirectly [Extracts 12]), affirm (Extract 19), counter-accuse (Extract 13), defend against (Extract 17), criticize (either directly [Extract 22] or indirectly [Extract 24]), or contribute to (Extract 18) something mentioned by other participants in preceding sequences, to justify previously self-expressed comments or views (Extract 23), to re-topicalize prior subjects (Extract 21), and to delegitimize (Extract 14) or criticize a moderator's line of questioning (Extract 20).

Considering the literature on broadcast-news-interview (and political-debate) talk, "First"-prefacing appears to project a specific type of agenda shift (see Clayman, 2001). As described by Clayman, politicians/debaters frequently work, during their responses, to shift the agenda of interviewers' questions, and can do so either covertly or overtly. Covert attempts are ones in which no explicit acknowledgement of agenda-shifting is made, and therefore there is a greater chance that the resistance may go unnoticed. Alternatively, overt attempts are ones in which, having already explicitly departed from a question's agenda, participants can take steps toward 'damage control;' the main disadvantage is that the resistance is often conspicuous to listeners, and thus damaging to 
politicians' images/reputations. Insofar as "First"-prefacing is recognizable - to speakers, moderators, and other debaters - as projecting a non-response, it is an overt strategy. Relative to other overt strategies, "First"-prefacing is unique in that it projects a temporary agenda shift - that is, an agenda displacement - and thus arguably does not initially accrue the same disadvantages (e.g., reputational damage in terms of evading the question; Clayman, 2001) because it 'promises' a return to the agenda. However, as seen in Extract 21, in the present context of political debates where politicians are given approximately 75 seconds to respond, moderators may only wait 'so long' before sanctioning politicians for evasion; the 'promise' of "First"-prefacing to return to the question's agenda is apparently monitored.

"First"-prefacing contributes to several other bodies of literature. First, it contributes to work on misplacement markers - such as "By the way" (Schegloff \& Sacks, 1973), “look” (Sidnell, 2007), “listen” (Jefferson, 1972; Sidnell, 2007), “so" (Bolden, 2008), “oh” (Bolden, 2006; Heritage, 1998; Jefferson, 1978), “okay” (Beach, 1993; Liddicoat, 2007, pp. 125-170), and “now” (Aijmer, 2002, pp. 57-95) - which project that the immediately next talk/action will somehow violate talk-in-interaction's fundamental principle of adjacency (Schegloff, 2007). With the possible exception of "look" (Sidnell, 2007), research has described the operation of misplacement markers in sequentially initial positions. In contrast, "First"-prefacing is the first misplacement marker to be shown to operate systematically in sequentially second (pair-part) position. Second, "First"-prefacing contributes to work on English turn-beginnings generally (Schegloff, 1996), and turn-initial particles specifically, such as "Well” (Heritage, 2015; Schegloff \& Lerner, 2009), “Oh” (Heritage, 1998), "Look” (Sidnell, 2007), and “And” 
(Heritage \& Sorjonen, 1994), etc. (for review, see Heritage, 2015). Turn-beginnings "project a 'shape"” for turns' development (Schegloff, 1987c, p. 74), and frequently contribute to the maintenance of sequential coherence and cohesion, for example by projecting a departure from prior talk (e.g., "well” and "oh" prefaces) or continuity with a prior activity (e.g., "and"-prefacing).

\section{Future Research: Expanding the Scope of "First"-Prefacing}

This thesis examined "First"-prefacing in one particular institutional context, and in one particular sequential position. Especially given this discussion's suggestion that "First"-prefacing may be particularly fitted to the speech-exchange system of political debates (i.e., which creates struggles for debaters regarding 'adjacency;' see above), the question arises as to whether or not "First"-prefacing operates in other contexts and sequential positions. While this subsection will not engage in extensive analysis, it reveals that "First"-prefacing: (1) operates similarly in other broadcast contexts, such as the traditional broadcast-news interview; (2) operates similarly in mundane conversation; and (3) operates in at least one different sequential context, that being first-pair parts of adjacency-pair sequences. After providing one example of each, the import of the increased generality of "First"-prefacing will be discussed.

For an example of "First"-prefacing in the traditional broadcast-news interview, see Extract 25. Debbie Stabenow, then a senior Democratic, United States Senator from Michigan, is being phone-interviewed by National Public Radio's David Greene. Prior to this interview, Stabenow had been publicly opposed to the confirmation of Neil Gorsuch as a Justice of the United States' Supreme Court, and had said that she would support a filibuster blocking his confirmation. Meanwhile, Mitch McConnell, a Republican Senate 
majority leader, was threatening to change the rules so that filibusters would not work with Gorsuch's nomination, a change that Stabenow openly contested. As a point of context, Stabenow had been part of the Senate's Democratic caucus when its leader, Harry Reid, changed the rules so that filibusters would not work with lower (vs. higher) court nominees, which leads to Greene's question regarding possible "hypocrisy” (line $10)$.

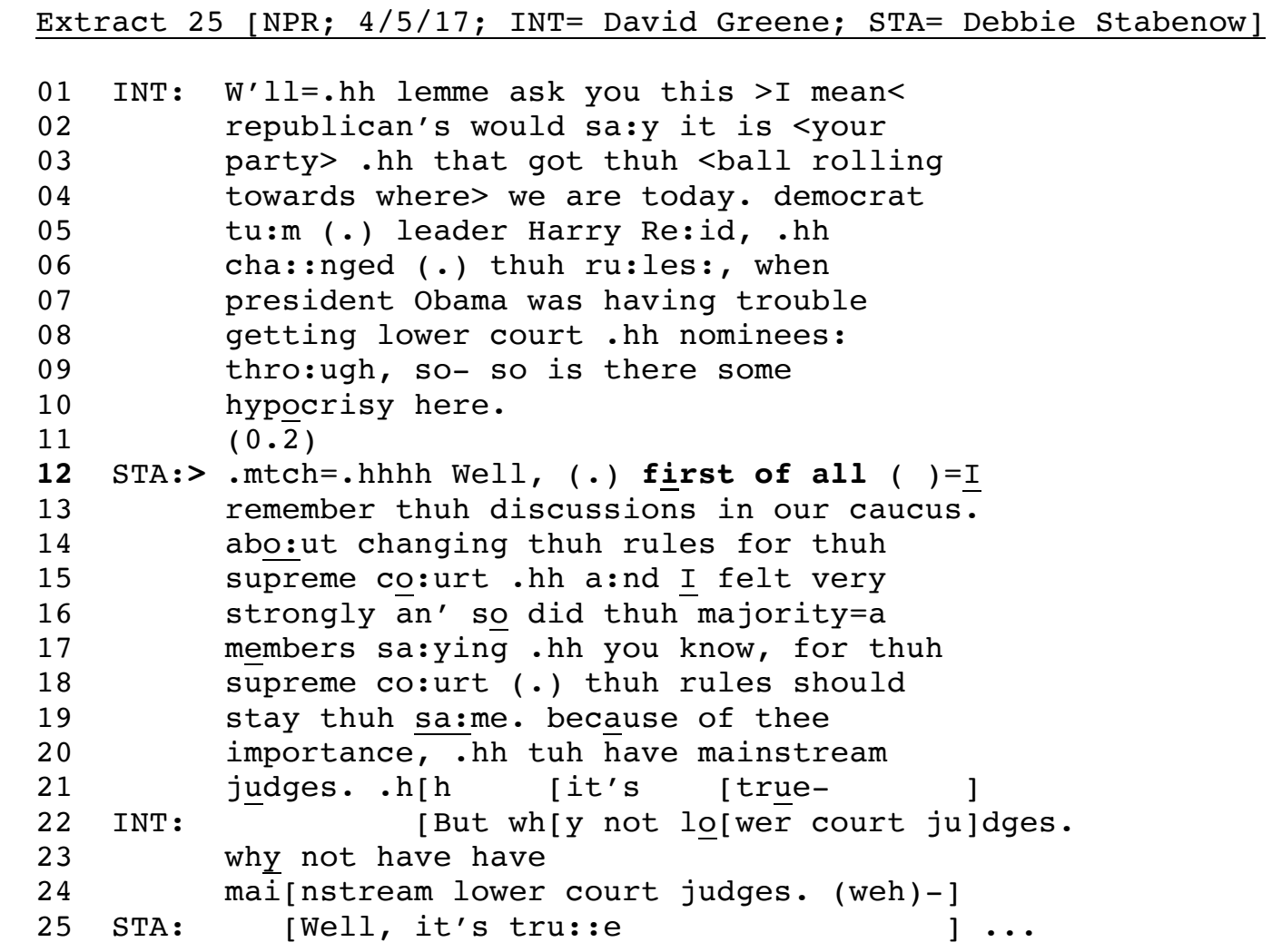

Greene’s question, “so is there some hypocrisy here.” (lines 09-10), makes conditionally relevant a 'Yes'- or ‘No'-type answer (i.e., the question’s action agenda). This question also makes relevant an answer that relates to the question's topical agenda of changing rules for lower court nominees (vs. higher court nominees, such as for the Supreme Court); evidence for this claim is found in Greene's pursuit, which displays his orientation to the focus of his original question: "But why not lower court judges." (line 
22). Immediately after "Well, (.) first of all” (line 12), Stabenow produces an utterance that is unresponsive to the question's action agenda (i.e., she does not produce a 'Yes'- or 'No'-type answer): "I remember thuh discussions in our caucus. abo:ut changing thuh rules for thuh supreme co:urt" (lines 12-15). Admittedly, this utterance does superficially relate to the question's topical agenda insofar as it addresses "changing thuh rules" (line 14; c.f., line 06: "cha::nged (.) thuh ru:les:,") during "thuh discussions in our caucus" (line 13), which were led by “Harry Re:id," (line 05). However, Stabenow's utterance is wholly unresponsive to the focus of the question on "lower court .hh nominees:" (line 08; c.f., lines 17-18: "for thuh supreme co:urt”). In the remainder of her 'first' matters, Stabenow goes on to defend her position regarding not changing the rules for Supreme (i.e., higher) Court nominees (lines 15-21).

Greene orients to Stabenow's 'first' matters as evading the question (Clayman, 2001) when he pursues his original question, "But why not lower court judges." (line 22), and does so even when this pursuit turns into a minor 'floor fight' of overlapping talk (Schegloff, 2000). That is, Greene continues his pursuit despite Stabenow's continued talk, "it's true-" (line 21), and Stabenow continues her talk despite being in overlap with Greene's pursuit: "But why not lower court ju..." (line 22; overlap is symbolized in the transcript with brackets). Perhaps Stabenow's perseverance is explained by the fact that, with "it's true-" (line 21), she begins her actual response to Greene's original question; note that Stabenow repeats "Well, it's tru::e" (line 25) in response to Greene's follow-up question (lines 22-23). By producing the non-conforming response, "it's true-" (line 21), Stabenow begins to partially concede to Greene's original question regarding 
"hypocrisy." As demonstrated in this thesis, Stabenow does, in fact, begin to produce a displaced response.

For an example of "First"-prefacing in ordinary conversation, see Extract 26. This exchange is drawn from a telephone call between two friends, Alan and Mary. Alan is calling to invite Mary to a "s"prise party" (line 05 ) for a mutual friend. In response to Mary's question, "Is it 'is birthday?" (line 11), Alan provides a non-serious (note the laughter throughout; Holt, 2013) and sarcastic 'No'-answer, “No:: we're j(h)us' g(h)unna g(h)ive .hhh surprise birthday $p(h)$ arty fer thuh h(h)ell (of it)." (lines 13-15). Not only does this answer forcefully confirm that the party is a 'birthday party,' but pragmatically - according to Levinson's (2000) quantity heuristic (i.e., 'make your contribution as informative as is required') - it conveys that the party is 'solely' a birthday party, which turns out not to be the case.

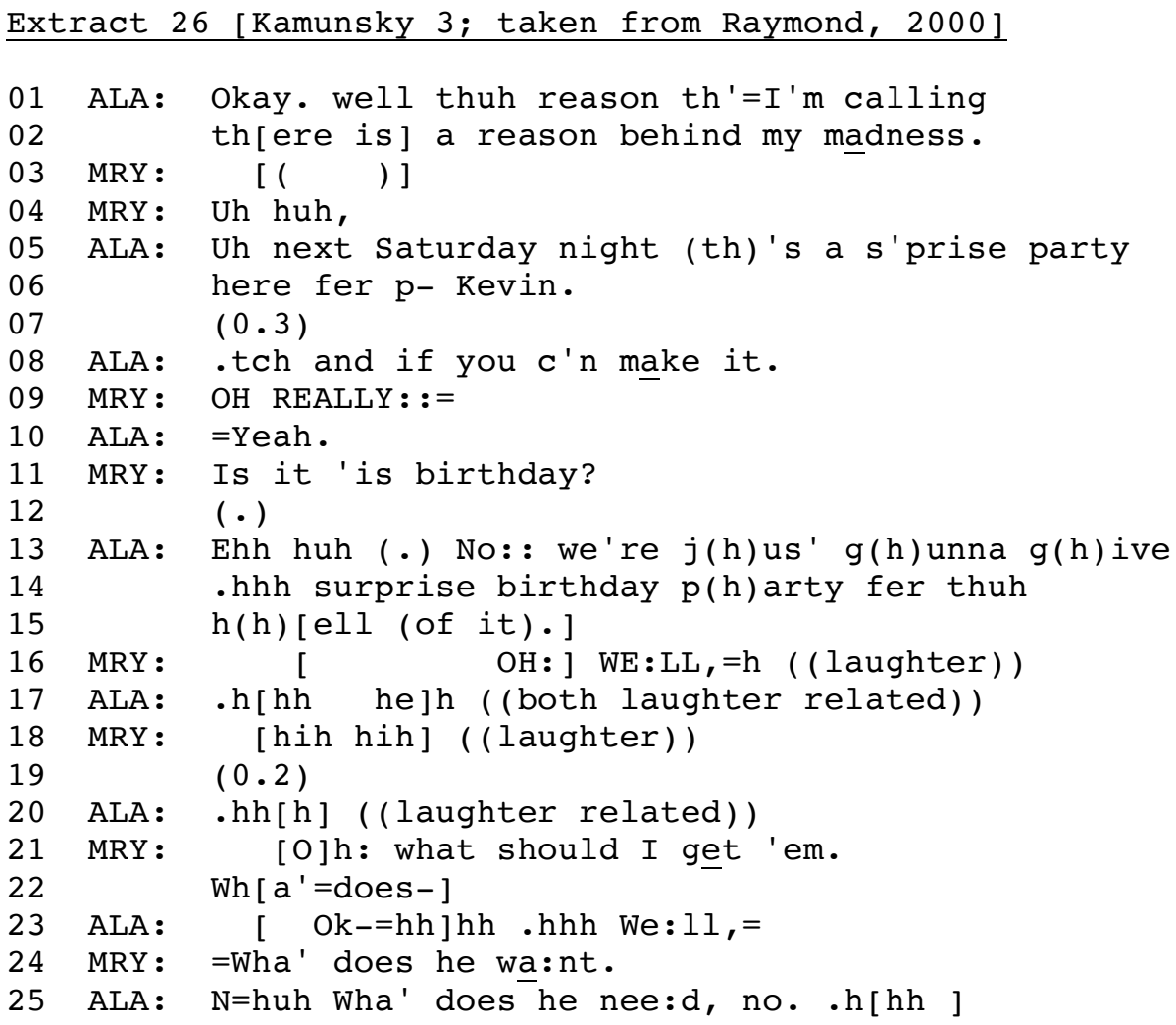




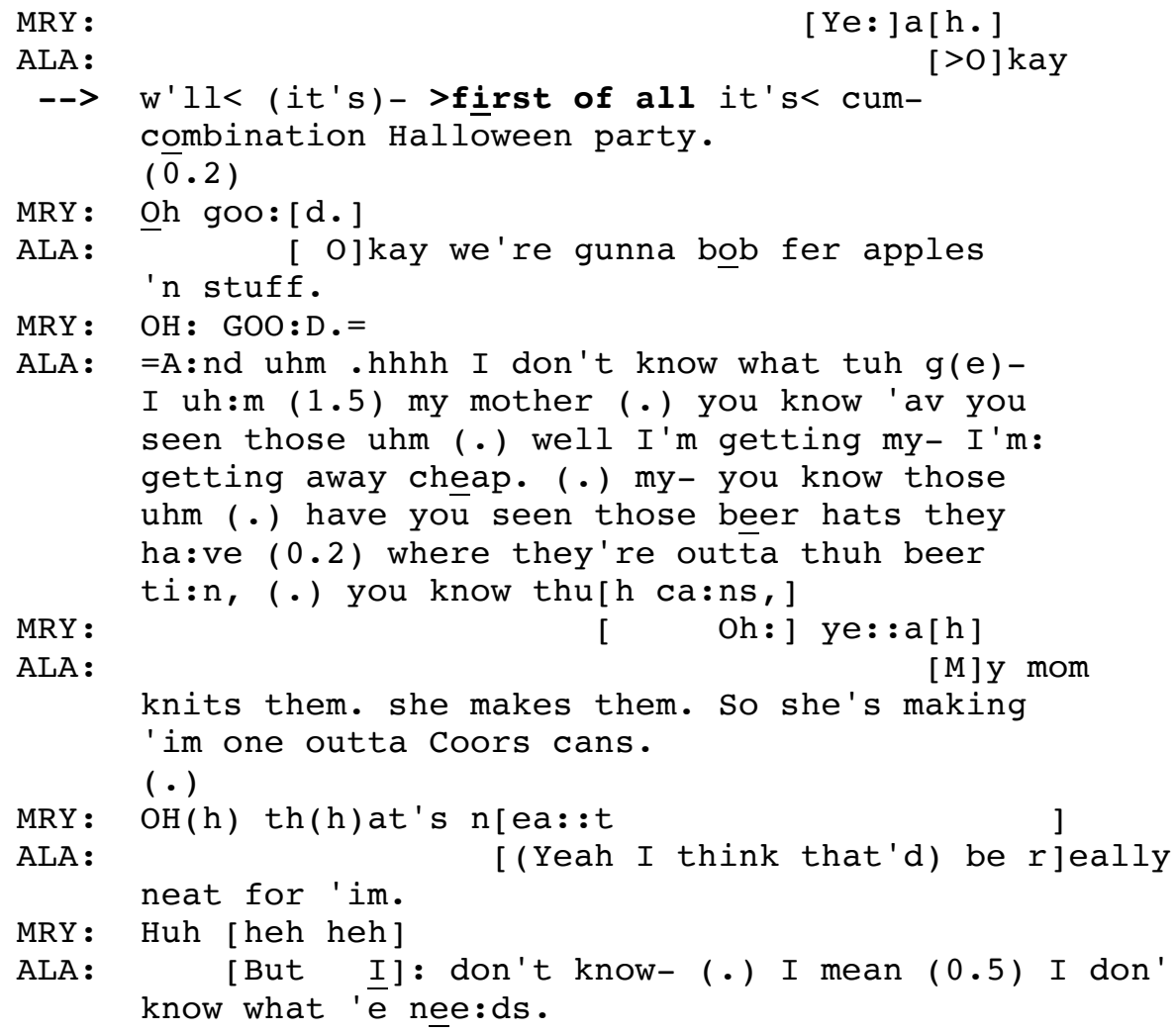

Mary’s questions, "Oh: what should I get 'em." (line 21) and "=Wha' does he wạ:nt.” (line 24) make conditionally relevant an object-reference formulation (specifically, a type of present; Schegloff \& Lerner, 2009). After the resolution of a brief joking sequence initiated by Alan's 'N=huh Wha' does he nee:d, no.” (note Alan's turninitial laughter, "N=huh”, and his joke-to-serious “no.”; Schegloff, 2001), Alan begins to respond to Mary's question with: ">Okay w'll< (it's)- " (lines 27-28). Alan cuts himself off after "(it's)-" (symbolized in the transcript by the hyphen) and inserts: "first of all" (line 28; see Schegloff, 2013). Alan's 'first matters,' "it's < cum- combination Halloween party" (lines 28-29) and "Okay we're gunna bob fer apples 'n stuff." (lines 32-33), are completely unrelated to the topical agenda of Mary's question, and completely nonresponsive to its action agenda. Additional evidence for this latter claim is that, in line with the practice of "First"-prefacing, Alan ultimately does respond to Mary's question, 
beginning with: "I don't know what tuh g(e)-" (line 35), where Alan virtually repeats the word "gete" (line 21) from Mary’s question (c.f., Alan's cut off "g(e)-"). In this case, Alan appears to use "First"-prefacing to correct his prior pragmatic implication that the party is 'only' a birthday party.

For an example of "First"-prefacing in the context of a first-pair part of an adjacency-pair sequence (in ordinary conversation), see Extract 27. Here, Kathy is calling her friend Joanne to discuss carpool arrangements for the upcoming week (apparently, they occasionally share rides to school). As context, several days prior to this call, Kathy's car was in danger of breaking down, and Joanne and her husband (Skeet) had 'followed Kathy home' (lines 15 and 17) to ensure her safe arrival. Thus, while Kathy is calling for the purpose of making arrangements for the upcoming week, there is apparently a distal 'matter' that is relevant, specifically thanking Joanne and her husband for their altruism.

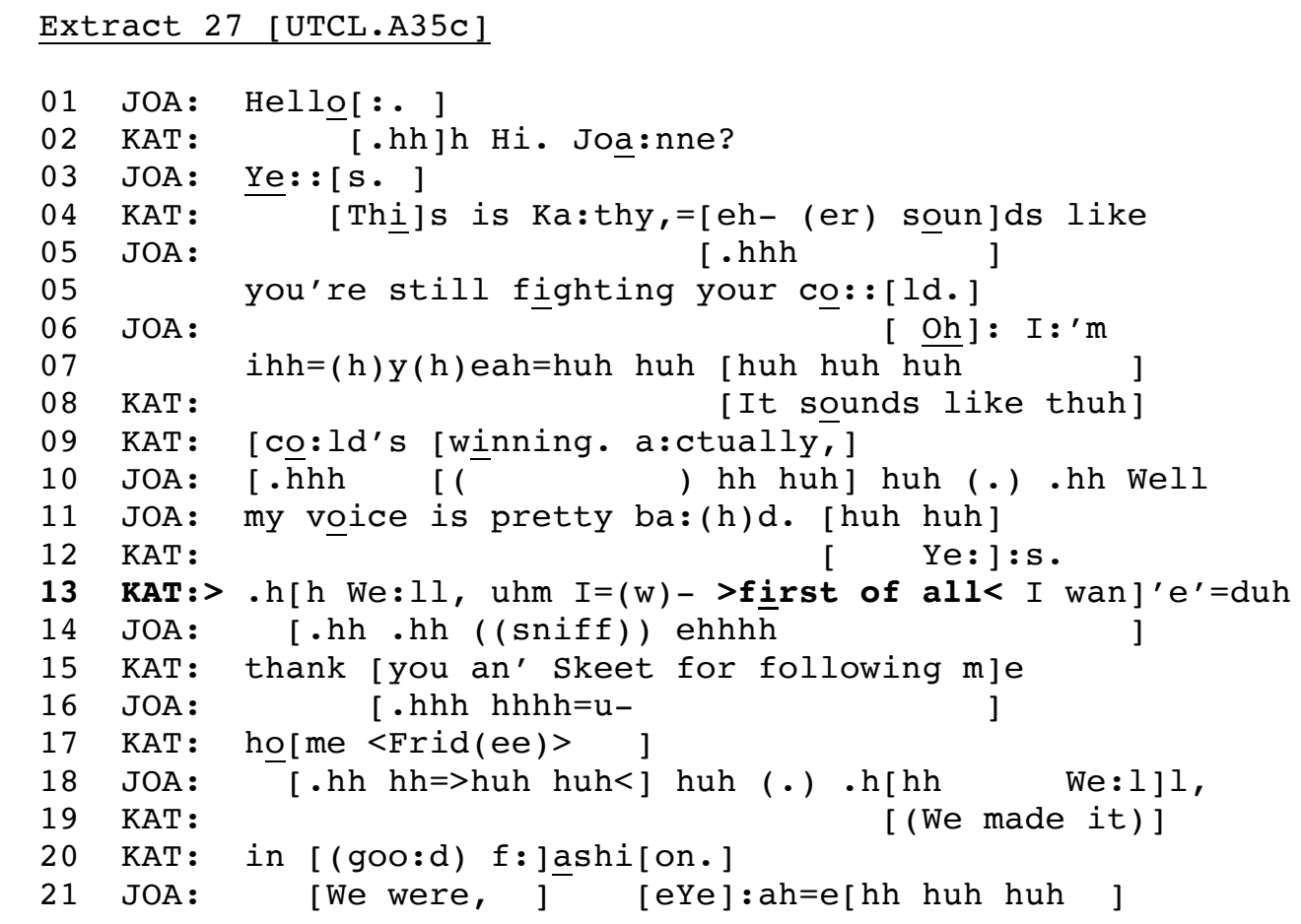




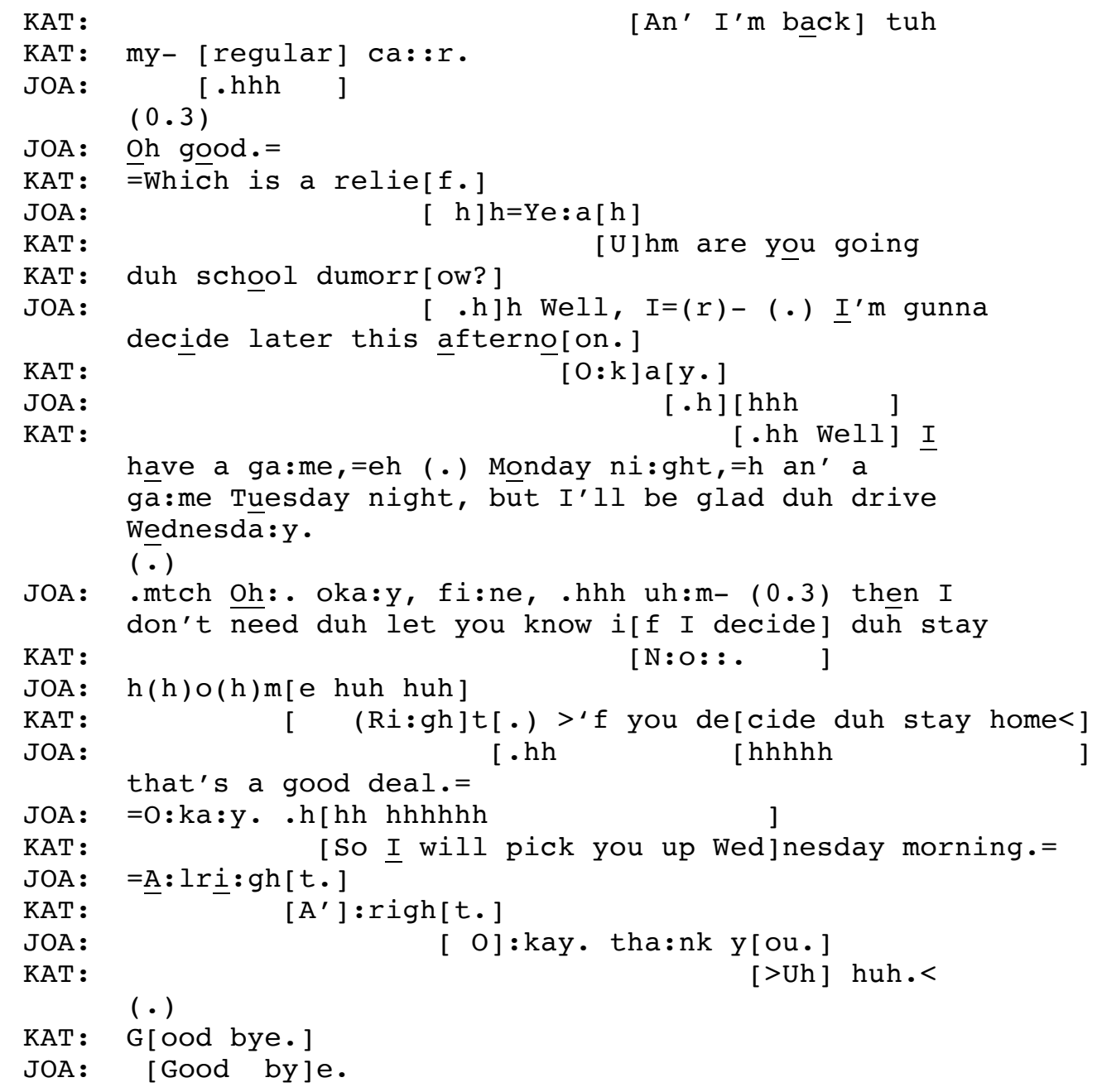

Kathy's "We:1l," (line 13) projects a topic shift (Heritage, 2015) and, in this

location, her "uhm" (line 13) projects a shift to the conversation's 'first topic' (Schegloff, 2010; see also Schegloff, 1986). Kathy begins her turn with "I=(w)-" (line 13), but cuts herself off and inserts: ">first of all<" (line 13). Kathy proceeds to initiate (vs. respond to) a topic: "I wan'e'=duh thank you an' Skeet for following me home $<$ Frid(ee) $>$ " (lines 13, 15, and 17). However, there is evidence that this is not the technical 'first topic' (Schegloff, 1986). Specifically, after the activity of thanking is resolved, Kathy again produces "Uhm" (line 29), which again projects a shift to the conversation's 'first topic,' and begins the topic of making driving arrangements for the following week: "are you 
going duh school dumorrow?” (lines 29-30). In this case, an argument can be made that "First"-prefacing is used as a misplacement marker, effectively displacing the 'first topic' for the action of thanking Joanne and her husband.

As Extracts 25-27 (above) demonstrate, "First"-prefacing can occur in various interactional settings, representing various speech-exchange systems, and can preface both sequence-initiating and sequence-responding actions, Thus, "First"-prefacing - at least when positioned turn-initially relative to sequence initiating and responding actions - appears to be a more generic type of interactional practice used to momentarily displace an immediately sequentially relevant action for one that more normatively relates/ties to a previous matter. However, as Heritage (2010a) noted, "an important test is to make sure that practices operate in a stable way across a wide range of social contexts" (p. 216). Although data in the present thesis is limited to one interactional context, because certain regularities of "First"-prefacing are repeatedly oriented to by participants in a similar fashion, the phenomenon is reproducible, and, thus, arguably generalizable across various speech contexts.

To note, a question arises as to whether "First"-prefacing implements an action that is more associated with establishing a priority. Indeed, prioritizing an utterance may sometimes involve relating or tying back to a previous matter; however, "First"-prefacing may also prioritize a 'first' matter that is prospective (vs. retrospective), or is a newly introduced matter to the conversational or sequential environment. Thus, future research should continue to collect instances of "First"-prefacing to ensure the validity of this thesis' analytic conclusions, and to determine the validity of its speculations. 


\section{References}

Aijmer, K. (2002). English discourse particles: Evidence from a corpus. Amsterdam; Philadelphia: John Benjamins Publishing.

Austin, J. L. (1962). How to do things with words (2nd ed.). J. O. Urmson \& M. Sbisà (Eds.) Cambridge, Massachusetts: Harvard University Press.

Beach, W. A. (1993). Transitional regularities for "casual" "Okay" usages. Journal of Pragmatics, 19(4), 325-352.

Benoit, W. L., \& Wells, W. T. (1996). Candidates in conflict: Persuasive attack and defense in the 1992 presidential debates. Tuscaloosa, AL: University of Alabama Press.

Bilmes, J. (1999). Questions, answers, and the organization of talk in the 1992 vice presidential debate: Fundamental considerations. Research on Language and Social Interaction, 32(3), 213-242. doi: 10.1207/S15327973RL320301

Bilmes, J. (2001). Tactics and styles in the 1992 vice presidential debate: Question placement. Research on Language and Social Interaction, 34(2), 151-181. doi: 10.1207/S15327973RLSI34-2_1

Bolden, G. B. (2006). Little words that matter: Discourse markers "so" and "oh" and the doing of other-attentiveness in social interaction. Journal of Communication, 56(4), 661-688. doi: 10.1111/j.1460-2466.2006.00314.x

Bolden, G. B. (2008). "So what's up?”: Using the discourse marker so to launch conversational business. Research on Language and Social Interaction, 41(3), 302-337. 
Bolden, G. B. (2009). Implementing delayed actions. In J. Sidnell (Ed.), Conversation analysis: Comparative perspectives (pp. 326-354). Cambridge, UK: Cambridge University Press.

Bolden, G. B., \& Robinson, J. D. (2011). Soliciting accounts with why-interrogatives in conversation. Journal of Communication, 61(1), 94-119. doi: 10.1111/j.14602466.2010.01528.x

Bolinger, D. L. M. (1957). Interrogative structures of American English: The direct question. University of Alabama Press.

Brown, P., \& Levinson, S. C. (Eds.) (1987). Politeness: Some universals in language usage. Cambridge, UK: Cambridge University Press.

Carlin, D. B., Morris, E., \& Smith, S. (2001). The influence of format and questions on candidates' strategic argument choices in the 2000 presidential debates. American Behavioral Scientist, 44(12), 2196-2218. doi: 10.1177/00027640121958276

Clayman, S. E. (1988). Displaying neutrality in television news interviews. Social Problems, 35(4), 474-492. doi: https://doi.org/10.2307/800598

Clayman, S. E. (1992). Footing in the achievement of neutrality: The case of news interview discourse. In P. Drew \& J. Heritage (Eds.) Talk at work (pp. 163-198). Cambridge: Cambridge University Press.

Clayman, S. E. (1993). Reformulating the question: A device for answering/not answering questions in news interviews and press conferences. TextInterdisciplinary Journal for the Study of Discourse, 13(2), 159-188. doi: https://doi.org/10.1515/text.1.1993.13.2.159 
Clayman, S. E. (2001). Answers and evasions. Language and Society, 30(3), 403-442. Retrieved from http://www.jstor.org/stable/4169122

Clayman, S. E. (2002). Tribune of the people: Maintaining the legitimacy of aggressive journalism. Media, Culture \& Society, 24(2), 197-216. doi: $10.1177 / 016344370202400203$

Clayman, S. E. (2007). Speaking on behalf of the public in broadcast news interviews. In E. Holt \& R. Clift (Eds.), Reporting talk: Reported speech in interaction (pp. 221243). Cambridge, UK: Cambridge University Press.

Clayman, S. E. (2010). Address terms in the service of other actions: The case of news interview talk. Discourse \& Communication, 4(2), 161-183.

Clayman, S. E. (2013). Conversation analysis in the news interview. In J. Sidnell \& T. Stivers (Eds.), The handbook of conversation analysis (pp. 630-656). West Sussex, UK: Blackwell Publishing.

Clayman, S. E. (2016). The nexus of politicians, issue positions, and the sociopolitical landscape. In J. D. Robinson (Ed.), Accountability in Social Interaction (pp. 141174). New York, NY: Oxford University Press.

Clayman, S. E., Elliott, M. N., Heritage, J., \& McDonald, L. L. (2006). Historical trends in questioning presidents, 1953-2000. Presidential Studies Quarterly, 36(4), 561583. doi: 10.1111/j.1741-5705.2006.02568.x

Clayman, S. E., \& Fox, M. P. (2017). Hardballs and softballs. Journal of Language and Politics, 16(1), 20-40. 
Clayman, S. E., \& Gill, V. T. (2004). Conversation analysis. In M. A. Hardy \& A. Bryman (Eds.), Handbook of data analysis (pp. 589-606). London: SAGE Publications.

Clayman, S. E., \& Heritage, J. (2002a). The news interview: Journalists and public figures on the air. Cambridge, UK: Cambridge University Press.

Clayman, S. E., \& Heritage, J. (2002b). Questioning presidents: Journalistic deference and adversarialness in the press conferences of U.S. Presidents Eisenhower and Reagan. Journal of Communication, 52(4), 749-775. doi: 10.1111/j.14602466.2002.tb02572.x

Clayman, S. E., Heritage, J., Elliott, M. N., \& McDonald, L. L. (2007). When does the watchdog bark? Conditions of aggressive questioning in presidential news conferences. American Sociological Review, 72(1), 23-41.

Clayman, S. E., \& Romaniuk, T. (2011). Questioning candidates. In M. Ekström \& M. Patrona (Eds.), Talking politics in broadcast media: Cross-cultural perspectives on political interviewing, journalism and accountability (pp. 1-11). Amsterdam, The Netherlands: John Benjamins Publishing.

De Smedt, E., \& Vandenbrande, K. (2011). Political television formats as strategic resources in achieving journalists' roles. In M. Ekström \& M. Patrona (Eds.) Talking politics in broadcast media: Cross-cultural perspectives on political interviewing, journalism and accountability (pp. 75-92). Amsterdam, The Netherlands: John Benjamins Publishing.

Drew, P. (1997). 'Open' class repair initiators in response to sequential sources of troubles in conversation. Journal of Pragmatics, 28(1), 69-101. 
Drew, P. (2013). Turn design. In J. Sidnell \& T. Stivers (Eds.), The handbook of conversation analysis (pp. 131-149). West Sussex, UK: Blackwell Publishing. Drew, P., \& Curl, T. (2008). Conversation analysis: Overview and new directions. In V. Bhatia, J. Flowerdew, \& R. H. Jones (Eds.), Advances in discourse studies (pp. 22-25). Abingdon, Oxon: Routledge.

Drew, P. \& Heritage, J. (Eds.) (1992). Talk at work: Interaction in institutional settings. Cambridge, UK: Cambridge University Press.

Du Bois, J. W. (1991). Transcription design principles for spoken discourse research. Pragmatics, 1(1), 71-106.

Ekström, M. (2009). Announced refusal to answer: A study of norms and accountability in broadcast political interviews. Discourse Studies, 11(6), 681-702. doi: $10.1177 / 1461445609347232$

Ekström, M., \& Patrona, M. (2011). Talking politics in broadcast media: An introduction. In M. Ekström \& M. Patrona (Eds.), Talking politics in broadcast media: Crosscultural perspectives on political interviewing, journalism and accountability (pp. 1-11). Amsterdam, The Netherlands: John Benjamins Publishing.

Enfield, N. J., Stivers, T., \& Levinson, S. C. (2010). Question-response sequences in conversation across ten languages: An introduction. Journal of Pragmatics, 42(10), 2615-2619.

Filipi, A., \& Wales, R. (2003). Differential uses of okay, right, and alright, and their function in signaling perspective shift or maintenance in a map task. Semiotica, 147(1/4), 429-456. doi: https://doi.org/10.1515/semi.2003.102 
Fox, B. A., \& Thompson, S. A. (2010). Responses to wh-questions in English conversation. Research on Language and Social Interaction, 43(2), 133-156.

Fox News hits ratings record with prime-time GOP debate. (2015, August 07). Fox News.com. Retrieved from http://www.foxnews.com/politics/2015/08/07/foxnews-makes-ratings-record-with-primetime-gop-debate.html

Gardner, R. (2005). Proceedings of the 2004 Conference of the Australian Linguistic Society: Acknowledging strong ties between utterances in talk: Connections through 'right' as a response token. Retrieved from http://hdl.handle.net/2123/115

Garfinkel, H. (1967). Studies in ethnomethodology. Englewood Cliffs, NJ: Prentice-Hall. Gibbs, R. W. (2000). Irony in talk among friends. Metaphor and Symbol, 15(1-2), 5-27.

Goffman, E. (1963). Stigma: Notes on a spoiled identity. Englewood Cliffs, NJ: PrenticeHall.

Goffman, E. (1964). The neglected situation. American Anthropologist, 66(6), 133-136. doi:10.1525/aa.1964.66.suppl_3.02a00090

Goffman, E. (1967). Interaction ritual. Chicago, Illinois: Aldine Publishing Company.

Goffman, E. (1974). Frame analysis: An essay on the organization of experience. New York, NY: Harper Colophon Books.

Goffman, E. (1981). Forms of talk. Philadelphia, Pennsylvania: University of Pennsylvania Press.

Goffman, E. (1983). The interaction order: American Sociological Association, 1982 presidential address. American Sociological Review, 48(1), 1-17. Retrieved from http://www.jstor.org/stable/2095141 
Goodwin, C. (2007). Interactive footing. In E. Holt \& R. Clift (Eds.), Reporting talk: Reported speech in interaction (pp. 16-46). Cambridge, UK: Cambridge University Press.

Goodwin, C., \& Heritage, J. (1990). Conversation analysis. Annual Review of Anthropology, 19, 283-307. Retrieved from http://www.jstor.org/stable/2155967 Greatbatch, D. (1986a). Aspects of topical organization in news interviews: The use of agenda-shifting procedures by interviewees. Media Culture \& Society, 8(4), 441455. doi: $10.1177 / 0163443786008004005$

Greatbatch, D. (1986b). Some standard uses of supplementary questions in news interviews. In J. Wilson \& B. Crow (Eds.), Belfast Working Papers in Language and Linguistics Vol. 8 (pp. 86-123). Jordanstown, Northern Ireland: University of Ulster.

Greatbatch, D. (1988). A turn-taking system for British news interviews. Language in Society, 17(3), 401-430. doi: http://dx.doi.org/10.1017/S0047404500012963

Harris, S. (1991). Evasive action: How politicians respond to questions in political interviews. In P. Scannell (Ed.), Broadcast talk (pp. 76-99). London: SAGE Publications.

Hayano, K. (2013). Question design in conversation. In J. Sidnell \& T. Stivers (Eds.), The handbook of conversation analysis (pp. 395-415). West Sussex, UK: Blackwell Publishing.

Heritage, J. (1984). Garfinkel and ethnomethodology. Cambridge: Polity Press. 
Heritage, J. (1985). Analyzing news interviews: Aspects of the production of talk for an overhearing audience. In T. A. Van Dijk (Ed.), Handbook of discourse analysis (Vol. 3, pp. 95-117). London: Academic Press.

Heritage, J. (1995). Conversation analysis: Methodological aspects. In U. M. Quasthoff (Ed.), Aspects of Oral Communication (pp. 391-418). Berlin: Walter de Gruyter. Heritage, J. (1998). Oh-prefaced responses to inquiry. Language in Society, 27(03), 291334. doi: https://doi.org/10.1017/S0047404500019990

Heritage, J. (2002). The limits of questioning: Negative interrogatives and hostile question content. Journal of Pragmatics, 34(10-11), 1427-1446.

Heritage, J. (2003). Designing questions and setting agendas in the news interview. In P. J. Glenn, C. D. LeBaron, \& J. Mandelbaum (Eds.), Studies in Language and Social Interaction (pp. 57-90). Mahwah, New Jersey: Lawrence Erlbaum Associates.

Heritage, J. (2009). Conversation analysis as social theory. In B. S. Turner (Ed.), The new Blackwell companion to social theory (pp. 300-320). Blackwell Publishing. Heritage, J. (2010a). Conversation analysis: Practices and methods. In D. Silverman (Ed.), Qualitative Sociology (4th ed., pp. 207-226). SAGE Publications. Heritage, J. (2010b). Questioning in medicine. In A. Freed \& S. Ehrlich (Eds.) "Why do you ask?": The function of questions in institutional discourse (pp. 42-68). New York, NY: Oxford University Press.

Heritage, J. (2012). Epistemics in action: Action formation and territories of knowledge. Research on Language \& Social Interaction, 45(1), 1-29. 
Heritage, J. (2013). Epistemics in conversation. In J. Sidnell \& T. Stivers (Eds.), The handbook of conversation analysis (pp. 370-394). West Sussex, UK: Blackwell Publishing.

Heritage, J. (2015). Well-prefaced turns in English conversation: A conversation analytic perspective. Journal of Pragmatics, 88, 88-104.

Heritage, J., \& Clayman, S. E. (2013). The changing tenor of questioning over time: Tracking a question form across US presidential news conferences, 19532000. Journalism Practice, 7(4), 481-501.

Heritage, J., \& Greatbatch, D. (1991). On the institutional character of institutional talk: The case of news interviews. In D. Boden \& D. H. Zimmerman (Eds.), Talk and social structure: Studies in ethnomethodology and conversation analysis (pp. 93137). Berkeley and Los Angeles, CA: University of California Press.

Heritage, J., \& Raymond, G. (2005). The terms of agreement: Indexing epistemic authority and subordination in talk-in-interaction. Social Psychology Quarterly, 68(1), 15-38.

Heritage, J., \& Raymond, G. (2012). Navigating epistemic landscapes: Acquiescence, agency and resistance in responses to polar questions. In J. P. de Ruiter (Ed.), Questions: Formal, functional and interactional perspectives (pp. 179192). Cambridge, UK: Cambridge University Press.

Heritage, J. C., \& Roth, A. L. (1995). Grammar and institution: Questions and questioning in the broadcast news interview. Research on Language and Social Interaction, 28(1), 1-60. 
Heritage, J., \& Sorjonen, M. L. (1994). Constituting and maintaining activities across sequences: And-prefacing as a feature of question design. Language in Society, 23(01), 1-29. doi: https://doi.org/10.1017/S0047404500017656

Hepburn, A. \& Bolden, G. B. (2013). The conversation analytic approach to transcription. In J. Sidnell \& T. Stivers (Eds.), The handbook of conversation analysis (pp. 5776). West Sussex, UK: Blackwell Publishing.

Holt, E. (1996). Reporting on talk: The use of direct reported speech in conversation. Research on Language and Social Interaction, 29(3), 219-245.

Holt, E. (2013). "There's many a true word said in jest": Seriousness and nonseriousness in interaction. In P. Glenn \& E. Holt (Eds.), Studies of laughter in interaction (pp. 69-90). London, UK: Bloomsbury.

Holt, E., \& Drew, P. (2005). Figurative pivots: The use of figurative expressions in pivotal topic transitions. Research on Language and Social Interaction, 38(1), 3561.

Hutchby, I. (2011). Non-neutrality and argument in the hybrid political interview. Discourse Studies, 13(3), 349-356. doi: 10.1177/1461445611400665

Hutchby, I. (2016). Hybridisation, personalisation and tribuneship in the political interview. Journalism, 18(1), 101-118. doi: 10.1177/1464884916657528

Jefferson, G. (1972). Side sequences. In D. Sudnow (Ed.), Studies in social interaction (pp. 294-338). New York, NY: The Free Press.

Jefferson, G. (1978). Sequential aspects of storytelling in conversation. In J. Schenkein (Ed.), Studies in the organization of conversational interaction (pp. 219-248). New York, NY: Academic Press. 
Jefferson, G. (1984). Notes on some orderlinesses of overlap onset. Discourse Analysis and Natural Rhetoric, 500, 11-38. Retrieved from http://www.liso.ucsb.edu/liso_archives/Jefferson/overlap_onset.pdf

Jefferson, G. (2004). Glossary of transcript symbols with an introduction. In G. H. Lerner (Ed.), Conversation analysis: Studies from the first generation (pp. 13-31). Amsterdam, The Netherlands: John Benjamins Publishing.

Kitzinger, C. (2013). Repair. In J. Sidnell \& T. Stivers (Eds.), The handbook of conversation analysis (pp. 229-256). West Sussex, UK: Blackwell Publishing.

Lee, S. H. (2013). Response design in conversation. In J. Sidnell \& T. Stivers (Eds.), The handbook of conversation analysis (pp. 415-432). West Sussex, UK: Blackwell Publishing.

Lerner, G. H. (1993). Collectivities in action: Establishing the relevance of conjoined participation in conversation. Text-Interdisciplinary Journal for the Study of Discourse, 13(2), 213-246. doi: https://doi.org/10.1515/text.1.1993.13.2.213

Levinson, S. C. (1983). Pragmatics. Cambridge, UK: Cambridge University Press. Levinson, S. C. (2000). Presumptive meanings: The theory of generalized conversational implicature. Cambridge, Massachusetts: The MIT Press.

Liddicoat, A. J. (Ed.) (2007). An introduction to conversation analysis. London; New York: Continuum.

Mills, C. W. (1940). Situated actions and vocabularies of motive. American Sociological Review, 5(6), 904-913. Retrieved from http://www.jstor.org/stable/2084524

Montgomery, M. (2008). The discourse of the broadcast news interview. Journalism Studies, 9(2), 260-277. doi: 10.1080/1461670701848303 
Montgomery, M. (2011). The accountability interview, politics and change in UK public service broadcasting. In M. Ekström \& M. Patrona (Eds.) Talking politics in broadcast media: Cross-cultural perspectives on political interviewing, journalism and accountability (pp. 33-55). Amsterdam, The Netherlands: John Benjamins Publishing.

Non sequitur. (2017). In Merriam-Webster. Retrieved from https://www.merriamwebster.com/dictionary/non\%20sequitur

Park, J. S. (2008). Negative yes/no question-answer sequences in conversation: Grammar, action, and sequence organization (Unpublished doctoral dissertation). University of California, Los Angeles.

Park, Y.Y. (1997). A cross-linguistic study of the use of contrastive connectives in English, Korean and Japanese conversation (Unpublished doctoral dissertation). University of California, Los Angeles.

Parsons, T. (1949). The structure of social action: A study in social theory with special reference to a group of recent European writers (2nd ed.). New York: Free Press. (Original work published 1937)

Patrona, M. (2009). 'A mess' and 'rows': Evaluation in prime-time TV news discourse and the shaping of public opinion. Discourse \& Communication, 3(2), 173-194. doi: $10.1177 / 1750481309102451$

Piirainen-Marsh, A. (2005). Managing adversarial questioning in broadcast interviews. Journal of Politeness Research, 1(2), 193-217. doi: https://doi.org/10.1515/jplr.2005.1.2.193 
Pomerantz, A. (1984). Agreeing and disagreeing with assessments: Some features of preferred/dispreferred turn shaped. In. M. J. Atkinson \& J. Heritage (Eds.), Structures of social action: Studies in conversation analysis (pp. 57-101). Cambridge, UK: Cambridge University Press.

Pomerantz, A. (1986). Extreme case formulations: A way of legitimizing claims. Human studies, 9(2), 219-229.

Pomerantz, A. (1990). Conversation analytic claims. Communications Monographs, 57(3), 231-235.

Pomerantz, A. \& Heritage, J. (2013). Preference. In J. Sidnell \& T. Stivers (Eds.), The handbook of conversation analysis (pp. 210-228). West Sussex, UK: Blackwell Publishing.

Psathas, G. (1995). Conversation analysis: The study of talk-in-interaction. Thousand Oaks, CA: SAGE Publications.

Raclaw, J. (2015). Conversation analysis, overview. In K. Tracy, C. Ilie, \& T. Sandel (Eds.) The international encyclopedia of language and social interaction $\left(1^{\mathrm{st}} \mathrm{ed}\right.$., pp. 1-11). John Wiley \& Sons, Inc. doi: 10.1002/9781118611463.wbielsi155

Raymond, G. (2000). The structure of responding: Type-conforming and nonconforming responses to yes/no type interrogatives (Unpublished doctoral dissertation). University of California, Los Angeles.

Raymond, G. (2003). Grammar and social organization: Yes/no interrogatives and the structure of responding. American Sociological Review, 939-967. Retrieved from http://www.jstor.org/stable/1519752 
Raymond, G. (2013). At the intersection of turn and sequence organization: On the relevance of "slots" in type-conforming responses to polar interrogatives. In B. S. Reeds \& G. Raymond (Eds.), Units of talk—units of action (pp. 169-206). Amsterdam, The Netherlands: John Benjamins Publishing Company.

Robinson, J. D. (2004). The sequential organization of "explicit" apologies in naturally occurring English. Research on Language and Social Interaction, 37(3), 291-330.

Robinson, J. D. (2007). The role of numbers and statistics within conversation analysis. Communication Methods and Measures, 1(1), 65-75.

Robinson, J. D. (2012). Introducing conversation analysis. In J. F. Nussbaum (Ed.), Reading in communication research methods: From theory to practice (pp. 95109). San Diego, CA: Cognella.

Robinson, J. D., \& Bolden, G. B. (2010). Preference organization of sequence-initiating actions: The case of explicit account solicitations. Discourse Studies, 12(4), 501533.

Romaniuk, T. (2013). Pursuing answers to questions in broadcast journalism. Research on Language \& Social Interaction, 46(2), 144-164. doi:

$10.1080 / 08351813.2013 .780339$

Roth, A. L. (2005). “Pop Quizzes” on the Campaign Trail Journalists, Candidates, and the Limits of Questioning. The Harvard International Journal of Press/Politics, 10(2), 28-46.

Sacks, H. (1972). An initial investigation of the usability of conversational data for doing sociology. In D. Sudnow (Ed.), Studies in social interaction (pp. 31-74). New York, NY: The Free Press. 
Sacks, H. (1984). Notes on methodology. In J. M. Atkinson \& J. Heritage (Eds.), Structures of social action: Studies in conversation analysis (pp. 21-27). Cambridge: Cambridge University Press.

Sacks, H. (1987). On the preferences for agreement and contiguity in sequences in conversation. In G. Button \& J. R. E. Lee (Eds.), Talk and Social Organization (pp. 54- 69). Clevedon, England: Multilingual Matters.

Sacks, H. (1992). Lectures on conversation (Volume I \& II). Oxford: Blackwell.

Sacks, H., Schegloff, E. A., \& Jefferson, G. (1974). A simplest systematics for the organization of turn-taking for conversation. Language, 50(4), 696-735. doi: $10.2307 / 412243$

Schegloff, E. A. (1968). Sequencing in conversational openings. American Anthropologist, 70(6), 1075-1095. doi: 10.1525/aa.1968.70.6.02a00030

Schegloff, E. A. (1978). On some questions and ambiguities in conversation. In W. U. Dressler (Ed.), Current Trends in Textlinguistics (pp. 81-102). Berlin: Walter de Gruyter.

Schegloff, E. A. (1982). Discourse as an interactional achievement: Some uses of 'uh huh' and other things that come between sentences. In D. Tanner (Ed.), Analyzing discourse: Text and talk (pp. 71-93). Washington, D.C.: Georgetown University Press.

Schegloff, E. A. (1986). The routine as achievement, Human Studies, 9(2), 111-151. doi: 10.1007/BF00148124

Schegloff, E. A. (1987a). Analyzing single episodes of interaction: An exercise in conversation analysis. Social Psychology Quarterly, 50(2), 101-114. 
Schegloff, E. A. (1987b). Between micro and macro: Contexts and other connections. In J. Alexander, B. Giesen, R. Munch \& N. Smelser (Eds.), The Micro-macro link (pp. 207-234). Berkeley; Los Angeles: University of California Press.

Schegloff, E. A. (1987c). Recycled turn beginnings: A precise repair mechanism in conversation's turn-taking organization. In G. Button \& J. R. E. Lee (Eds.), Talk and Social Organisation (pp. 70-85). Clevedon, England: Multilingual Matters.

Schegloff, E. A. (1988). Goffman and the analysis of conversation. In P. Drew \& A. J. Wootton (Eds.), Erving Goffman: Exploring the interaction order (pp. 89-135). Boston: Northeastern University Press.

Schegloff, E. A. (1990). On the organization of sequences as a source of 'coherence' in talk-in-interaction. In B. Dorval (Ed.), Conversational organization and its development (pp.51-77). Norwood, New Jersey: Ablex Publishing.

Schegloff, E. A. (1992). Repair after next turn: The last structurally provided defense of intersubjectivity in conversation. American Journal of Sociology, 97(5), 12951345.

Schegloff, E. A. (1996a). Turn organization: One intersection of grammar and Interaction. In E. Ochs, E. A. Schegloff, \& S. Thompson (Eds.), Interaction and grammar (pp. 52- 133). Cambridge: Cambridge University Press.

Schegloff, E. (1996b). Confirming allusions: Toward an empirical account of action. American Journal of Sociology, 102(1), 161-216. Retrieved from http://www.jstor.org.proxy.lib.pdx.edu/stable/2782190

Schegloff, E. A. (1997). Third turn repair. In G. R. Guy, C. Feagin, D. Schiffrin, \& J. Baugh (Eds.), Towards a Social Science of Language, Papers in honor of William 
Labov, Volume 2: Social interaction and discourse structures (pp. 31-40). John Benjamins Publishing.

Schegloff, E. A. (2000). Overlapping talk and the organization of turn-taking for conversation. Language in Society, 29(1), 1-63.

Schegloff, E. A. (2001). Getting serious: Joke - > serious 'no'. Journal of Pragmatics, 33(12), 1947-1955.

Schegloff, E. A. (2007). Sequence organization in interaction: A primer in conversation analysis. Cambridge, UK: Cambridge University Press.

Schegloff, E. A. (2010). Some other “Uh(m)”s. Discourse Processes, 47(2), 130-174.

Schegloff, E. A. (2013). Ten operations in self-initiated, same-turn repair. In M. Hayashi, G. Raymond, \& J. Sidnell (Eds.), Conversational repair and human understanding (pp. 41-70). New York: Cambridge University Press.

Schegloff, E. A. (2016). Increments. In J. D. Robinson (Ed.), Accountability in Social Interaction (pp. 238-263). New York, NY: Oxford University Press.

Schegloff, E. A., Jefferson, G., \& Sacks, H. (1977). The preference for self-correction in the organization of repair in conversation. Language, 53(2), 361-382. doi: $10.2307 / 413107$

Schegloff, E. A., \& Lerner, G. H. (2009). Beginning to respond: Well-prefaced responses to wh-questions. Research on Language and Social Interaction, 42(2), 91-115.

Schegloff, E. A., \& Sacks, H. (1973). Opening up closings. Semiotica, 8(4), 289-327. https://doi.org/10.1515/semi.1973.8.4.289 
Schiffrin, D. (1980). Meta-talk: Organizational and evaluative brackets in discourse. Sociological Inquiry, 50(3-4), 199-236. doi: 10.1111/j.1475682X.1980.tb00021.X

Schiffrin, D. (1987). Discourse markers. Cambridge: Cambridge University Press.

Sidnell, J. (2007). 'Look'-prefaced turns in first and second position: launching, interceding and redirecting action. Discourse Studies, 9(3), 387-408.

Sidnell, J. (Ed.) (2009). Conversation analysis: Comparative perspectives. Cambridge, UK: Cambridge University Press.

Sidnell, J., \& Stivers, T. (Eds.) (2013). The handbook of conversation analysis. West Sussex, UK: Blackwell Publishing.

Stivers, T. (2010). An overview of the question-response system in American English conversation. Journal of Pragmatics, 42(10), 2772-2781. https://doi.org/10.1016/j.pragma.2010.04.011

Stivers, T. (2013). Sequence Organization. In J. Sidnell \& T. Stivers (Eds.), The handbook of conversation analysis (pp. 191-209). West Sussex, UK: Blackwell Publishing.

Stivers, T., \& Hayashi, M. (2010). Transformative answers: One way to resist a question's constraints. Language in Society, 39(1), 1-25. doi: https://doi.org/10.1017/S0047404509990637

Stivers, T., \& Robinson, J. D. (2006). A preference for progressivity in interaction. Language in Society, 35, 367-392. doi: 10.10170S0047404506060179

Stivers, T., \& Rossano, F. (2010). Mobilizing response. Research on Language and social interaction, 43(1), 3-31. 
Tolson, A. (2013). The telegenic politician? Communication strategies in the UK election 2010 party leader debates. In M. Ekström \& A. Tolson (Eds.), Media talk and political elections in Europe and America (pp. 133-155). England, UK: Palgrave Macmillan UK.

2016 Republican Presidential Nomination. ( ). Real Clear Politics. Retrieved from http://www.realclearpolitics.com/epolls/2016/president/us/2016_republican_presi dential_nomination-3823.html 


\section{Appendix A: List of 2015-2016 CNN Republican Primary Debates}

Table 1. CNN Broadcast Events Information

\begin{tabular}{|c|c|c|c|c|c|}
\hline Date/Time & Location & Event & Network & Participants & Duration \\
\hline $\begin{array}{l}\text { September } \\
16,2015 \text {, } \\
8: 00 \mathrm{pm} \\
\text { EST }\end{array}$ & $\begin{array}{l}\text { Reagan } \\
\text { Library, Simi } \\
\text { Valley, } \\
\text { California }\end{array}$ & $\begin{array}{l}\text { 2nd Primary } \\
\text { Republican } \\
\text { political } \\
\text { campaign } \\
\text { debate }\end{array}$ & $\begin{array}{l}\text { CNN/ Salem } \\
\text { Radio } \\
\text { Network }\end{array}$ & $\begin{array}{l}\text { Moderators: Jake Tapper, } \\
\text { Dana Bash, Hugh Hewitt } \\
\text { Candidates: Donald Trump, } \\
\text { Jeb Bush, Scott Walker, Mike } \\
\text { Huckabee, Marco Rubio, } \\
\text { Chris Christie, Ben Carson, } \\
\text { Rand Paul, Ted Cruz, John } \\
\text { Kasich, Carly Fiorina }\end{array}$ & $02: 54: 38$ \\
\hline $\begin{array}{l}\text { December } \\
15,2015, \\
8: 30 \mathrm{pm} \\
\text { EST }\end{array}$ & $\begin{array}{l}\text { The Venetian, } \\
\text { Las Vegas, } \\
\text { Nevada }\end{array}$ & $\begin{array}{l}\text { 5th Primary } \\
\text { Republican } \\
\text { political } \\
\text { campaign } \\
\text { debate }\end{array}$ & $\begin{array}{l}\text { CNN/ } \\
\text { Facebook/ } \\
\text { Salem Radio } \\
\text { Network }\end{array}$ & $\begin{array}{l}\text { Moderators: Wolf Blitzer, } \\
\text { Dana Bash, Hugh Hewitt } \\
\text { Candidates: Rand Paul, Chris } \\
\text { Christie, Jeb Bush, Ted Cruz, } \\
\text { Donald Trump, Ben Carson, } \\
\text { Marco Rubio, Carly Fiorina, } \\
\text { John Kasich }\end{array}$ & $02: 15: 51$ \\
\hline $\begin{array}{l}\text { February } \\
25,2016, \\
8: 30 p m \\
\text { EST }\end{array}$ & $\begin{array}{l}\text { University of } \\
\text { Houston in } \\
\text { Houston, } \\
\text { Texas }\end{array}$ & $\begin{array}{l}\text { 10th } \\
\text { Primary } \\
\text { Republican } \\
\text { political } \\
\text { campaign } \\
\text { debate }\end{array}$ & $\begin{array}{l}\text { CNN/ } \\
\text { Telemundo/ } \\
\text { Salem Radio } \\
\text { Network }\end{array}$ & $\begin{array}{l}\text { Moderators: Wolf Blitzer, } \\
\text { Maria Celeste Arrarás, Dana } \\
\text { Bash, Hugh Hewitt } \\
\text { Candidates: John Kasich, Ted } \\
\text { Cruz, Donald Trump, Marco } \\
\text { Rubio, Ben Carson }\end{array}$ & 02:00:07 \\
\hline $\begin{array}{l}\text { March 10, } \\
2016, \\
9: 00 \mathrm{pm} \\
\text { EST }\end{array}$ & $\begin{array}{l}\text { University of } \\
\text { Miami in } \\
\text { Miami, } \\
\text { Florida }\end{array}$ & $\begin{array}{l}12 \text { th } \\
\text { Primary } \\
\text { Republican } \\
\text { political } \\
\text { campaign } \\
\text { debate }\end{array}$ & $\begin{array}{l}\text { CNN/ The } \\
\text { Washington } \\
\text { Times/ } \\
\text { Salem Radio } \\
\text { Network }\end{array}$ & $\begin{array}{l}\text { Moderators: Jake Tapper, } \\
\text { Dana Bash, Hugh Hewitt, } \\
\text { Stephen Dinan } \\
\text { Candidates: John Kasich, Ted } \\
\text { Cruz, Donald Trump, Marco } \\
\text { Rubio }\end{array}$ & 01:55:02 \\
\hline
\end{tabular}




\section{List of 2015-2016 Republican Primary Debates}

Table 2. All Broadcast Events Information

\begin{tabular}{|c|c|c|c|c|c|}
\hline Date/Time & Location & Event & Network & Participants & Duration \\
\hline $\begin{array}{l}\text { August 06, } \\
2015, \\
\text { 9:00pm EST }\end{array}$ & $\begin{array}{l}\text { Quicken } \\
\text { Loans Arena } \\
\text { in Cleveland, } \\
\text { Ohio }\end{array}$ & $\begin{array}{l}\text { First } \\
\text { Primary } \\
\text { Republican } \\
\text { political } \\
\text { campaign } \\
\text { debate }\end{array}$ & $\begin{array}{l}\text { FOX } \\
\text { News/ } \\
\text { Facebook }\end{array}$ & $\begin{array}{l}\text { Moderators: Brett Baier, Megyn } \\
\text { Kelly, Chris Wallace } \\
\text { Candidates: Donald Trump, Jeb } \\
\text { Bush, Scott Walker, Marco } \\
\text { Rubio, Chris Christie, Ben } \\
\text { Carson, Rand Paul, Ted Cruz, } \\
\text { John Kasich, Mike Huckabee }\end{array}$ & $01: 50: 51$ \\
\hline $\begin{array}{l}\text { September } \\
16,2015 \text {, } \\
\text { 8:00pm EST }\end{array}$ & $\begin{array}{l}\text { Reagan } \\
\text { Library, Simi } \\
\text { Valley, } \\
\text { California }\end{array}$ & $\begin{array}{l}2^{\text {nd }} \text { Primary } \\
\text { Republican } \\
\text { political } \\
\text { campaign } \\
\text { debate }\end{array}$ & $\begin{array}{l}\text { CNN/ } \\
\text { Salem } \\
\text { Radio } \\
\text { Network }\end{array}$ & $\begin{array}{l}\text { Moderators: Jake Tapper, Dana } \\
\text { Bash, Hugh Hewitt } \\
\text { Candidates: Donald Trump, Jeb } \\
\text { Bush, Scott Walker, Mike } \\
\text { Huckabee, Marco Rubio, Chris } \\
\text { Christie, Ben Carson, Rand } \\
\text { Paul, Ted Cruz, John Kasich, } \\
\text { Carly Fiorina }\end{array}$ & $02: 54: 38$ \\
\hline
\end{tabular}

\begin{tabular}{|c|c|c|c|c|c|}
\hline $\begin{array}{l}\text { October } 28, \\
2015, \\
8: 00 \text { pm EST }\end{array}$ & $\begin{array}{l}\text { University of } \\
\text { Colorado in } \\
\text { Boulder, } \\
\text { Boulder } \\
\text { Colorado }\end{array}$ & $\begin{array}{l}3^{\text {rd }} \text { Primary } \\
\text { Republican } \\
\text { political } \\
\text { campaign } \\
\text { debate }\end{array}$ & $\mathrm{CNBC}$ & $\begin{array}{l}\text { Moderators: Carl Quintanilla, } \\
\text { Becky Quick, John Harwood } \\
\text { Candidates: John Kasich, Mike } \\
\text { Huckabee, Jeb Bush, Marco } \\
\text { Rubio, Donald Trump, Ben } \\
\text { Carson, Carly Fiorina, Ted } \\
\text { Cruz, Chris Christie, Rand } \\
\text { Paul }\end{array}$ & 01:52:07 \\
\hline $\begin{array}{l}\text { November } \\
\text { 10, 2015, } \\
\text { 9:00pm EST }\end{array}$ & $\begin{array}{l}\text { Milwaukee } \\
\text { Theater, } \\
\text { Milwaukee, } \\
\text { Wisconsin }\end{array}$ & $\begin{array}{l}4^{\text {th }} \text { Primary } \\
\text { Republican } \\
\text { political } \\
\text { campaign } \\
\text { debate }\end{array}$ & $\begin{array}{l}\text { FOX } \\
\text { Business } \\
\text { Network/ } \\
\text { Wall Street } \\
\text { Journal }\end{array}$ & $\begin{array}{l}\text { Moderators: } \\
\text { Neil Cavuto, Maria Bartiromo, } \\
\text { Gerald Baker } \\
\text { Candidates: Donald Trump, } \\
\text { Ben Carson, Marco Rubio, Ted } \\
\text { Cruz, Jeb Bush, Carly Fiorina, } \\
\text { John Kasich, Rand Paul }\end{array}$ & $01: 54: 50$ \\
\hline $\begin{array}{l}\text { December } \\
15,2015, \\
8: 30 \mathrm{pm} \mathrm{EST}\end{array}$ & $\begin{array}{l}\text { The Venetian, } \\
\text { Las Vegas, } \\
\text { Nevada }\end{array}$ & $\begin{array}{l}5^{\text {th }} \text { Primary } \\
\text { Republican } \\
\text { political } \\
\text { campaign } \\
\text { debate }\end{array}$ & $\begin{array}{l}\text { CNN/ } \\
\text { Facebook/ } \\
\text { Salem } \\
\text { Radio } \\
\text { Network }\end{array}$ & $\begin{array}{l}\text { Moderators: Wolf Blitzer, Dana } \\
\text { Bash, Hugh Hewitt } \\
\text { Candidates: Rand Paul, Chris } \\
\text { Christie, Jeb Bush, Ted Cruz, } \\
\text { Donald Trump, Ben Carson, } \\
\text { Marco Rubio, Carly Fiorina, } \\
\text { John Kasich }\end{array}$ & $02: 15: 51$ \\
\hline
\end{tabular}




\begin{tabular}{|c|c|c|c|c|c|}
\hline $\begin{array}{l}\text { January } 14, \\
2016, \\
\text { 9:00pm EST }\end{array}$ & $\begin{array}{l}\text { North } \\
\text { Charleston } \\
\text { Coliseum, } \\
\text { North } \\
\text { Charleston, } \\
\text { South } \\
\text { Carolina }\end{array}$ & $\begin{array}{l}6^{\text {th }} \text { Primary } \\
\text { Republican } \\
\text { political } \\
\text { campaign } \\
\text { debate }\end{array}$ & $\begin{array}{l}\text { FOX } \\
\text { Business } \\
\text { Network/ } \\
\text { Facebook }\end{array}$ & $\begin{array}{l}\text { Moderators: Neil Cavuto, } \\
\text { Maria Bartiromo } \\
\text { Candidates: Donald Trump, Ted } \\
\text { Cruz, Marco Rubio, Ben } \\
\text { Carson, Chris Christie, Jeb } \\
\text { Bush, John Kasich }\end{array}$ & 02:00:19 \\
\hline $\begin{array}{l}\text { February 6, } \\
2016, \\
9: 00 \text { pm EST }\end{array}$ & $\begin{array}{l}\text { Saint Anselm } \\
\text { College, } \\
\text { Manchester, } \\
\text { New } \\
\text { Hampshire }\end{array}$ & $\begin{array}{l}8^{\text {th }} \text { Primary } \\
\text { Republican } \\
\text { political } \\
\text { campaign } \\
\text { debate }\end{array}$ & $\begin{array}{l}\text { ABC } \\
\text { News/ } \\
\text { Independen } \\
\text { t Journal } \\
\text { Review }\end{array}$ & $\begin{array}{l}\text { Moderators: David Muir, } \\
\text { Martha Raddatz } \\
\text { Candidates: Chris Christie, } \\
\text { Ben Carson, Ted Cruz, Donald } \\
\text { Trump, Marco Rubio, Jeb } \\
\text { Bush, John Kasich }\end{array}$ & 02:30:06 \\
\hline $\begin{array}{l}\text { February } 13, \\
2016, \\
9: 00 \text { pm EST }\end{array}$ & $\begin{array}{l}\text { The Peace } \\
\text { Center, } \\
\text { Greenville, } \\
\text { South } \\
\text { Carolina }\end{array}$ & $\begin{array}{l}9^{\text {th }} \text { Primary } \\
\text { Republican } \\
\text { political } \\
\text { campaign } \\
\text { debate }\end{array}$ & CBS News & $\begin{array}{l}\text { Moderators: John Dickerson } \\
\text { Candidates: Ben Carson, } \\
\text { Marco Rubio, Donald Trump, } \\
\text { Ted Cruz, Jeb Bush, John } \\
\text { Kasich }\end{array}$ & 01:39:20 \\
\hline $\begin{array}{l}\text { February } 25, \\
2016, \\
8: 30 \text { pm EST }\end{array}$ & $\begin{array}{l}\text { University of } \\
\text { Houston in } \\
\text { Houston, } \\
\text { Texas }\end{array}$ & $\begin{array}{l}10^{\text {th }} \\
\text { Primary } \\
\text { Republican } \\
\text { political } \\
\text { campaign } \\
\text { debate }\end{array}$ & $\begin{array}{l}\text { CNN/ } \\
\text { Telemundo/ } \\
\text { Salem } \\
\text { Radio } \\
\text { Network }\end{array}$ & $\begin{array}{l}\text { Moderators: Wolf Blitzer, } \\
\text { Maria Celeste Arrarás, Dana } \\
\text { Bash, Hugh Hewitt } \\
\text { Candidates: John Kasich, Ted } \\
\text { Cruz, Donald Trump, Marco } \\
\text { Rubio, Ben Carson }\end{array}$ & 02:00:07 \\
\hline $\begin{array}{l}\text { March 03, } \\
2016, \\
\text { 9:00pm EST }\end{array}$ & $\begin{array}{l}\text { Fox Theatre } \\
\text { in Detroit, } \\
\text { Michigan }\end{array}$ & $\begin{array}{l}11^{\text {th }} \\
\text { Primary } \\
\text { Republican } \\
\text { political } \\
\text { campaign } \\
\text { debate }\end{array}$ & FOX News & $\begin{array}{l}\text { Moderators: Brett Baier, } \\
\text { Megyn Kelly, Chris Wallace } \\
\text { Candidates: Donald Trump, } \\
\text { Ted Cruz, Marco Rubio, John } \\
\text { Kasich }\end{array}$ & $00: 52: 33$ \\
\hline $\begin{array}{l}\text { March 10, } \\
2016, \\
9: 00 \mathrm{pm} \mathrm{EST}\end{array}$ & $\begin{array}{l}\text { University of } \\
\text { Miami in } \\
\text { Miami, } \\
\text { Florida }\end{array}$ & $\begin{array}{l}12^{\text {th }} \\
\text { Primary } \\
\text { Republican } \\
\text { political } \\
\text { campaign } \\
\text { debate }\end{array}$ & $\begin{array}{l}\text { CNN/ The } \\
\text { Washingto } \\
\text { n Times/ } \\
\text { Salem } \\
\text { Radio } \\
\text { Network }\end{array}$ & $\begin{array}{l}\text { Moderators: Jake Tapper, } \\
\text { Dana Bash, Hugh Hewitt, } \\
\text { Stephen Dinan } \\
\text { Candidates: John Kasich, Ted } \\
\text { Cruz, Donald Trump, Marco } \\
\text { Rubio }\end{array}$ & 01:55:02 \\
\hline
\end{tabular}




\section{Appendix B: Initial Data Collection}

Table 3. Selected Question Threads from Standardized Transcripts

\section{Debate: CNN 2nd Republican Primary Debate 9/16/2015}

1.

Moderator: Jake Tapper

Subject round: Current events/comments on the campaign trail

Tapper: Let's move to Russia if we could. Russia is sending troops and tanks into Syria right now to prop up a U.S. enemy, Bashar al-Assad. President Obama's incoming top general says, quote, "Russia presents the greatest threat to our national security."

Tapper to Donald Trump

Q1.1: Mr. Trump, you say you can do business with President Vladimir Putin, you say you will get along, quote, "very well." What would you do right now if you were president, to get the Russians out of Syria?

\section{Tapper to Marco Rubio}

Q1.2: Senator Rubio, you've taken a very different approach to the - the question of Russia. You've called Vladimir Putin a, quote, "gangster." Why would President Rubio’s approach be more effective than President Trump's?

2.

Moderator: Jake Tapper

Subject round: Immigration

Tapper to Ted Cruz

Q2.1: Senator Cruz - Senator Cruz, this week, we learned more about Dr. Carson's plan for the 11 million to 12 million undocumented immigrants in this country. Dr. Carson proposed giving these undocumented immigrants a six-month grace period to pay back taxes then to let them become guest workers and only to deport people who failed to do that.

[... Ben Carson interjection ...]

Tapper: OK, from the horse's mouth, Senator Cruz, does that fit your definition of amnesty?

Tapper: I want to talk about the issue of birthright citizenship, which — which has emerged since the first debate as — as an a - a major issue in this campaign.

Tapper to Donald Trump

Q2.2: Mr. Trump, you say that babies born in the United States to undocumented immigrants should not any longer get automatic American citizenship. Ms. Fiorina says that you are pandering on this issue and acting like the politicians that you rail against. What's your message to Ms. Fiorina on birthright citizenship?

3.

Moderator: Jake Tapper

Subject round: Economy and jobs 
Tapper: Let's turn to a new topic. We've received a lot of questions on social media about the economy and about jobs. We have two CEOs on stage right now.

Tapper to Donald Trump

Q3.1: Mr. Trump - Mr. Trump, why would you be better at creating jobs than Carly Fiorina?

Tapper to John Kasich

Q3.2: Donald Trump says that the hedge fund guys are getting away with murder by paying a lower tax rate. He wants to raise the taxes of hedge fund managers, as does Governor Bush. Do you agree?

4.

Moderator: Jake Tapper

Subject round: Domestic issues

Tapper: We received a lot of questions from social media about climate change.

Tapper to March Rubio

Q4.1: Senator Rubio, Ronald Reagan's secretary of state, George Shultz, reminds us that when Reagan was president he faced a similar situation to the one that we're facing now. There were dire warnings from the mass consensus of the scientific community about the ozone layer shrinking.

Shultz says Ronald Reagan urged skeptics in industry to come up with a plan. He said, do it as an insurance policy in case the scientists are right. The scientists were right. Reagan and his approach worked. Secretary Shultz asks, why not take out an insurance policy and approach climate change the Reagan way?

Tapper: A backlash against vaccines was blamed for a measles outbreak here in California. Dr. Carson, Donald Trump has publicly and repeatedly linked vaccines, childhood vaccines, to autism, which, as you know, the medical community adamantly disputes.

\section{Tapper to Donald Trump}

Q4.2: Mr. Trump, as president, you would be in charge of the Centers for Disease Control and the National Institutes of Health, both of which say you are wrong. How would you handle this as president?

5.

Moderator: Jake Tapper

Subject round: How will the world look different

Tapper: OK, here's the more serious question, Ronald Reagan, the 40th President, used the plane behind you to accomplish a great many things. Perhaps, most notably, to challenge Mikhail Gorbachev to tear down the wall, and ultimately, to make peace with the USSR.

Tapper to all participating candidates

Q5.1: How will the world look different once your Air Force One is parked in the hangar of your presidential library?

\section{Debate: CNN 5th Republican Primary Debate 12/15/2015}

6.

Moderator: Wolf Blitzer 
Subject round: Approaches to keeping the country safe

Blitzer to Donald Trump

Q6.1: Mr. Trump, as you mentioned in your opening statement, part of your strategy is to focus in on America's borders. To keep the country safe, you say you want to temporarily ban non-American Muslims from coming to the United States; ban refugees fleeing ISIS from coming here; deport 11 million people; and wall off America's southern border. Is the best way to make America great again to isolate it from much of the rest of the world?

Blitzer to John Kasich

Q6.2: Governor Kasich, one of the killers in San Bernardino was an American who was not on anyone's watch list. How are you going to find that radicalized person and stop another such attack?

7.

Moderator: Wolf Blitzer

Subject round: Surveillance and privacy

Blitzer to Donald Trump

Q7.1: Mr. Trump, you recently suggested closing that Internet up, those were your words, as a way to stop ISIS from recruiting online. Are you referring to closing down actual portions of the Internet? Some say that would put the U.S. in line with China and North Korea.

$\underline{\text { Blitzer to John Kasich }}$

Q7.2: Thank you. Governor Kasich, is shutting down any part of the Internet a good idea?

8.

Moderator: Wolf Blitzer

Subject round: Foreign policy and dictatorships in the Middle East

Blitzer: The war against ISIS will pose many new challenges for the next commander-in-chief. The last two presidents pursued a Middle East policy that supported toppling dictators to try to promote democracy.

\section{$\underline{\text { Blitzer to Ted Cruz }}$}

Q8.1: Senator Cruz, you have said the world would be safer today if Saddam Hussein were still in power in Iraq, Moammar Gadhafi ruled Libya, and Hosni Mubarak ruled Egypt. So would it be your policy to preserve dictatorships, rather than promoting democracy in the Middle East?

Blitzer to Donald Trump

Q8.2: We're going to talk about Assad in a moment. Mr. Trump, are Americans safer with dictators running the world in the Middle East?

\section{Debate: CNN 10th Republican Primary Debate 2/25/2016}

9.

Moderator: Wolf Blitzer

Subject round: Immigration

Blitzer: Immigration is a key issue in this state, for all voters nationwide, including the many people watching us on Telemundo. So, that's where we begin. 
Blitzer to Donald Trump

Q9.1: Mr. Trump, you've called for a deportation force to remove the 11 million undocumented immigrants from the United States. You've also promised to let what you call, "the good ones", come back in. Your words, "the good ones", after they've been deported. Senator Cruz would not allow them to come back in. He says that's the biggest difference between the two of you. He calls your plan amnesty. Is it?

\section{$\underline{\text { Blitzer to Marco Rubio }}$}

Q9.2: Senator Cruz has called your immigration plan amnesty, and has an ad out there comparing it to President Obama's. He says both of you support allowing undocumented immigrants legal status here in the United States after a background check, paying a fine, and paying taxes. Are those claims correct?

10.

Moderator: Wolf Blitzer

Subject round: Immigration

Blitzer to Ted Cruz

Q10.1: Senator Cruz, you say you want to deport the 11 million undocumented immigrants, but you never want to allow them to come back to the United States. What would happen to the children who are U.S.- born citizens whose parent will be deported under your plan?

\section{Blitzer to Donald Trump}

Q10.2: Mr. Trump, your campaign, as you well remember, began with the idea of building a wall along the southern border. It's about 315 miles southwest of where we are right now. You've said the Mexican government will pay for it. The spokesperson for the current president of Mexico says that will never happen. The last two presidents of Mexico say that will never happen. In fact, the former president of Mexico, Vicente Fox -- he said today, and I'm quoting him -- he said, "I'm not going to pay for that," quote, "effing wall." So if you don't get an actual check from the Mexican government for $\$ 8$ billion or $\$ 10$ billion or $\$ 12$ billion, whatever it will cost, how are you going to make them pay for the wall?

11.

Moderator: Hugh Hewitt

Subject round: Supreme Court

Wolf Blitzer: I want to turn our attention now to another critically important issue for the American people, the United States Supreme Court, where filling the vacancy left by the late Justice Antonin Scalia has become a major campaign issue. I want to bring in Salem Radio Network host, Hugh Hewitt. Hugh?

\section{Hewitt to Donald Trump}

Q11.1: Mr. Trump, Senator Cruz mentioned the issue that keeps me up at night, which is religious liberty. Churches, Catholic and Christian colleges, Catholic adoption agencies -- all sorts of religious institutions fear that Hobby Lobby, if it's repealed, it was a five-four decision, they're going to have to bend their knee and provide morning-after pills. They fear that if Bob Jones is expanded, they will lose their tax exemption. Will you commit to voters tonight that religious liberty will be an absolute litmus test for anyone you appoint, not just to the Supreme Court, but to all courts?

Hewitt to John Kasich

Q.11.2: Governor Kasich, back to religious liberty. You've been a little bit less emphatic. You've said, same-sex couple approaches a cupcake maker, sell them a cupcake. Can we trust you as much on religious liberty as the rest of these people? 
12.

Moderator: Wolf Blitzer

Subject round: Economy

Blitzer to Donald Trump

Q12.1: Mr. Trump, you want to cut taxes more than President Ronald Reagan did, more than President George W. Bush did. The Independent Tax Foundation says the cost to the country of your proposal would be about $\$ 10$ trillion, and that takes into account the economic growth that would emerge from your proposed tax cuts. How would you cut $\$ 10$ trillion over 10 years, but make sure the country isn't saddled with even more debt?

Blitzer to John Kasich

Q12.2: Governor Kasich. When you were in Congress, you were chairman of the Budget Committee. You helped craft the last balanced budget the United States had. Can Mr. Trump's plan work?

13.

Moderator: Hugh Hewitt

Subject round: Economy

\section{Hewitt to Donald Trump}

Q13.1: Mr. Trump, a year ago you told me on my radio show, the audio and the transcript are out there on YouTube, that you would release your tax returns. Are you going back on your commitment?

Hewitt to Marco Rubio

Q13.2: So, Senator Rubio, Mitt Romney also called upon to you release your tax returns. Your campaign said last spring that you would release your returns that you had not previously released.

And you said, coming out any day momentarily. When are we going to see your returns?

14.

Moderator: Hugh Hewitt

Subject round: National Security

Hewitt to Donald Trump

Q14.1: Thank you, Wolf. Mr. Trump, we are less than 24 hours away from a ceasefire in Syria that has been brokered between the U.S. and Russia. Do you support this ceasefire?

Hewitt to Ted Cruz

Q14.2: Senator Cruz, your opinion on the ceasefire.

\section{Debate: CNN 12th Republican Primary Debate 03/10/2016}

15.

Moderator: Jake Tapper

Subject round: Jobs and the economy

Tapper: Let's begin with jobs and the economy, which Republican voters say is the most important issue to them in this election. There have been some real differences expressed in - on this stage on whether trade deals have been good for the American workers. One of Mr. Trump's, the front runner's, signature issues is ending what he calls "disastrous trade deals" in order to bring jobs back to America. 
Tapper to Donald Trump

Q15.1: Mr. Trump, your critics say your campaign platform is inconsistent with how you run your businesses, noting that you've brought in foreign workers instead of hiring Americans, and your companies manufacture clothing in China and Mexico. Why should voters trust that you will run the country differently from how you run your businesses?

\section{Tapper to Ted Cruz}

Q15.2: Senator Cruz, you were a supporter of the Pacific trade deal, but after taking some heat from conservatives, you changed your position. Why should these voters who don't like these trade deals trust that you will fight for them all the time and not just in election years?

16.

Moderator: Jake Tapper

Subject round: Education

Tapper: Education obviously plays a large role when it comes to jobs and the economy. The United States has long been falling behind others in the industrialized world. American students currently rank 27th out of 34 countries in math and 17 th in reading.

\section{Tapper to Donald Trump}

Q16.1: Mr. Trump, you've called the education standards known as Common Core a disaster. What are your specific objections to Common Core?

\section{Tapper to Ted Cruz}

Q16.2: So, Senator Cruz, let me bring you in. You object to Common Core. Governor Kasich says it's local school boards developing local curriculum to meet higher standards. What's wrong with that?

17.

Moderator: Dana Bash

Subject round: Social Security

Jake Tapper: Let's move on to another topic of particular interest here in Florida. Florida has the highest percentage of seniors in the country. There are 3.1 million senior citizens here who receive Social Security benefits, and they're very interested in hearing what you candidates intend to do to keep Social Security going for future generations. Let me turn now to my colleague Dana Bash.

\section{Bash to Marco Rubio}

Q17.1: Senator Rubio, you argue Americans your age must have an honest conversation about making Social Security sustainable. For people under 55, you want to raise the retirement age and also reduce benefits for wealthier Americans. So, what should the new retirement age be? And how much will those benefits be cut?

\section{Bash to Donald Trump}

Q17.2: Mr. Trump, you don't want to raise the retirement age, and you also don't want to cut benefits even for wealthier Americans. But according to the Social Security Administration, unless adjustments are made, Social Security is projected to run out of money within 20 years. So specifically, what would you do to stop that from happening?

18.

Moderator: Jake Tapper

Subject round: Islam 
Tapper to Donald Trump

Q18.1: Welcome back to the CNN Republican presidential debate in Miami, Florida. Mr. Trump, let me start with you. Last night, you told CNN quote, "Islam hates us?" Did you mean all 1.6 billion Muslims.

Tapper to John Kasich

Q18.2: Governor Kasich, do you think Islam hates us?

19.

Moderator: Jake Tapper

Subject round: Terrorists

\section{Tapper to Donald Trump}

Q19.1: Mr. Trump, I want to ask you about something else you've said during the course of this campaign. You said that the U.S. has to, quote, "take out" the families of terrorists. When it was pointed out that targeting civilians is against the Geneva Conventions, you said, quote, "So they can kill us, but we can't kill them?" It is against federal, military and international law to target civilians. So how will you order the military to target the families of suspected terrorists, while also abiding by the law?

\section{Tapper to Marco Rubio}

Q19.2: Senator Rubio, would you as president pursue a policy of targeting the families of suspected terrorists?

20.

Moderator: Hugh Hewitt

Subject round: Palestinian authority

Hewitt to Donald Trump

Q20.1: Mr. Trump, I want to follow-up on the quote that Senator Cruz used. You said you would want to be, quote, "sort of a neutral guy". He did mention Taylor Force. He was a West Point graduate, he was a war hero. He was a Vanderbilt graduate student. He was killed in a Palestinian terror attack near Tel Aviv, many others were killed. And the Israeli government says the Palestinian authority is inciting this. Do you still want to stay neutral when the Palestinian authority is inciting these attacks.

Hewitt to Marco Rubio

Q20.2: I want to go back to the Israeli government's assertion that the Palestinian Authority is inciting the convulsion of violence. Do you agree.

21.

Moderator: Hugh Hewitt

Subject round: Troops on the ground

\section{Hewitt to Ted Cruz}

Q21.1: Senator Cruz, I want to stay in the region. Just this week the head of U.S. Central Command, General General Lloyd Austin, essentially said it's going to take a lot more troops on the ground to fix to end the ISIS threat in Syria and Iraq. From the beginning of this campaign, you have said you will follow the judgment of military commanders in the Pentagon. So here's the commander saying we need a lot more troops on the ground. Will you follow that advice and inject Americans again into what is in essence is metastasizing Sunni-Shia civil war? 
Hewitt to Donald Trump

Q21.2: Mr. Trump, more troops?

22.

Moderator: Dana Bash

Subject round: Cuba

Jake Tapper: Let's turn to another issue of real importance here in Florida. Just over a week from now, President Obama will visit Cuba, the first time in 88 years that a sitting U.S. president will set foot in Cuba. Two of you on this stage have parents who were born in Cuba and moved to the United States. Let's go back to my colleague Dana Bash.

Bash to Marco Rubio

Q22.1: Senator Rubio, Donald Trump agrees with President Obama in his decision to reengage diplomatically in Cuba. The majority of Americans seem to agree with that as well. So why are President Obama, Donald Trump and the majority of Americans wrong?

Bash to Donald Trump

Q22.2: Mr. Trump, you said the concept of opening Cuba is fine. You said the concept of opening Cuba is fine. Why do you agree with President Obama and disagree with what Senator Rubio just said?

23.

Moderator: Jake Tapper

Subject round: How do you see the world?

Tapper to Ted Cruz

Q23.1: Senator Cruz, I want to talk a little bit right now about how you gentlemen see the world. Senator Cruz, Colin Powell this week said that the nasty tone of this presidential election is hurting the image of the U.S. abroad. He said, quote, "foreigners of the world looking at this are distressed." Does it matter to you what the rest of the world thinks of the United States?

\section{Tapper to Donald Trump}

Q23.2: Mr. Trump, some of your Republican critics have expressed concern about comments you have made praising authoritarian dictators. You have said positive things about Putin as a leader and about China's massacre of pro-democracy protesters at Tiananmen Square, you've said: "When the students poured into Tiananmen Square, the Chinese government almost blew it, then they were vicious, they were horrible, but they put it down with strength. That shows you the power of strength." How do you respond.

24.

Moderator: Jake Tapper

Subject round: Violence at rallies

\section{$\underline{\text { Tapper to Donald Trump }}$}

Q24.1: Mr. Trump, I want to start with you in this block. Earlier today, a man was arrested and charged with assault after sucker- punching a protester in the face at your rally in Fayettville, North Carolina. This is hardly the first incident of violence breaking out at one of your rallies. Today, Hillary Clinton, your potential general election opponent, clearly indicated she sees this as an issue for the campaign. She said, quote, "this kind of behavior is repugnant. We set the tone for our campaigns, we should encourage respect, not violence." Do you believe that you've done anything to create a tone where this kind of violence would be encouraged? 
Tapper to John Kasich

Q24.2: Governor Kasich, do you worry about the scenes of violence at some of these rallies affecting the Republican party's chances in November?

25.

Moderator: Hugh Hewitt

Subject round: Contested convention

Jake Tapper: The math suggests that it possible that not one of you will reach the magic number of 1,237 delegates before the Republican convention, which would mean a contested convention. Let's go back to Salem Radio's Hugh Hewitt.

Hewitt to John Kasich

Q25.1: Governor Kasich, the math and the maps say that you can only become the nominee if in fact there is a contested convention. If we arrive on the shores of Lake Erie, Donald Trump has the most delegates. Why shouldn't the person with the most delegates, even if it's not a majority of delegates, be the nominee?

Hewitt to Donald Trump

Q25.2: Mr. Trump, if you arrive in Cleveland with a plurality and the most, but not a majority, is it legitimate for someone else to emerge from that convention the nominee? And if so, would you support that person?

Total Pairs $=25$

Total Questions $=49$

Responses $=50$

Trump $=25$

Cruz $=8$

Kasich $=9$

Rubio $=8$

Tapper $=21$

Blitzer $=12$

Hewitt $=12$

$\mathrm{Bash}=4$ 


\section{Appendix C: Transcription Conventions}

The following transcription conventions are based on and slightly adapted from Jefferson's (2004) glossary of transcript symbols, in G. H. Lerner (Ed.), Conversation analysis: Studies from the first generation (pp. 13-31). Amsterdam: John Benjamins.

1. Temporal and sequential relationships

[ A left bracket indicates the onset of overlapping speech

] A right bracket indicates the point at which overlapping utterances end

$=\quad$ An equals sign indicates latched speech (no break or gap between talk)

(0.5) Silences are indicated as pauses in tenths of a second

(.) A period in parentheses indicates a hearable micropause (less than two tenths of a

second)

\section{Aspects of speech delivery}

$\begin{array}{ll}\cdot & \text { A period indicates a falling intonation contour } \\ ? & \text { A comma indicates continuing intonation } \\ & \text { A question mark indicates rising intonation contour } \\ : & \text { An underscore indicates a level intonation contour } \\ & \text { Colons indicate lengthening of preceding sound (the more colons, the } \\ \text { longer the lengthening) } \\ \text { ye- } & \text { A hyphen indicates an abrupt cutoff sound (phonetically, a glottal stop) } \\ \text { yes } & \text { Underlining indicates stress or emphasis, by increased amplitude or pitch } \\ \text { YES } & \text { Upper case letters indicates noticeably louder speech } \\ { }^{\circ} \text { yes }{ }^{\circ} & \text { The degree sign indicates noticeably quiet or soft speech } \\ \wedge & \text { A caret indicates a sharp rise in pitch } \\ >\text { yes }< & \text { Indicates talk that is noticeably faster than surrounding talk } \\ <\text { yes }> & \text { Indicate talk that is noticeably slower than surrounding talk } \\ \text { hh } & \text { The letter ' } h \text { ' indicates audible aspirations (the more hs the longer the } \\ \text { breath) } & \\ . h h & \text { A period preceding the letter ' } h \text { ' indicates audible inhalations (the more hs } \\ & \text { the longer the breath) } \\ y(h) e s & h \text { within parentheses within a word indicates 'laugh-like" sound } \\ £ y e s £ & \text { A pound sign indicates smile voice }\end{array}$

3. Other notational devices

(guess) Words within single parentheses indicate likely hearing of that word

((coughs)) Information in double parentheses indicate the transcriber's descriptions of events rather than representations of them

( ) Empty parentheses indicate hearable yet indecipherable talk 